\title{
Field Lysimeter Test Facility: Second Year (FY 1989) \\ Test Results
}

M. D. Campbell

G. W. Gee

M. J. Kanyid

M. L. Rockhold

April 1990

Prepared for the U.S. Department of Energy under Contract DE-AC06-76RLO 1830

Pacific Northwest Laboratory Operated for the U.S. Department of Energy by Battelle Memorial Institute 


\title{
DISCLAIMER
}

This report was prepared as an account of work sponsored by an agency of the United States Government. Neither the United States Government nor any agency thereof, nor Battelle Memorial Institute, nor any of their employees, makes any warranty, expressed or implied, or assumes any legal liability or responsibility for the accuracy, completeness, or usefulness of any information, apparatus, product, or process disclosed, or represents that its use would not infringe privately owned rights. Reference herein to any specific commercial product, process, or service by trade name, trademark, manufacturer, or otherwise, does not necessarily constitute or imply its endorsement, recommendation, or favoring by the United States Government of any agency thereof, or Battelle Memorial Institute. The views and opinions of authors expressed herein do not necessarily state or reflect those of the United States Government or any agency thereof.

\author{
PACIFIC NORTHWEST LABORATORY \\ operated by \\ BATTELLE MEMORIAL INSTITUTE \\ for the \\ UNITED STATES DEPARTMENT OF ENERGY \\ under Contract DE-AC06-76RLO 1830
}

Printed in the United States of America

Available to DOE and DOE contractors from the

Office of Scientific and Technical Information, P.O. Box 62, Oak Ridge, TN 37831;

prices available from (615) 576-8401. FTS 626-8401.

Available to the public from the National Technical Information Service,

U.S. Department of Commerce, 5285 Port Royal Rd., Springfield, VA 22161.

NTIS Price Codes, Microfiche A01

Printed Copy

\begin{tabular}{cr}
\hline Price Code & Page Range \\
\hline A02 & $1-10$ \\
A03 & $11-50$ \\
A04 & $51-75$ \\
A05 & $76-100$ \\
A06 & $101-125$ \\
A07 & $126-150$ \\
A08 & $151-175$ \\
A09 & $176-200$ \\
A10 & $201-225$ \\
A11 & $226-250$ \\
A12 & $251-275$ \\
A13 & $276-300$ \\
A14 & $301-325$
\end{tabular}

\begin{tabular}{cc}
\hline Price Code & Page Range \\
\hline A15 & $326-350$ \\
A16 & $351-375$ \\
A17 & $376-400$ \\
A18 & $401-425$ \\
A19 & $426-450$ \\
A20 & $451-475$ \\
A21 & $476-500$ \\
A22 & $501-525$ \\
A23 & $526-550$ \\
A24 & $551-575$ \\
A25 & $576-600$ \\
A99 & $601-U p$
\end{tabular}


FIELD LYSIMETER TEST FACILITY: SECOND YEAR (FY 1989) TEST RESULTS
M. D. Campbe11
G. W. Gee
M. J. Kanyid
M. L. Rockhold

Apri1 1990

Prepared for the U.S. Department of Energy under Contract DE-AC06-76RLO 1830

Pacific Northwest Laboratory

Richland, Washington 99352 


\section{EXECUTIVE SUMMARY}

Permanent, safe disposal of the large volumes of radioactive wastes now buried at the Hanford Site involves one of three processes: translocation to a deep repository, in situ vitrification, or environmental isolation by a barrier (DOE 1987). The Record of Decision associated with the Hanford Defense Waste Environmental Impact Statement (53 FR 12449-53) commits to an evaluation of the use of protective barriers placed over near-surface wastes. The barrier must protect against wind and water erosion and limit plant and animal intrusion and infiltration of water. Pacific Northwest Laboratory (PNL) and Westinghouse Hanford Company (WHC) jointly designed and Kaiser Engineers Hanford (KEH) constructed a Field Lysimeter Test Facility (FLTF) during FY 1987 (November 1986 through June 1987) to test properties and functions of various protective barrier designs. Successful conclusion of this program will yield the necessary protective barrier design for near-surface waste isolation. This report presents results from the second year of tests at the FLTF.

The primary objective of testing protective barriers at the FLTF was to measure the water budgets within the various barriers and assess the effectiveness of their designs in limiting water intrusion into the zone beneath each barrier. Information obtained from these measurements is intended for use in refining barrier designs. Four elements of water budget were measured during the year: precipitation, evaporation, storage, and drainage. Runoff, which is a fifth element of a complete water budget, was made negligible by a lip on the lysimeters that protrudes $5 \mathrm{~cm}$ above the soil surface to prevent run-off.

A secondary objective of testing protective barriers at the FLTF was to refine procedures and equipment to support data collection for verification of the computer model needed for long-term projections of barrier performance. Detailed procedures are included in the Appendix covering calibration and use of the neutron probe, the gamma probe, tensiometers, and weighing lysimeters. Equipment refinements during the year included:

- installation of two clear-tube lysimeters that allow visual observations of water and root penetration 
- a more reliable power supply for datalogging equipment

- use of voltage and temperature calibration standards

- replacement of a lysimeter scale that had hysteresis error

- precise calibration of weighing lysimeters traceable to national standards.

Breakthrough tests completed and reported in FY 1988 were not extended into FY 1989. However, the two lysimeters treated to breakthrough (D09-7 and D11-7) were covered during FY 1989 to prevent evaporation and were monitored. During the FY 1988 tests on D09-7 and D11-7, soil water began to move downward at 25 vol\% and breakthrough occurred at 42 vol\%. Water drained slowly during the following year, leaving 36 vol\% at the bottom of the two soil profiles. The hydraulic barrier provided a stable water holding capacity increase of 11 vol\% at the lower soil boundary. The barrier increased average water storage capacity by $8 \mathrm{~cm}$ in the silt loam soil. Storage capacity in the $1.5 \mathrm{~m}$ of silt loam soil was $36 \mathrm{~cm}$ above the plant extraction limit, or $4 \mathrm{~cm}$ more than the $32 \mathrm{~cm} / \mathrm{yr}$ representing twice-average precipitation at the FLTF site. Thus, twice-average precipitation would not be enough to cause breakthrough if the silt loam soil barriers were vegetated. Without vegetation, however, evaporation depleted the soil moisture to $20 \mathrm{vol \%}$. This level of depletion would accommodate $16 \mathrm{~cm}$ of added water without drainage. Drainage through bare soil would depend on the time and amount of precipitation and would be expected whenever the soil moisture content reached 42 vol\%.

During FY 1989, the bare soils of treatment 4 received twice-average precipitation, and the soil moisture content approached 38 vol\%. While no breakthrough occurred, the treatment 4 soil profiles assumed shapes similar to those of D09-7 and D11-7, but with slightly less magnitude. A similar storm pattern would be expected to cause drainage through barriers with more sand or less depth. Thus, the hydraulic barrier created by layering fine over coarse soil allowed water to perch above the textural boundary for an extended time where evaporation from bare soil and transpiration from plants recycled the water to the atmosphere. 
Water distribution in the soil profiles became treatment specific. Soil moisture values were measured in all lysimeters using the neutron probe. Initial cross calibration between the neutron probe and a weighing lysimeter led to reasonable agreement between water budgets measured by the two methods. We conclude from these tests that measurements and methods used in water budget accounting are adequate and sufficiently precise to continue evaluation of barrier performance and, furthermore, to use the data for model calibration or verification. 


\section{ACKNOWLEDGMENTS}

The Field Lysimeter Test Facility (FLTF) was constructed and operated on funds provided by the Hanford Site Protective Barrier Development Program sponsored by the U.S. Department of Energy. Westinghouse Hanford Company (WHC) and Pacific Northwest Laboratory (PNL) staff worked with Kaiser Engineers Hanford (KEH) staff to design and construct the facility. Personnel from PNL and WHC operated the facility following construction. J. W. Camman, N. R. Wing, and C. J. Kemp from WHC, and 0. B. Abbey, P. R. Heller, D. Felmy, D. Strenge, J. Nelson, C. K. Russe11, S. 0. Link, and L. L. Cadwell from PNL contributed during the past year, and we gratefully acknowledge and express appreciation for their efforts. We also acknowledge with appreciation the efforts of the PNL text processing and editing staff. 


\section{CONTENTS}

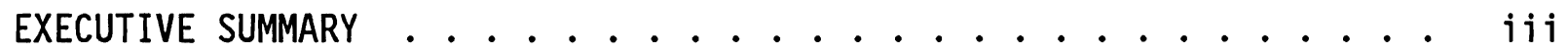

ACKNOWLEDGMENTS ................................. vii

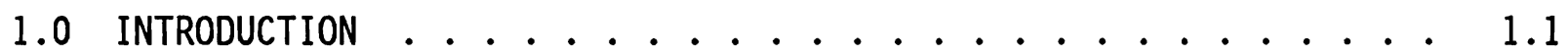

2.0 DATA COLLECTION AND PROCESSING . . . . . . . . . 2.1

2.1 EQUIPMENT AND PROCEDURES . . . . . . . . . . . 2.2

2.1.1 Neutron Probe Calibration, Standardization,

2.1.2 Gamma Probe Calibration, Standardization,
and Use...................... 2.4

2.1.3 Tensiometer Calibration and Standardization . . . 2.6

2.1.4 Datalogger and Power Supply . . . . . . . 2.6

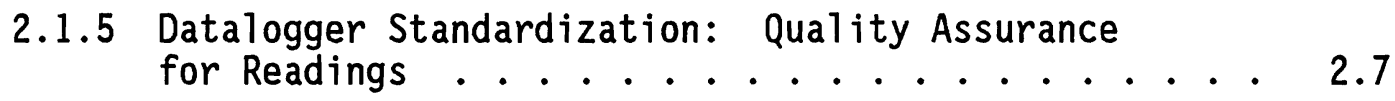

2.1.6 Thermocouple Psychrometer Calibration and Use . . . 2.8

2.1.7 Weighing Lysimeter Scale Calibration and
Standardization......................... 2.10

2.1.8 Thermocouple Calibration .......... 2.12

2.1.9 Spraybar Water Application and Measurement .... 2.13

2.1.10 Plant Measurements and Equipment ........ 2.13

2.2 OPERATIONAL CONSIDERATIONS . . . . . . . . . . 2.14

3.0 RESULTS AND DISCUSSION OF SECOND-YEAR TESTS . . . . . . . 3.1

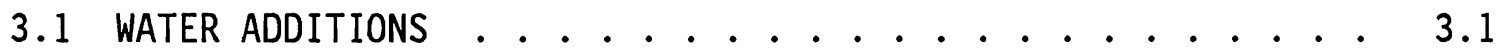

3.1 .1 Precipitation Timing and Amounts ....... 3.1

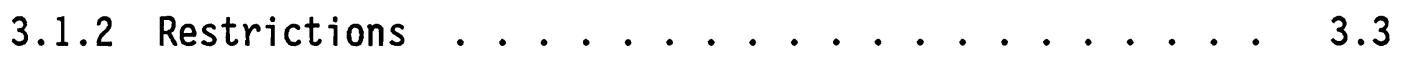

3.2 SOIL MOISTURE MEASUREMENTS . . . . . . . . . . 3.3

3.2.1 Neutron Probe Measurements . . . . . . . . 3.4 
3.2.2 Soil Moisture Tension Measurements . . . . . . . 3.6

3.2.3 Weighing Lysimeter Measurements . . . . . . . . 3.7

3.2.4 Weighing Lysimeter and Neutron Probe

Measurement Comparisons ............ 3.11

3.2.5 Soil Moisture Profile Measurements . . . . . . 3.15

3.2.6 Initial Gamma Probe Measurements . . . . . . . 3.20

3.3 WATER BALANCE IN THE LYSIMETERS . . . . . . . . . . 3.23

3.3.1 Precipitation ............. 3.24

3.3.2 Run-0ff and Drainage ............ 3.24

3.3.3 Water Storage ................ 3.27

3.3.4 Evaporation ................ . 3.30

3.4 VEgetATION EFFECTS ................. 3.30

3.4.1 Plant Measurements ............. 3.31

3.4.2 Root Observations ............. 3.32

4.0 CONCLUSIONS AND RECOMMENDATIONS . . . . . . . . . . . . . 4.1

5.0 REFERENCES . . . . . . . . . . . . . . . . . 5.1

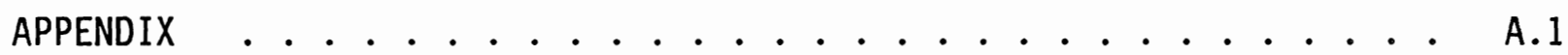




\section{FIGURES}

1.1 Plan View of the FLTF and Treatment Descriptions for

Each Lysimeter . . . . . . . . . . . . . . 1.2

2.1 Neutron Probe Shield Counts Taken at the Arid Lands

Ecology Reserve Over a 4-Year Period ........... 2.4

2.2 Gamma Probe Initial Calibration with Upper and Lower Limits . . 2.6

2.3 Diagram of Voltage Divider Used with Mercury Standard Ce11 . . 2.8

2.4 Temperature and Standard Cell Voltage Readings by Datalogger from December 1988 to April 1989 ............ 2.9

2.5 Weighing Lysimeter Scale Calibration Results, May 1989 . . . 2.11

2.6 Thermocouple Locations in W03-3 . . . . . . . . . . . 2.12

3.1 Ambient and Twice-Average Precipitation and Total Water Application from November 1, 1987, to Apri1 1, 1989 . . . . 3.3

3.2 An Example of Soil Moisture Profile Variation with Time . . . . 3.5

3.3 Treatment 4 Water Profile Distribution and Tension in Response to Hydraulic Barrier............ 3.5

3.4 Comparison of Soil Moisture Profiles in Treatments 4 and 7, April 14,1989 ....................... 3.6

3.5 Storage Changes as the Difference Between Two Soil Profiles Measured by the Neutron Probe . . . . . . . . . 3.7

3.6 Water Storage Changes Within Each Treatment Over Time . . . . 3.8

3.7 Soil Moisture Tension Profile in Lysimeters D09-7 . . . . . 3.9

3.8 Soil Water Content Profile in Lysimeter D09-7 . . . . . . . 3.9

3.9 Water Storage Change Based on Weight Changes in Lysimeters . . . 3.10

3.10 Water Storage in Weighing Lysimeters Since November 1987 . . . 3.12

3.11 Evapotranspiration and Evaporation as Difference in Storage in Weighing Lysimeters W01-1 and W02-2, Respectively ..... 3.13

3.12 Evapotranspiration and Evaporation as Difference in Storage in Weighing Lysimeters W03-3 and W04-4, Respectively ..... 3.14

3.13 Water Removal Patterns in Weighing Lysimeters . . . . . . 3.15 
3.14 Comparison of Neutron Probe and Weighing Lysimeter Measurements of Water Storage ........... 3.16

3.15 Initial Moisture Distribution in Lysimeter Soil Profiles . . . 3.17

3.16 Soil Moisture Distribution in Lysimeters in January 1988 . . 3.17

3.17 Soil Moisture Distribution in Lysimeters in April $1988 \ldots . . .3 .17$

3.18 Soil Moisture Distribution in Lysimeters in June $1988 \ldots . . .3 .18$

3.19 Soil Moisture Distribution in Lysimeters in August $1988 \ldots . .3 .18$

3.20 Soi1 Moisture Distribution in Lysimeters in November 1988 . . 3.18

3.21 Soil Moisture Distribution in Lysimeters in January 1989 . . 3.19

3.22 Soil Moisture Distribution in Lysimeters in April 1989 . . . . 3.19

3.23 Profiles of Lysimeters Receiving Ambient, Twice-Average, and Breakthrough Water Applications ........... 3.21

3.24 Soil Moisture Profiles in Lysimeters, November $1987 \ldots . . . .3 .22$

3.25 Soil Moisture Profiles in Lysimeters, November 1988 . . . . 3.22

3.26 Soil Moisture Profiles in Lysimeters, April 1989 . . . . . 3.23

3.27 Soil Profiles of Treatment 4 Measured by the Gamma Probe . . . 3.24

3.28 Twice-Average Water Application Schedule . . . . . . 3.26

3.29 Profile from Twice-Average Precipitation Without Vegetation . . 3.26

3.30 Profile from Twice-Average Precipitation with Vegetation . . 3.27

3.31 Soil Surface Profiles Following Breakthrough and Subsidence . . 3.28

3.32 Water Storage by Treatment in Lysimeters . . . . . . . . 3.29

3.33 Water Removal from Soil by Evaporation and Transpiration . . . 3.30

3.34 Vegetation Locations on Lysimeters ............ 3.33 


\section{TABLES}

3.1 Water Application and Precipitation Record for the FLTF from November 1, 1987, to April 1, 1989 . . . . . . . 3.2

3.2 Water Balance in the FLTF Lysimeters, by Treatment . . . . . 3.25

3.3 Lysimeter Vegetation Measurements . . . . . . . . . 3.32

3.4 Root Counts from Mini-Rhizotrons in Vegetated Lysimeters . . . 3.34 


\subsection{INTRODUCTION}

Permanent, safe disposal of the large volumes of radioactive wastes now buried at the Hanford Site involves one of three processes: translocation to a deep repository, in situ vitrification, or environmental isolation by a barrier (DOE 1987). The Record of Decision associated with the Hanford Defense Waste Environmental Impact Statement (53 FR 12449-53) commits to an evaluation of the use of protective barriers placed over near-surface wastes. The barrier must protect against wind and water erosion and limit plant and animal intrusion and infiltration of water.

If infiltration of water through a barrier can be controlled, then leaching of radioactive or other hazardous wastes beneath the barrier can be controlled, limiting movement of contaminants through the vadose zone and into the groundwater. In the present design, the part of the barrier used to control water infiltration consists of a hydraulic break in the soil caused by placing a fine-texture soil over a coarse-texture soil. This design permits the fine-texture soil to hold more water against the force of gravity than it would without the hydraulic break, thus allowing more time for the water to cycle back to the atmosphere through evaporation.

The Field Lysimeter Test Facility (FLTF) was designed and constructed to test whether and under what conditions protective barriers can provide environmental isolation by limiting biotic and water intrusion into the radioactive wastes. Treatments applied at the FLTF were designed to test ranges of factors influencing barrier performance and lead to a final barrier design (Kirkham, Gee, and Downs 1987). Treatments include three levels of water applications, two soil profile depths, two vegetative cover conditions, and two surface armor (bare soil and gravel cover) treatments (see Figure 1.1). This second annual report focuses mainly on water infiltration and its long-term influence on the function of the hydraulic barrier. Initial (first year) data from this facility have been previously reported (Gee et al. 1989).

During the past several years, both drainage and weighing lysimeters have been used to limit water movement to one dimension while measuring 
precipitation, run-off, evaporation, drainage, and storage. Some of these lysimeters had textural breaks that influenced water retention and nearly all lacked some element of the complete barrier, such as the biointrusion barrier of graded rock. The lysimeters used in the present study contain the elements currently perceived to be a complete, acceptable barrier. Data are being collected and processed on all facets of barrier performance related to the present conceptual design.

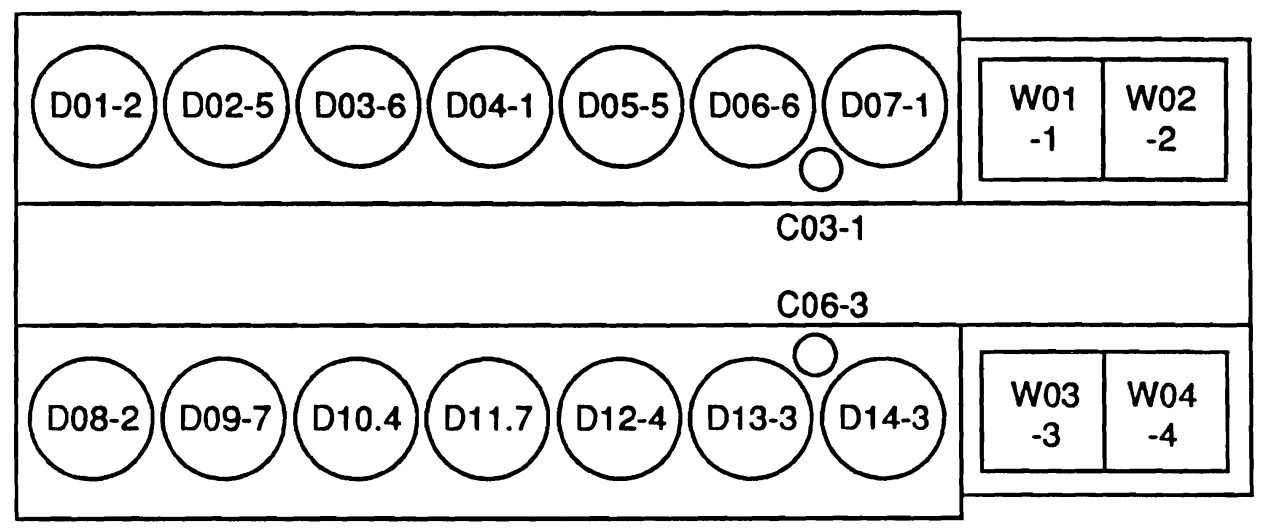

\begin{tabular}{|c|c|c|c|c|c|c|c|c|}
\hline \multirow[b]{2}{*}{ Treatment } & \multicolumn{3}{|c|}{ Precipitation } & \multicolumn{2}{|c|}{ Surface } & \multicolumn{2}{|c|}{$\begin{array}{l}\text { Soil } \\
\text { Thickness } \\
\end{array}$} & \multirow[b]{2}{*}{ Lysimeter \# } \\
\hline & $\overline{A^{(a)}}$ & $2 A^{(b)}$ & $\mathrm{B}^{(c)}$ & Bare Veg & Admix & $1.0 \mathrm{~m}$ & $1.5 \mathrm{~m}$ & \\
\hline 1 & $\bar{x}$ & & & $x$ & & & $x$ & $\overline{W 01-1, ~ D 04-1, ~ D 07-1, ~ C 03-1 ~}$ \\
\hline 2 & $\mathrm{x}$ & & & $\mathrm{X}$ & & & $\mathrm{x}$ & W02-2, D01-2, D08-2 \\
\hline 3 & & $x$ & & $x$ & & & $x$ & W03-3, D13-3, D14-3, C06-3 \\
\hline 4 & & $x$ & & $x$ & & & $\mathrm{x}$ & W04-4, D10-4, D12-4 \\
\hline 5 & $x$ & & & $x$ & $x$ & & $x$ & $\mathrm{D} 02-5, \mathrm{D} 05-5$ \\
\hline 6 & $\mathrm{x}$ & & & $\mathrm{x}$ & & $\mathrm{x}$ & & D03-6, D06-6 \\
\hline 7 & & & $x$ & $\mathrm{x}$ & & & $\mathrm{x}$ & D09-7, D11-7 \\
\hline
\end{tabular}

(a) Ambient precipitation
(b) Twice average Precipitation
(c) Precipitation until breakthrough

S8908090.2

FIGURE 1.1. Plan View of the FLTF and Treatment Descriptions for Each Lysimeter 


\subsection{DATA COLLECTION AND PROCESSING}

Barrier design and function are linked irrevocably to soil water status and to factors that influence it. Measurements that are considered essential include

- air temperature

- solar radiation

- wind speed

- relative humidity

- precipitation

- soil water content and distribution

- soil moisture tension

- soil temperatures

- drainage.

The first five items are measured hourly and transported to us via phone modem at least quarterly by the Hanford Meteorological Station (HMS), which is adjacent to the FLTF. We measured the last four items and remeasured precipitation by recorded weight change in the weighing lysimeters (1arge, soilfilled boxes on platform scales). Based on these measurements, a water budget was developed for each lysimeter to account for precipitation, runoff, evaporation (including transpiration), storage, and drainage; drainage was the consequence of the other four. Equipment was selected to measure al1 but run-off, which was prevented by extending the perimeter on each lysimeter $5 \mathrm{~cm}$ above the ground surface. While drainage depends on precipitation, evaporation, and storage, these three depend on driving forces of temperatures and tensions acting within the barrier and on solar radiation, wind, humidity, and temperatures acting on the soil surface. Measurements of these elements that affect water budget helped us understand how and why hydraulic barriers function and how to improve their design. Data collection focused on soil water content and drainage measurements in the lysimeter facility. 


\subsection{EQUIPMENT AND PROCEDURES}

In addition to direct measurements of drainage using a scale, six other types of sensors are currently being used to monitor the soil water to assess barrier hydraulic function. These sensors are the neutron probe, gamma probe, tensiometers, thermocouple psychrometers (TCPs), weighing lysimeters, and thermocouples. The latter three of these sensors are monitored by automatic dataloggers. All of the sensors and the datalogger require functional certification. A brief description of each sensor function is included here. The detailed procedures are included in the Appendix.

\subsubsection{Neutron Probe Calibration, Standardization, and Use}

Although there is no nationally accepted standard for calibration of the neutron probe, we are assisting the American Society of Testing and Materials (ASTM) in preparing a definitive procedure. In the meantime, we are relying on a procedure we devised that is a sufficiently precise method for probe calibration to assess barrier performance. An outline of the probe operation and calibration method is described below.

A neutron probe consists of a fast neutron source, a slow neutron detector, and a scaler. The scaler on the neutron probe counts the slow neutrons that have been slowed down and reflected back to the detector by the water in the soil. The number of slow neutrons measured during a selected measurement interval must be precisely related to the amount of water present in the soil. Thus related, the neutron probe is capable of making accurate comparisons between known and unknown concentrations of water in soil. Initial calibration of the neutron probe consists of three steps: 1) install an access tube in a uniformly wet soil that is to be used for calibration, 2) take at least 20 probe readings with the source and detector at least $15 \mathrm{~cm}$ below the soil surface, and 3 ) measure precisely the volumetric water content of the same volume of soil measured by the probe. Repeat these three steps over the full range of the water-holding capacity of that soil, including a barrel of oven-dry soil. Fit a linear regression line through the data points and obtain the slope and intercept of the regression line. This completes the initial calibration. Following initial calibration, a wet and a dry transfer standard must be prepared to ensure proper transfer of the 
initial calibration values to all probes, including the original one that will change with time. The wet transfer standard may be made from any invariant material in the shape of a cylinder at least $40 \mathrm{~cm}$ in diameter and $60 \mathrm{~cm}$ high, containing large concentrations of hydrogen, such as water, wax, or plastic. The dry transfer standard should be prepared in a barrel using an access tube and dry soil identical to those used during calibration. Once the transfer standards have been prepared, the probe is placed within each of them in turn and an average of eighty 30 -s counts (or equivalent total time) is obtained. The average of the 80 counts in each transfer standard is assigned the corresponding water content from the regression line. Thus, the dry transfer standard will always represent 0 v01\% water content and the wet transfer standard may represent, for example, 70 vol\% water content. These become the transfer standard values for that soil for all future measurements for all neutron probes of that same type. These transfer standards are to be measured before and after each session of soil moisture measurements. If the transfer standard measurements differ more than two standard errors of the mean, a new slope and intercept must be calculated for the probe. If more than 1 reading in 20 lies more than 2 standard deviations below the mean and none lies more than 2 standard deviations above the mean, warm-up error should be suspected and checked before use of the probe.

During the past several years, the manufacturer's recommended procedure has been followed in using the probe shield as the calibrated transfer standard. Recently, we examined shield counts taken over a period of several years and selected the example in Figure 2.1 to show all three common problems. The data plotted show warm-up errors, random errors, and long-term drift. While the warm-up errors do not apply to the neutron probe used in FLTF measurements, they do represent a spread pattern similar to that found from equivalent data taken using the FLTF probe. The data from both probes confirmed the need to use a more reproducible standard and to use it in a way different from that specified by the manufacturer. This discussion, based on work done during the past two years, is presented to enhance appropriate use of the neutron probe and to improve the quality of soil moisture measurements in the barrier development program. 


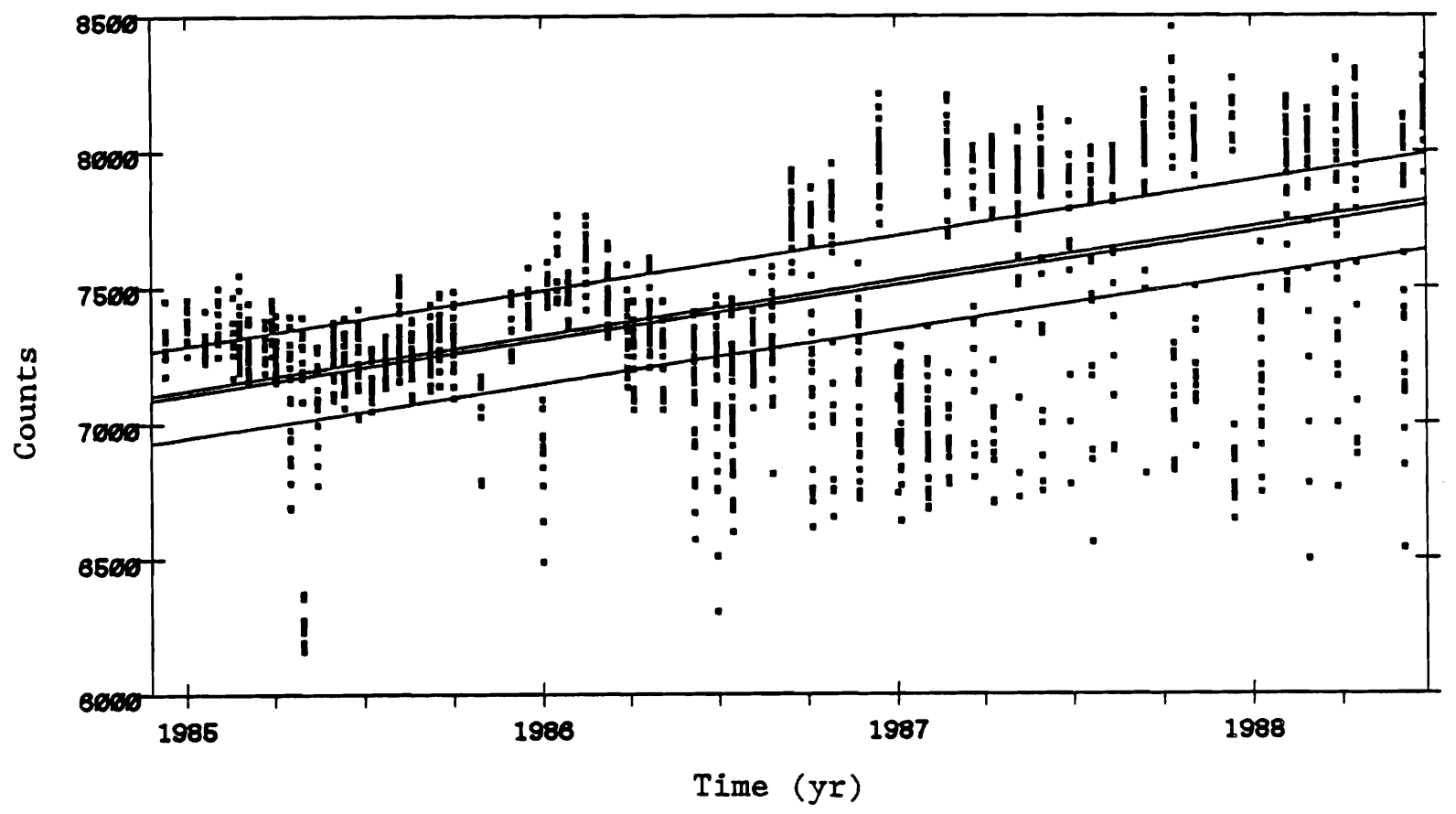

FIGURE 2.1. Neutron Probe Shield Counts Taken at the Arid Lands Ecology Reserve Over a 4-Year Period

The shield counts shown in Figure 2.1 were taken at the Arid Lands Ecology (ALE) reserve over a period of 4 years. They show the influences of three significant factors: 1) a difference between beginning and ending readings taken during a single day (as a consequence of high-voltage system warm-up), 2) an upward trend in readings over several years (as a consequence of normal electronic component drift), and 3 ) a random variation between measurements (as a consequence of very small variations between the shield and probe). In this particular case, the difference in readings caused by warm-up was attributable to changes in the boron-trifluoride detector as demonstrated by replacing it with a helium-3 detector. The influences from factors 2 and 3 can be removed by periodic calibration in an invariant transfer standard such as wax, plastic, or water. The calibration procedure is detailed in the Appendix, Section A.1.

\subsubsection{Gamma Probe Calibration, Standardization, and Use}

The gamma probe operates on the principle of gamma radiation attenuation by comparing direct gamma-ray transmission through a soil with various 
amounts of water present. Like the neutron probe, the gamma probe requires precise calibration in the soil to be measured. Unlike the neutron probe, the gamma probe has the source in one probe and the detector in another probe $30 \mathrm{~cm}$ distant. This arrangement facilitates water measurement in thin layers near a soil surface or a textural interface. The source is placed at the desired depth in the same access tube used for neutron probe measurements. The detector is placed at the same depth as the source but in a parallel access tube that is $30 \mathrm{~cm}$ distant. A pulse height discriminator is used to distinguish between radiation detected directly from the source and that reflected from the soil. Only direct-transmitted radiation is used to measure moisture in the soil. Low soil moisture content allows more radiation to be transmitted from the source to the detector than is possible with high soil moisture content. Thus, the intensity of the direct radiation transmission becomes a measure of soil moisture content. Since density of the bulk soil also influences radiation transmission, it is held constant while moisture is changed during the calibration process. Also like the neutron probe, the gamma probe requires a transfer standard. The factory provided a set of transfer standards for soil density, but additional transfer standards of wet and dry soil are planned for use at the FLTF.

During initial calibration of the gamma probe, we were unable to demonstrate clearly the $662-\mathrm{KeV}$ energy peak that is needed to distinguish transmitted radiation from scattered radiation; this may be related to detector failure or incorrect factory setup. When the probe cover was removed following the initial attempt at calibration, the 0 -ring seal was found broken and moisture was found within the probe cover. Initial calibration revealed inadequate function of the gamma probe, and it will be returned to the factory for repair and recalibration. Variations in soil profile water content were not eliminated as sources of error during the initial calibration attempt but will be before calibration is complete. Initial calibration results are shown in Figure 2.2. The upper and lower lines represent two standard deviations from the mean of a Poisson distribution. Scatter outside these lines is attributed to unidentified errors in probe operation, including failure to discriminate the $622-\mathrm{KeV}$ energy peak. The procedure for gamma probe use is detailed in the Appendix, Section A.2. 


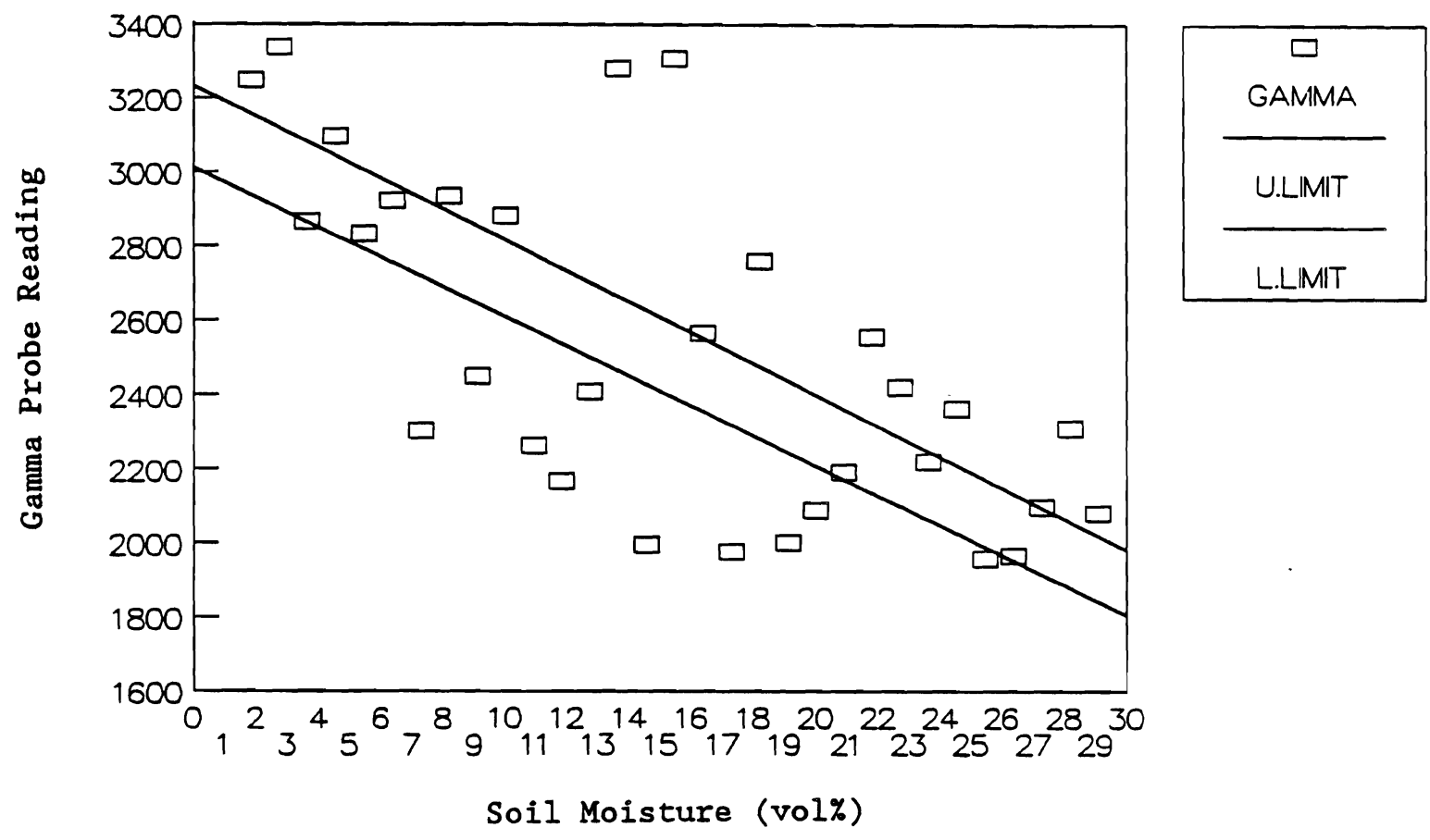

FIGURE 2.2. Gamma Probe Initial Calibration with Upper and Lower Limits

\subsubsection{Tensiometer Calibration and Standardization}

Tensiometers used in connection with barrier development do not require calibration, but the Tensimeter ${ }^{\text {m }}$ used to monitor them does. The Tensimeter uses a pressure transducer that requires calibration against a water column standard. In addition, the elevation difference between the ceramic cup and water level in the sight tube of each tensiometer is accounted during each measurement. The detailed calibration procedure is presented in the Appendix, Section A.3.

\subsubsection{Datalogger and Power Supply}

The remaining sensors require datalogger monitoring to yield needed data. Both the sensors and the datalogger require frequent checking to ensure correct operation and measurement. Appropriate function of the datalogger is essential to valid automatic data collection. Several problems

m Tensimeter is a trademark of Soil Measurement Systems, 1906 South Espina Street, Suite 6, Las Cruces, New Mexico 88001 
relative to the datalogger have been identified since monitoring began. Electric power failures during 1988 resulted in datalogger shutdown with a loss of data. A 20-amp, ground fault interrupt (GFI) circuit breaker was identified as the source of the problem. The GFI circuit breaker would cut off power at unpredictable times. These failures occurred most often during rain storms. Without breaker reset, the battery backup would discharge in a few days and the datalogger would fail. Initially, we planned to update the 110-V power system. After reconsideration, we decided to lower the voltage level for safety and to use batteries for the main power supply and recharge the batteries using the $110-V$ supply system. Consequently, we changed to a $12-V$ battery power system with $110-V$ backup for battery recharge. The quality assurance audit team concurred with the change we proposed to correct the power supply problem. We learned recently that we need larger batteries to prevent datalogger overranging as battery voltage drops. We also modified other parts of the monitoring program to improve data reliability.

\subsubsection{Datalogger Standardization: Quality Assurance for Readings}

Tests of dataloggers confirmed that the data value shifted as reported by the manufacturer when the power supply dropped below $9.6 \mathrm{~V}$. (The manufacturer specified a minimum of $11.76 \mathrm{~V}$ for a lead-acid battery.) Because of this shift and the need to verify the quality of measured values, we connected a mercury cell with a voltage divider to the datalogger as a reference standard so we could detect reading shifts greater than $10 \mu \mathrm{V}$ when they occurred. We measured the divided voltage to $1 \mu \mathrm{V}$ with a calibrated microvoltmeter. A diagram of the voltage divider is shown in Figure 2.3. Figure 2.4 shows the measured voltages from the standardized microvoltmeter and the voltage and temperature readings recorded by the datalogger from the time of installation through the end of March 1989. We requested a standardized nanovoltmeter measurement of the divided voltage. The Hanford Engineering Development Laboratory (HEDL) reported that they could not calibrate reliably below $1 \mu \mathrm{V}$. On the basis of microvolt measurements, we concluded that voltages measured by the dataloggers were acceptable during the entire interval covered in this report and that temperature dependence was 


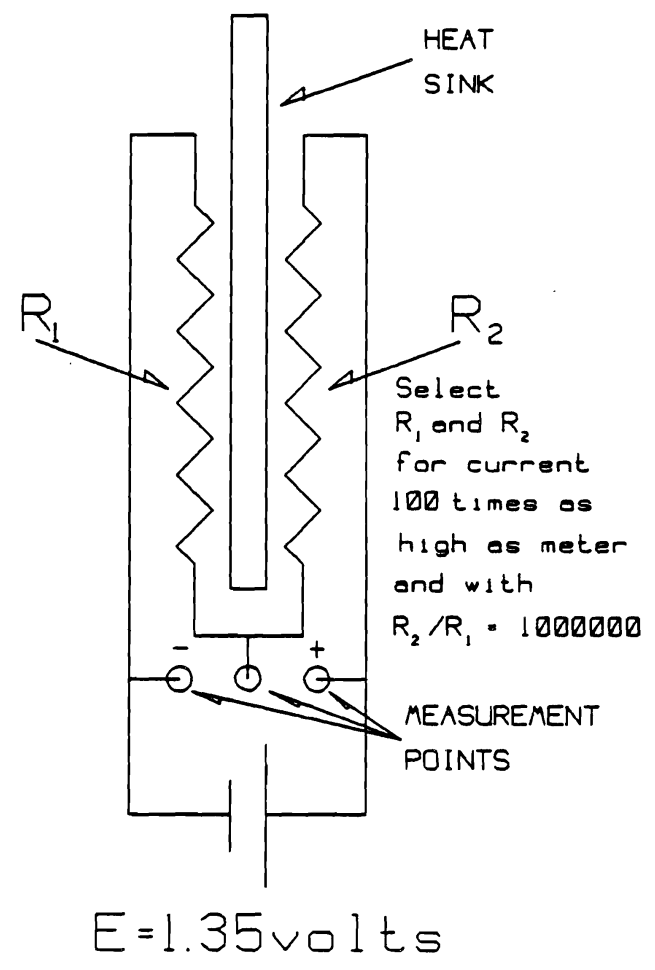

FIGURE 2.3. Diagram of Voltage Divider Used with Mercury Standard Cell

adequately compensated. However, we are now testing a voltage ratio device using the mercury cell to create an invariant voltage standard. This will be installed late in 1989.

\subsubsection{Thermocouple Psychrometer Calibration and Use}

The use of the TCP for measuring soil humidity and soil water potential is described in detail by Rawlins and Campbell (1986). The TCPs used at the FLTF are to measure the energy level of water (e.g., soil humidity or soil water potential) in moderately dry to very dry soil. Reverse normal current flow is forced through the thermocouple by applying opposing external voltage. Peltier cooling of one junction and heating of the other of the thermocouple results in condensation of water on the cooled junction. As external voltage is removed, temperature depression follows from evaporation of the condensed water back into the surrounding atmosphere. The temperature 


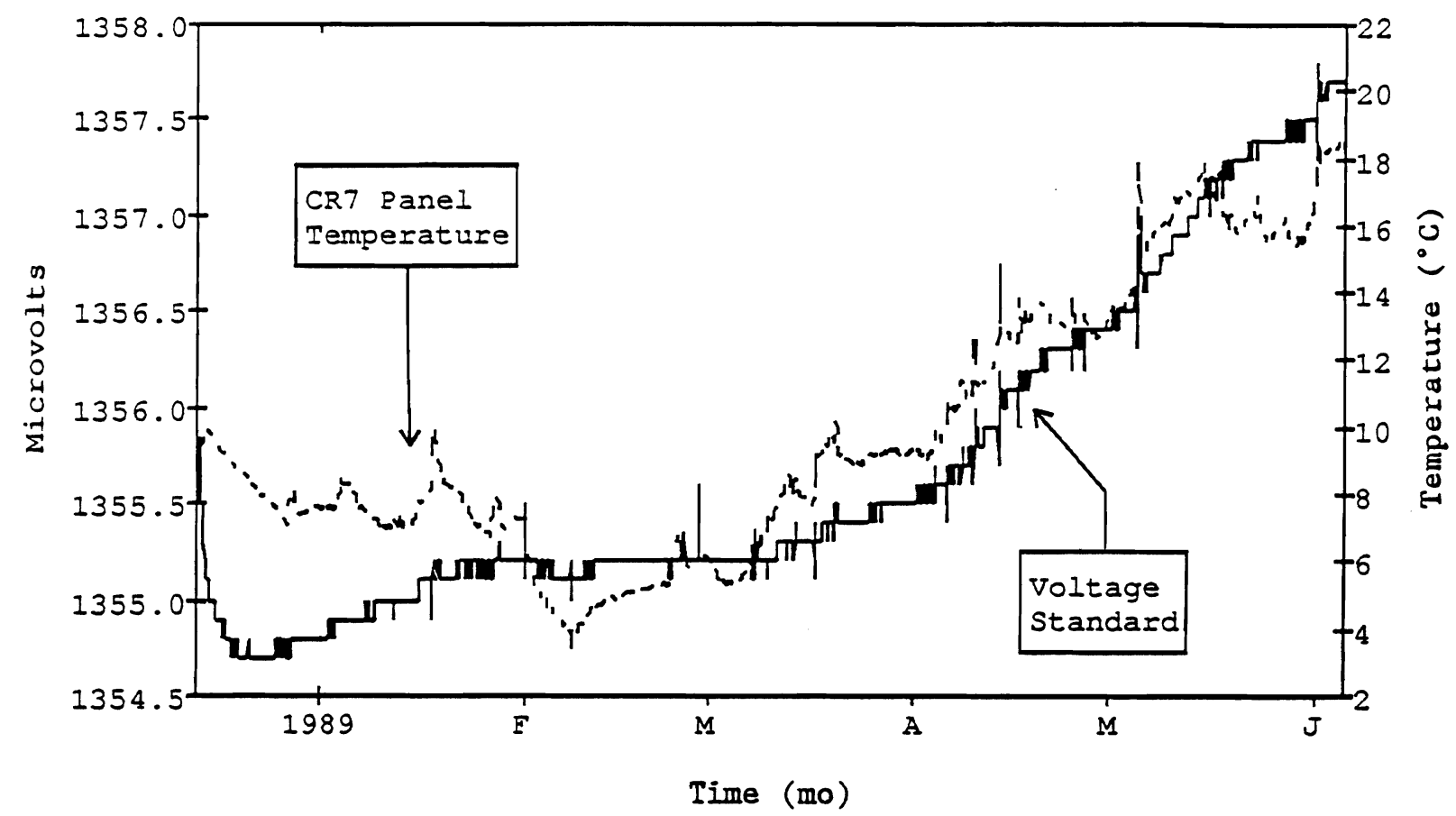

FIGURE 2.4. Temperature and Standard Ce11 Voltage Readings by Datalogger from December 1988 to Apri1 1989

depression is proportional to the rate of evaporation and is detectable as a differential voltage output from the thermocouple. Because standard saltwater solutions have fixed relative humidity levels at constant temperatures, they are typically used to calibrate TCPs. Each TCP was calibrated at the factory to measure moderately dry to very dry soils. TCPs are relatively short-lived instruments, with an indefinite life expectancy ranging from a few weeks under moist conditions to a few years under dry conditions.

Failures in TCPs usually occur from corrosion under moist conditions in the soil moisture range detectable with tensiometers. Corrosion is the main cause of TCP failure and usually occurs gradually over a period of a few months and is detectable as an open circuit. At the tensions above the tensiometer range, water flow due to gravity is insignificant. Such soil conditions of low flow would be confirmed by low readings of the neutron probe and high readings of the gamma probe. The TCPs have been read twice since installation, but the data have not been evaluated. It is our intent to observe operation of the TCPs during FY 1990, under the full range of 
ambient conditions, without carry-over influence from the initial soil moisture status. We expect to be able to evaluate long-term performance of the TCPs and their usefulness in monitoring soil water potential. Recalibration of TCPS is impractical because it would require removal and reinstallation in relatively inaccessible places. For these reasons, factory calibration alone was and will be used.

\subsubsection{Weighing Lysimeter Scale Calibration and Standardization}

Weighing lysimeters have water run-off constrained while measuring precipitation, evaporation, drainage, and storage of water. The specific design of these lysimeters is described by Kirkham, Gee, and Jones (1985). The scales are able to resolve $\pm 50 \mathrm{~g}(0.002 \mathrm{~cm})$ of water. The water content profiles are measured by neutron and gamma probes, and the water potentials in the profiles are measured by tensiometers and TCPS.

Weighing lysimeter scales are tested each year by HEDL for sensitivity and hysteresis and are certified traceable to national standards. Because of high costs of removing lysimeters from the scales during calibration, we devised a method of calibration in which we measured deviations from expected changes as a result of standard weight changes. The stepwise procedure is presented in the Appendix, Section A.4. Figure 2.5 shows the calibration test results from May 1989. (Calibration will be repeated near the end of August and will cover a larger range to include the entire operating range in the test.)

When the scales were first installed, the voltage output ratio was measured with 0,1000 , and 7000 1b of standard weights applied. A regression line through these three points was compared with the regression line through the 11 points of the displaced calibration outlined above for each scale. A11 paired regression 1 ines were equivalent when one of the $7000-1 \mathrm{~b}$ test point readings on one scale was discarded. We believe that the discarded reading was in error because of agreement among all 13 of the remaining points for that scale. Perhaps a lifting harness was inadvertently left on the scale with the weights, for example, but the problem was not detected at the time of measurement nor within memory of it. All of the 10 scale calibration slopes are now in agreement within a standard deviation of 0.0010282 . 

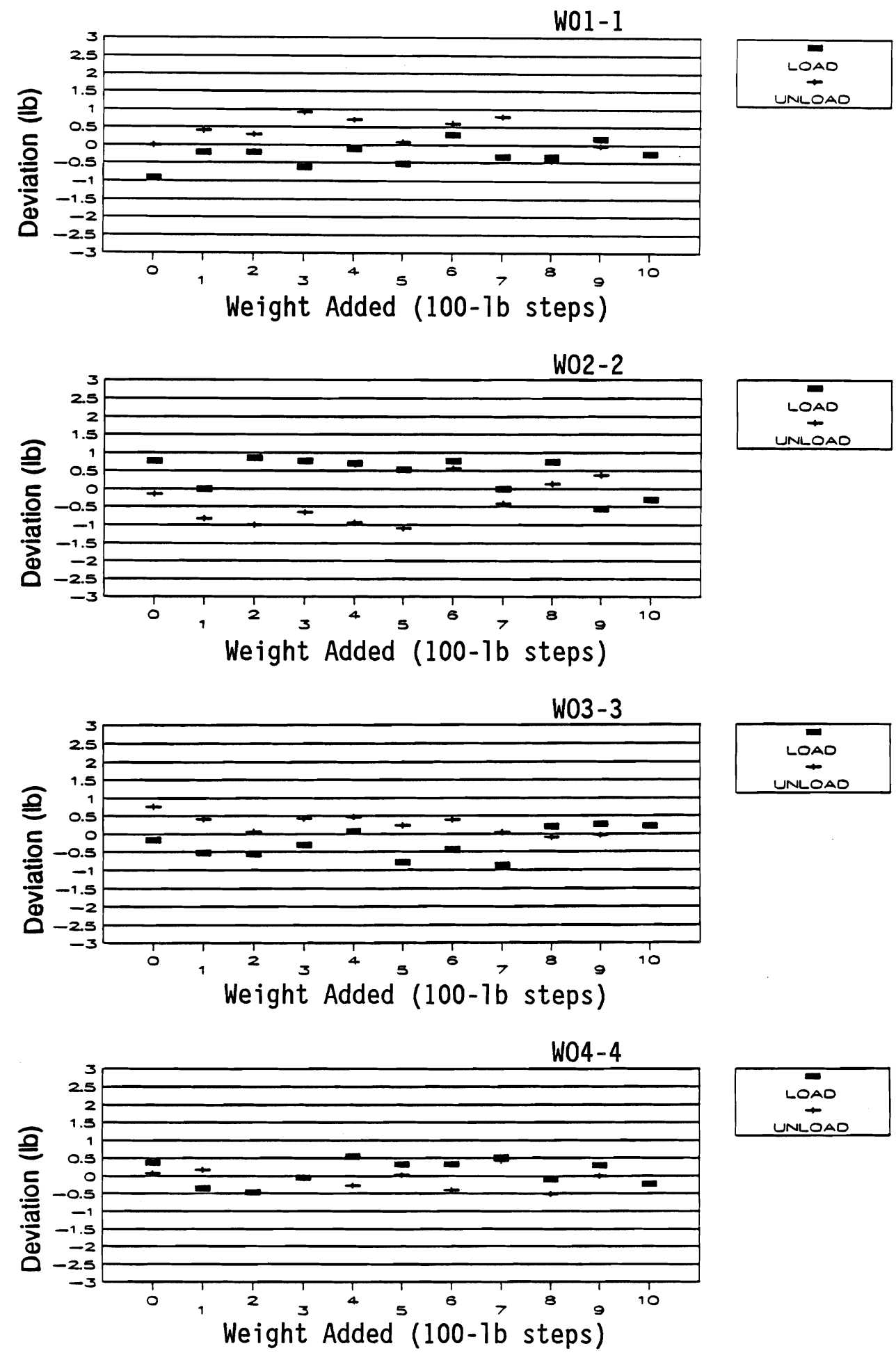

FIGURE 2.5. Weighing Lysimeter Scale Calibration Results, May 1989 
This implies a maximum deviation from the mean of 40 parts in 20,000 , thus justifying exclusion of the one point at $7000 \mathrm{lb}$ which exceeded this amount by a factor of 9 .

\subsubsection{Thermocouple Calibration}

Two types of thermocouples are installed at the FLTF to monitor temperature: copper-constantan and chromel-constantan. The two chromel-constantan thermocouples are installed in the soil just outboard from D07-1 at two levels below the soil surface. All other thermocouples are copperconstantan, and they are installed inside several different lysimeters in configurations designed to reveal horizontal and vertical temperatures. A drawing showing thermocouple locations in weighing lysimeter W03-3 is shown in Figure 2.6.

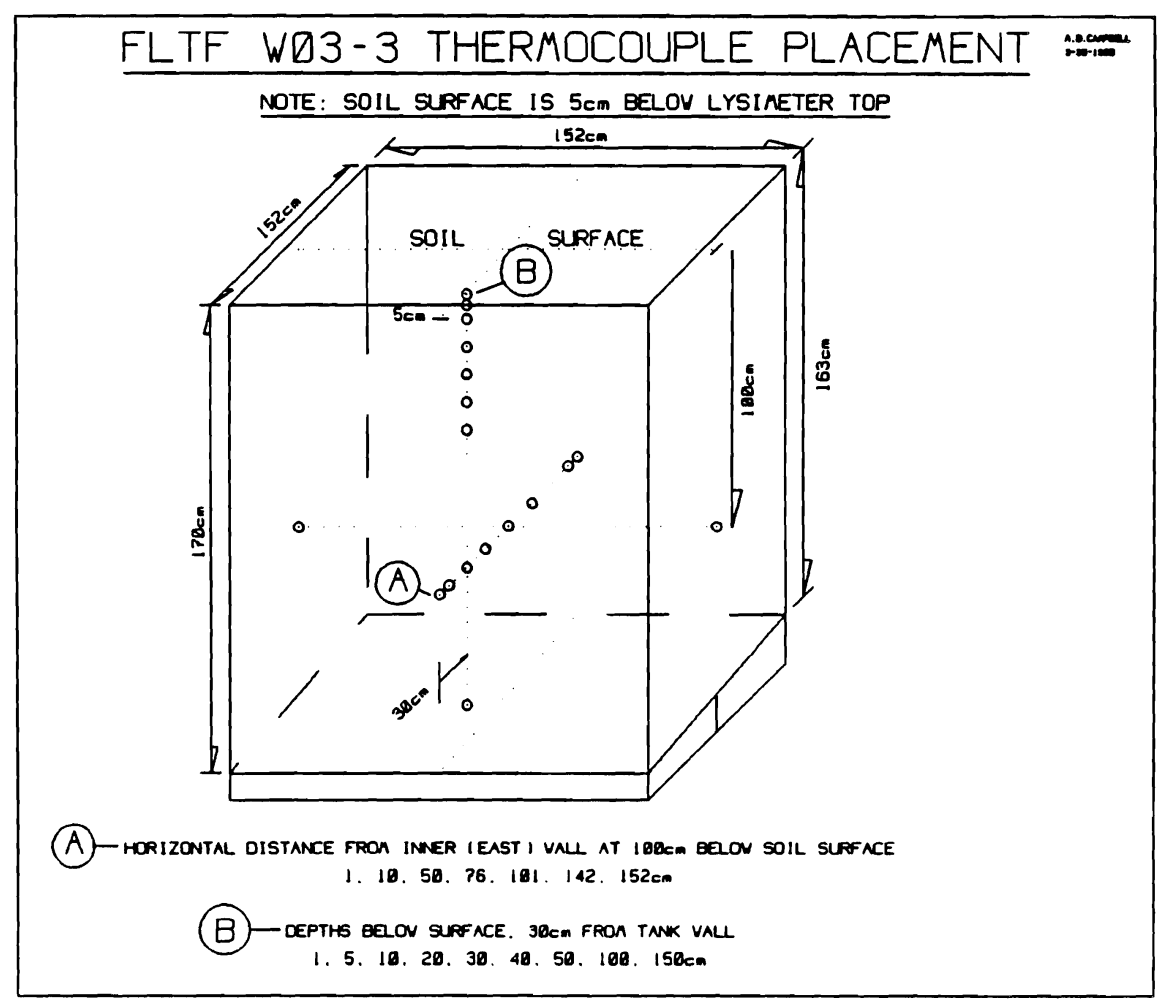

FIGURE 2.6. Thermocouple Locations in W03-3 
Thermocouples at the FLTF are not recalibrated directly; instead, the datalogger is tested using a similar thermocouple placed in a stirred icewater bath. If the temperature displayed by the datalogger is correct, then the other thermocouples are assumed to be correct, if ground-loop errors are not detected. The TCPs discussed earlier are chromel-constantan but are used only for differential temperature measurement.

\subsubsection{Spraybar Water Application and Measurement}

Water was applied to treatments 3,4 , and 7 through a spraybar mounted on the FLTF carriage. During application, water delivery was monitored in two ways: 1) two of the weighing lysimeters measured the water applied to their surfaces on an hourly basis, so the net application was recorded, and 2) up to four tubular, plastic, rain gages were placed randomly in the area where water was applied. Their readings were recorded immediately following application. An outline of the process is described below.

At regular intervals (normally on a 2-week basis, weather permitting), total water application was calculated and, when needed, water was added to the lysimeters designed to receive more than ambient precipitation. The design amount total minus the amount of precipitation received during the period was the amount to be added, but this was reduced by $1 \mathrm{~cm}$ to accommodate a normal storm without overapplication. After deviating from the longterm average precipitation pattern during 1988, we decided to apply water as described above and to remove all deficits by November 1 , the beginning of the new water year. The stepwise instructions are presented in the Appendix, Section A.5.

\subsubsection{Plant Measurements and Equipment}

Vegetation growing on the lysimeters during early 1989 was measured. Plant species occupying the surfaces were identified and measured for both size and location within the lysimeters. Leaf area was estimated from measurements of similar size plants that were harvested outside the lysimeters. The plant roots were also examined by use of a camera lowered into the glass rhizotrons located in each vegetated lysimeter. Special equipment used included the special camera to fit in the rhizotrons and the area meter. Results are reported in Section 3.4.1. 


\subsection{OPERATIONAL CONSIDERATIONS}

Several factors necessarily interact to create useful information on barrier function. Among the more obvious factors are stable and reliable power supply to dataloggers and continuous calibration traceability of transducers and dataloggers. These factors deserve comment because they are important but often neglected.

Electric power interruptions on the 110-V line have occurred several times since the changeover to battery power for the dataloggers. Since the changeover, one of these power interruptions caused overranging of one data set. Low battery voltage readings alerted us to power failures, and we checked the circuit breaker and found it tripped. We have observed the circuit breaker during stormy weather and have witnessed its tripping several times in a $1-h$ interval during a storm. There should be no problem as long as battery voltage is maintained above $11.8 \mathrm{~V}$. When lead-acid batteries drop below the 11.8-V level, they cannot reliably be recharged. We have found it necessary to replace the gel-cell batteries (which are sealed, low-current, lead-acid batteries) just because of their previous history of discharge. Replacement of the two 16 ampere-hour batteries with two 100 ampere-hour batteries now appears advisable because of the relatively high current draw imposed on the batteries when the charger was off.

Scale calibrations not previously considered a problem have become important because of hysteresis errors detected. Until the spring of 1988, the platform scales used for weighing lysimeters were checked only over a 200-1b range. Rigorous calibration was not done because of the cost and inconvenience of unloading each scale. However, a method was devised to adequately measure the precision and hysteresis of each scale without unloading it and to do so over the normal annual range of use. The 1000-1b range now in use will be further extended for lysimeters that may receive more precipitation by experimental design. In addition, a load-cell harness is being designed to unload the lysimeter scale in a precise, calibrated way that will allow full-range calibration of each weighing lysimeter scale.

Datalogger measurements, though not yet standardized, are being monitored and compared periodically with a standardized microvoltmeter. We have 
been unable to locate a reliable nanovolt reference standard. Although we have not resolved the problem, we are currently comparing datalogger measurements with a stable microvolt standard and plan to install a ratiometric standard for testing during late FY 1989.

A top-loading scale with a $120-\mathrm{kg}$ load capacity is being used to weigh drainage water to $\pm 1 \mathrm{~g}$. The scale is calibrated using national standards by HEDL to ensure valid measurements of water from leak tests and drainage. Thus, drainage measurements can be resolved at least ten times as precisely as is required by the experimental design.

While Tensimeter calibrations have been verified using a water column, care is needed to avoid errors from use. For example, when the needle is inserted into the septum to take a measurement, it is important not to do more than just relax the depression of the septum before the measurement. Also, tensiometers installed in dry soil can give erroneous readings if water is added to them repeatedly after they break tension. It is for this reason that they are not to be refilled and read when soil moisture is below that water content where the release characteristic tension exceeds 0.7 bar.

Thermocouple temperatures not previously tested were verified. Periodically, comparisons were made with similar thermocouple readings taken during immersion in a stirred ice-water bath. A standard voltage was simultaneously measured by the datalogger. These two tests ensured adequate datalogger function and correct temperature measurement. 


\subsection{RESULTS AND DISCUSSION OF SECOND-YEAR TESTS}

During FY 1989, we were concerned mainly with the amount, the concentration, the distribution, the energy level, and the final disposition of water added to each barrier system. These concerns are discussed in this chapter.

\subsection{WATER ADDITIONS}

Initial design (Kirkham, Gee, and Downs 1987) called for three levels of precipitation: normal, twice-normal, and breakthrough amounts. Normal meant ambient; twice normal meant twice ambient; breakthrough meant that added water should produce drainage. These definitions placed unacceptable limits on water application as precipitation approached historic lows. We therefore replaced "normal" with "ambient" and twice-normal with twice-average, as will be discussed in Section 3.1.2.

\subsubsection{Precipitation Timing and Amounts}

Water was applied twice each month to treatments 3 and 4 , which were to receive twice-average precipitation. The spraybar output was measured during each water application to ensure correct water delivery. Table 3.1 shows the water applications record. Each water application began with the following calculation:

Amount to apply = Twice-average - ambient - applied - $1 \mathrm{~cm}$

This water application scheme was to be followed for all but the last application in October, when all deficits were to be removed. Figure 3.1 shows ambient, twice-average, and total water applications since uncovering the 1ysimeters in November 1987.

Twice-average precipitation did not produce breakthrough during the first year of testing, perhaps because of a change from the normal storm pattern with time. Among November and December 1987 and January, February, and March 1988, only December was above normal, and by the end of March 1988, 
TABLE 3.1. Water Application and Precipitation Record for the FLTF from November 1, 1987, to April 1, 1989 (cm)

$\begin{array}{lccc}\text { November 1, } 1987 & \begin{array}{c}\text { Twice- } \\ \text { Average }\end{array} & \begin{array}{c}\text { Total } \\ \text { Applied }\end{array} & \begin{array}{c}\text { Cumulative } \\ \text { Precipitation }\end{array} \\ \text { December } & 0 & 0 & 0 \\ \text { January } & 4.4 & 1.6 & 1.0 \\ \text { February } & 9.0 & 9.7 & 5.2 \\ \text { March } & 13.6 & 12.3 & 6.4 \\ \text { Apri1 } & 16.6 & 12.3 & 6.4 \\ \text { May } & 18.5 & 15.3 & 7.4 \\ \text { June } & 20.5 & 22.6 & 10.2 \\ \text { July } & 22.9 & 25.4 & 11.0 \\ \text { August } & 25.7 & 27.1 & 11.3 \\ \text { September } & 26.4 & 27.4 & 11.7 \\ \text { October } & 27.6 & 27.4 & 11.7 \\ \text { November 1, 1988 } & 29.2 & 28.3 & 12.6 \\ \text { December } & 32.0 & 28.4 & 12.7 \\ \text { January } & 36.4 & 33.5 & 14.8 \\ \text { February } & 41.0 & 39.7 & 15.8 \\ \text { March } & 45.6 & 43.5 & 16.3 \\ \text { April 1, 1989 } & 48.6 & 47.7 & 20.5 \\ & 50.5 & 51.7 & 24.5\end{array}$

there was more than a $3-\mathrm{cm}$ deficit to be made up, as shown in Table 3.1. The unusually wet spring of 1988 was warm enough to allow reevaporation at a high enough rate to prevent percolation of water deep into the soil profile. The application of twice-average precipitation was continued for the second year because of the possibility that a change in storm timing over the year could cause breakthrough. February and March 1989 were among the wettest on record for this area and led to the deep percolation of water in treatment 4 lysimeters to add to water that had accumulated from the previous year. Drainage was undetected as of mid-April 1989. 


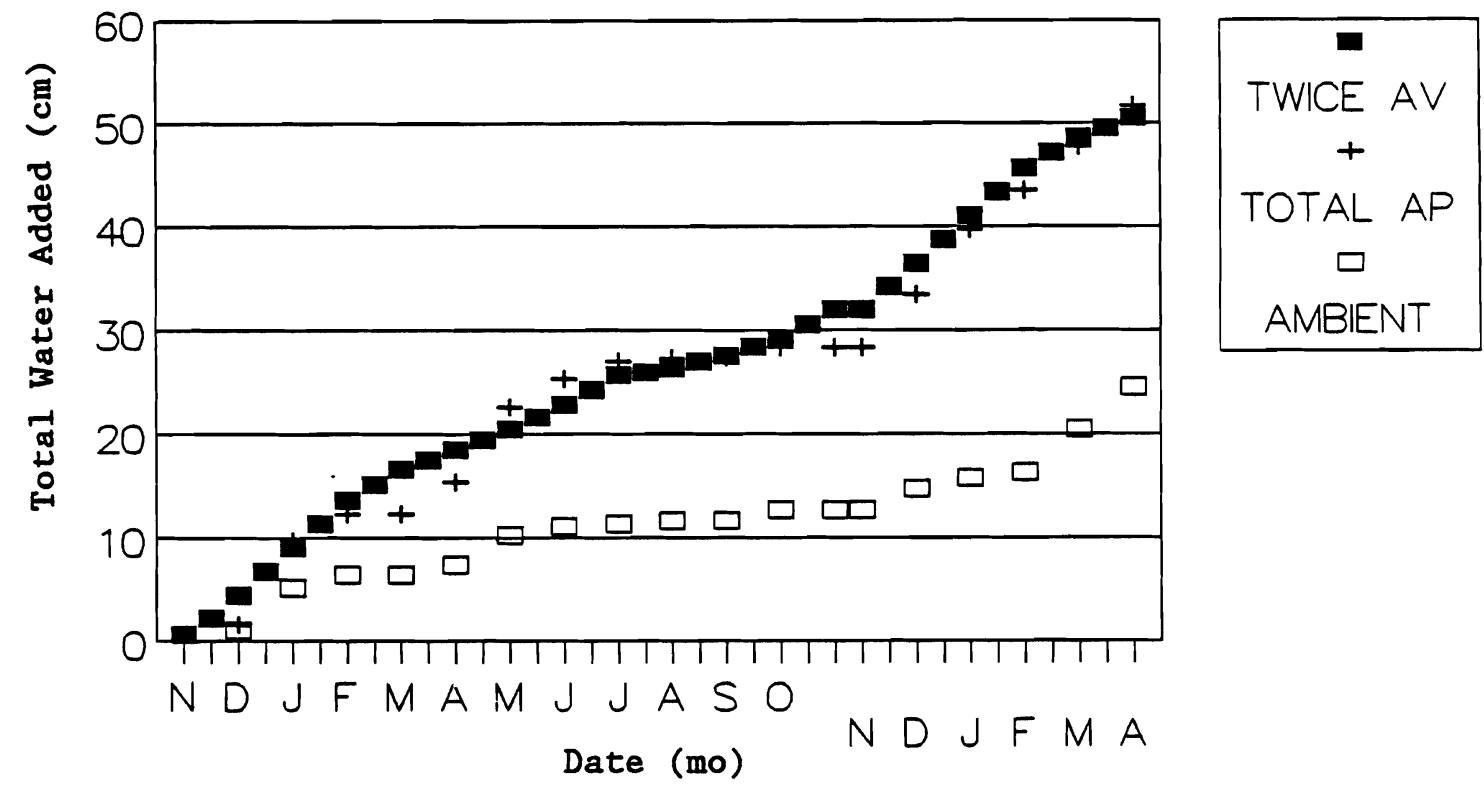

FIGURE 3.1. Ambient and Twice-Average Precipitation and Total Water Application from November 1, 1987, to Apri1 1, 1989

\subsubsection{Restrictions}

Unusually dry or cold weather caused timing and amounts of water applied to become more important issues than originally expected. The unusually dry winter and spring of 1988 dictated a change from twice normal to twice average precipitation. Later, as a result of overwatering, we decided to 1 ag far enough behind the target application to accommodate a normal rainstorm without risking inappropriate breakthrough. We also adjusted the watering pattern to avoid application during the coldest weather when the ground surface was frozen. Subfreezing temperatures made irrigations impractical. Consequently, we avoided irrigating during freezing weather or when the ground was frozen.

\subsection{SOIL MOISTURE MEASUREMENTS}

Soil water contents and tensions were measured twice each month in the soil profiles. The instruments used for routine soil moisture measurement were the neutron probe, tensiometers, and weighing lysimeters. 


\subsubsection{Neutron Probe Measurements}

The neutron probe used was a Model 503-DR Hydroprobe. (a) The Hydroprobe was calibrated initially by fitting a least-squares, linear regression 1 ine through measurements of gravimetric water content multiplied by bulk density. Changes in soil moisture storage that were obtained from probe readings using the regression line were compared with storage changes measured by weighing lysimeters, as described earlier.

The wax and oven-dry soil transfer standards were used before and after each reading set to ensure correct probe function and measurement accuracy. The neutron probe measurements showed moisture distribution in the soil profile and provided an estimate of total soil moisture storage.

We measured soil moisture at $15-\mathrm{cm}$ intervals, beginning just below the fine soil layer in each lysimeter and ending with a measurement in the probe shield located $20 \mathrm{~cm}$ above the soil surface. The profile measurements displayed in Figure 3.2 show how soil water content varied over time.

Water content measurements were also used to determine when tensiometer measurements should be valid at the tensiometer positions in the profiles. Without using water content measurements, reliable management of tensiometers was impossible, as discussed earlier. The profile measurements displayed in Figure 3.3 show tension and content and how water in treatment 4 was responding to the barrier.

Both water content and tension measurements confirm that water moved through the upper soil. Evidently water did not move into the underlying sand or grave1. Profile measurements in Figure 3.4 show that water distribution in the profiles of treatment 4 were approaching the level of treatment 7 , which had drained about 5 vol\% following breakthrough.

The profile measurements show that water was able to move through the silt-loam soil to the hydraulic barrier when the water content was slightly above 20 vol\%, but that the water did not drain through the barrier, even at concentrations of 35 vol\%.

(a) Hydroprobe is a tradename of CPN Corporation, 2830 Howe Road, Martinez, California 94553. 


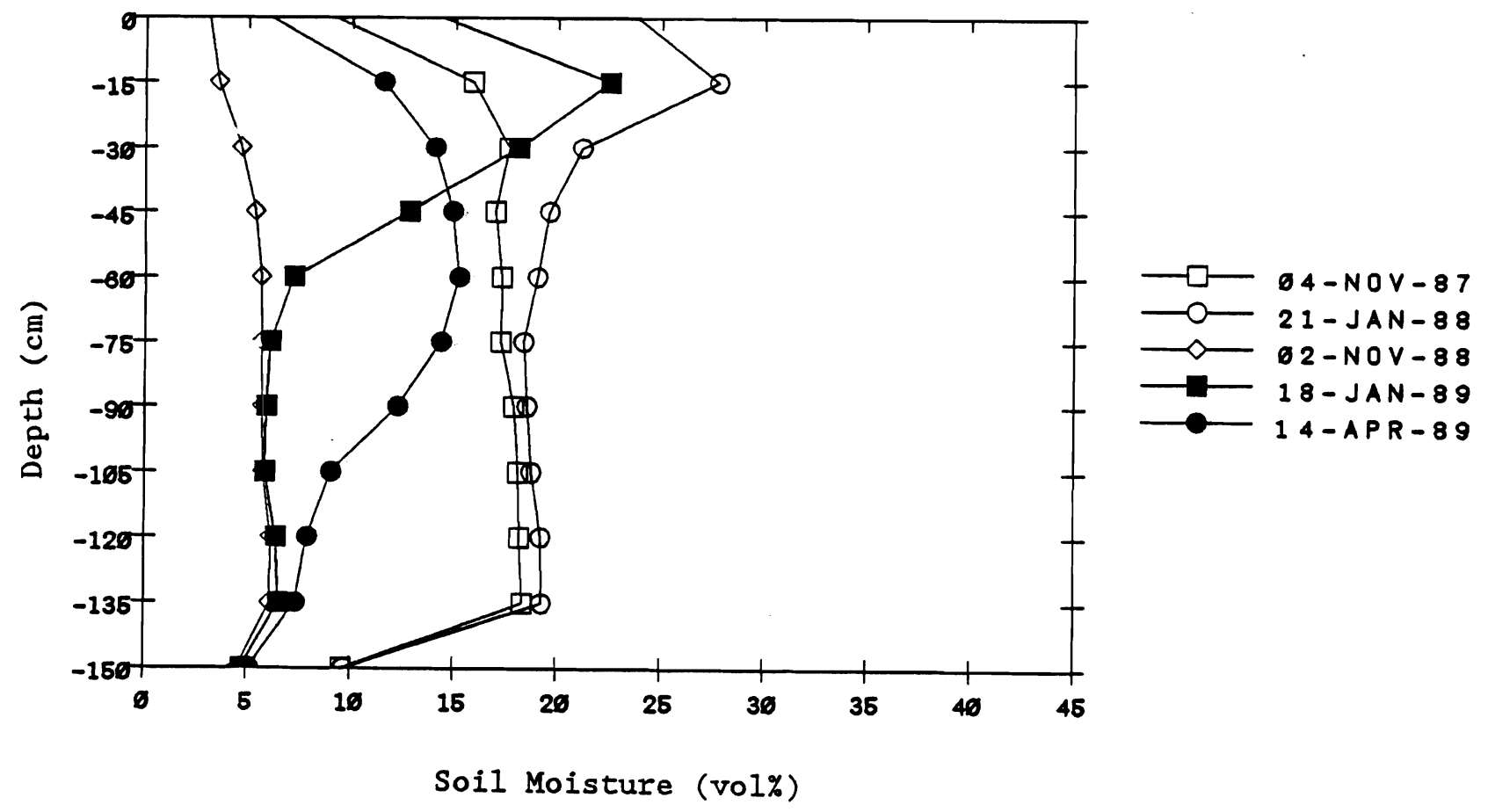

FIGURE 3.2. An Example of Soil Moisture Profile Variation with Time (twice-average precip. with vegetation)

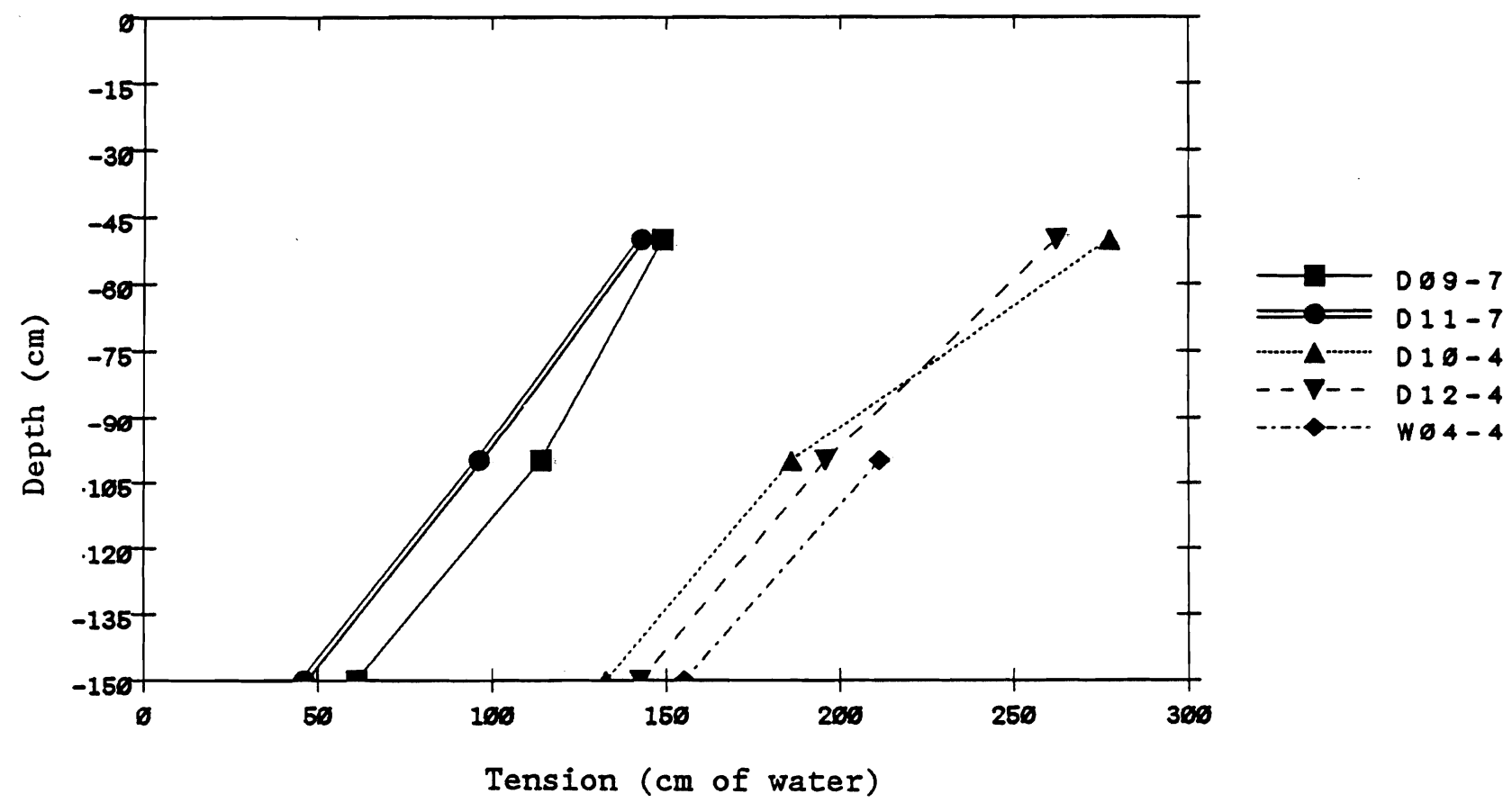

FIGURE 3.3. Treatment 4 (bare, $2 \times$ precip., $1.5-\mathrm{m}$ soil depth) Water Profile Distribution and Tension in Response to Hydraulic Barrier 

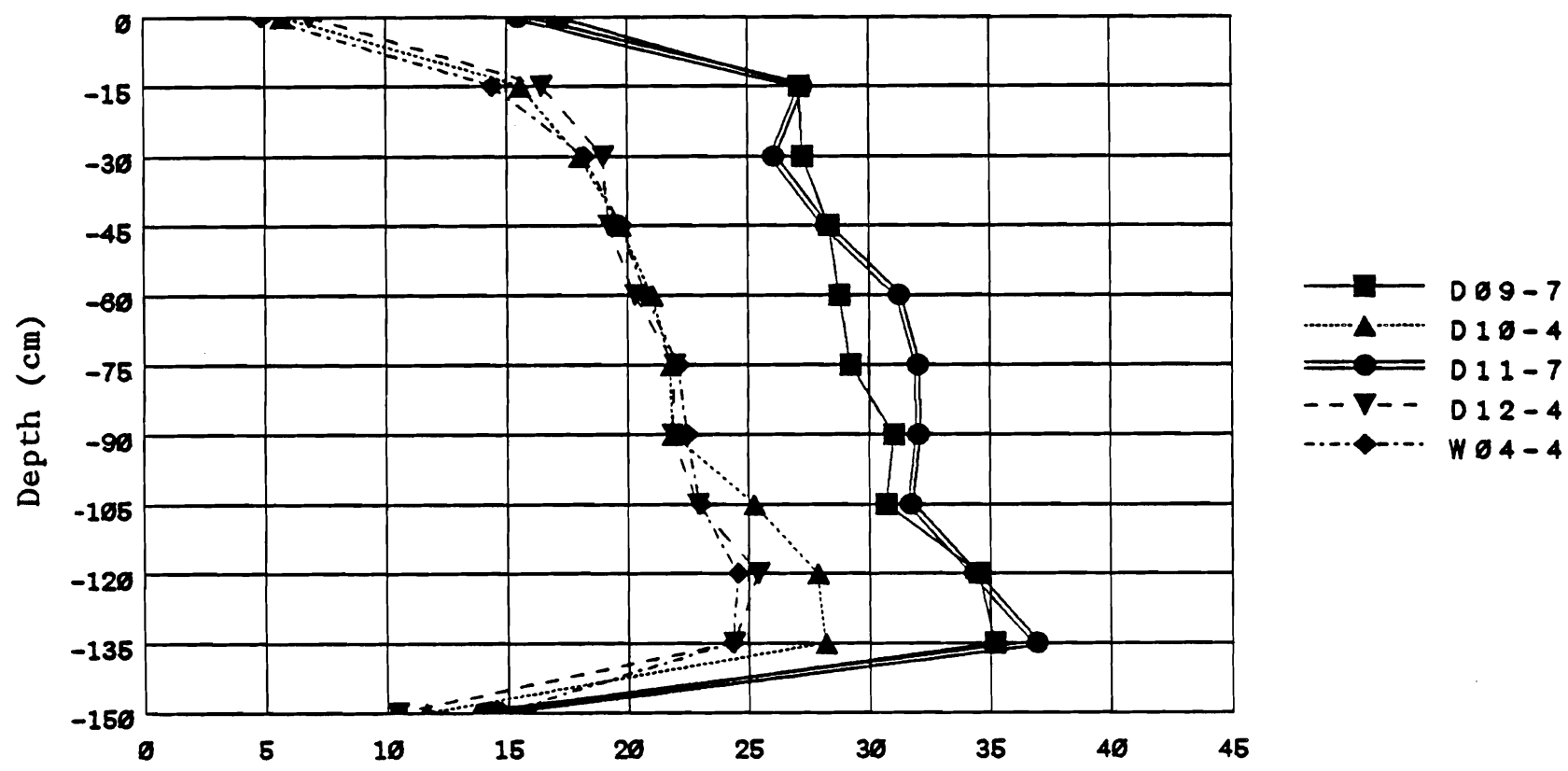

Soil Moisture (vol\%)

FIGURE 3.4. Comparison of Soil Moisture Profiles in Treatments 7 (breakthrough) and 4 (twice-average precip., bare), Apri1 14, 1989

Storage changes were deduced from changes in profile measurements such as those depicted in Figure 3.5. Figure 3.6 shows the various treatments and how the water storage changed over time within each treatment. Treatment effects become evident from comparisons between graphs.

\subsubsection{Soil Moisture Tension Measurements}

Measurements of soil moisture tension were made using a Tensimeter to read conventional ceramic cup tensiometers. Measurements shown in Figure 3.7 reveal a change in the tension pattern that corresponds with the change in the soil water content shown in Figure 3.8. That is, as the water content increased near the sand layer, the tension decreased. Corrections were applied to tension readings taken by the Tensimeter to account for waterlevel displacements in the site tubes.

Measurements were restricted to silt-loam soils having above 18 vol\% moisture, as discussed previously. Tensiometers within the required moisture range were serviced quickly to avoid adding water to the soil immediately 


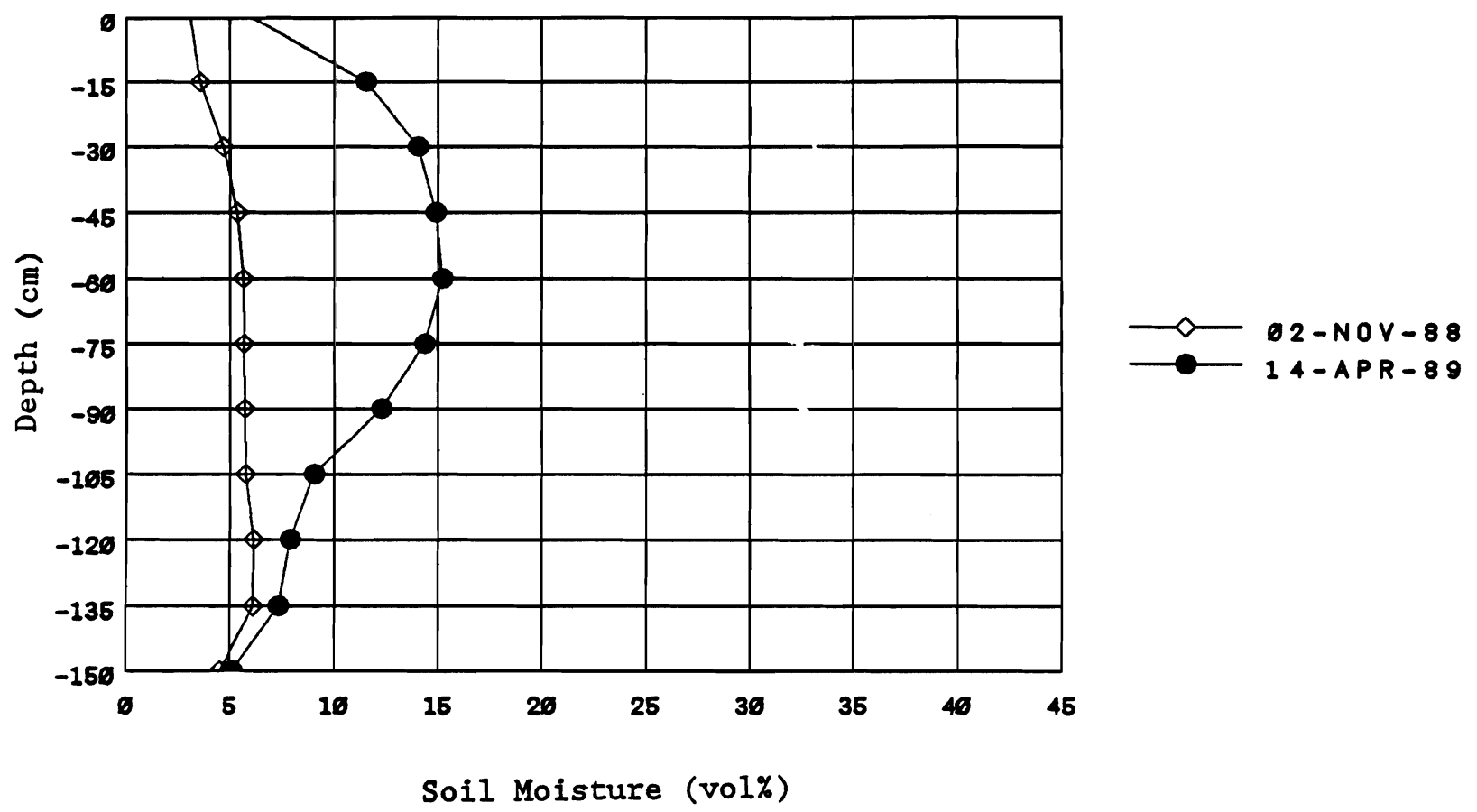

FIGURE 3.5. Storage Changes as the Difference Between Two Soil Profiles Measured by the Neutron Probe (twice-average precip. with vegetation)

surrounding the ceramic cup. The tension readings taken during the 1988 tests to breakthrough (treatment 7 ) indicated that a perched water table existed temporarily as positive pressure values were obtained, suggesting that saturation occurred prior to observed drainage. Thus, tension and content readings of water above the barrier were in agreement.

\subsubsection{Weighing Lysimeter Measurements}

Weight changes after the water was added agreed with the weights (amounts) of water added. Rain events and irrigation events agreed with each other and rain amounts agreed with the values reported by the meteorological station.

\subsubsection{Lysimeter Weight Changes With Time}

Figure 3.9 shows the change in weighing lysimeter water storage since November 1987. Evidently, vegetation contributed to water loss in both the ambient and twice-average treatments. 
Ambient Precipitation
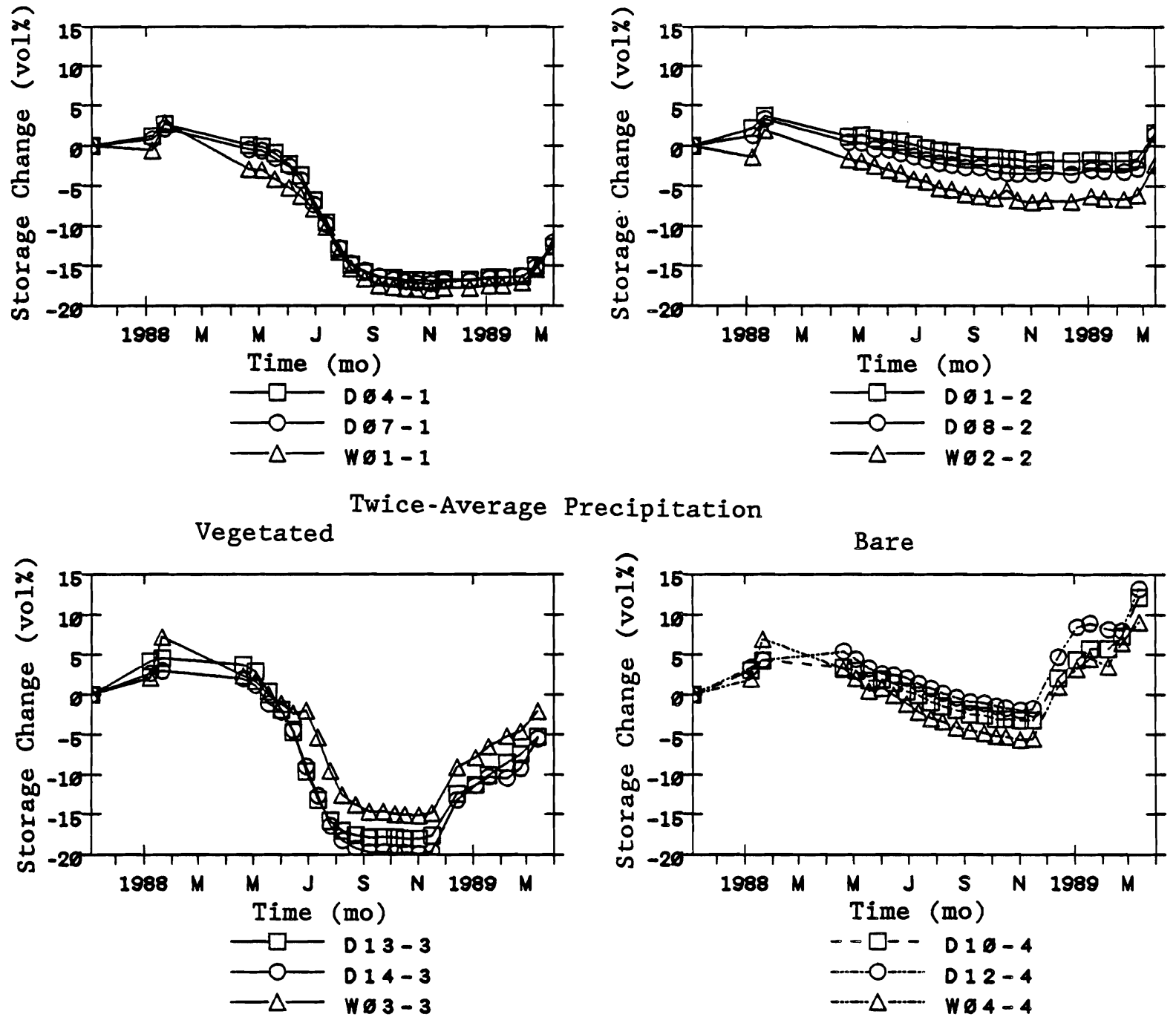

Ambient Precipitation
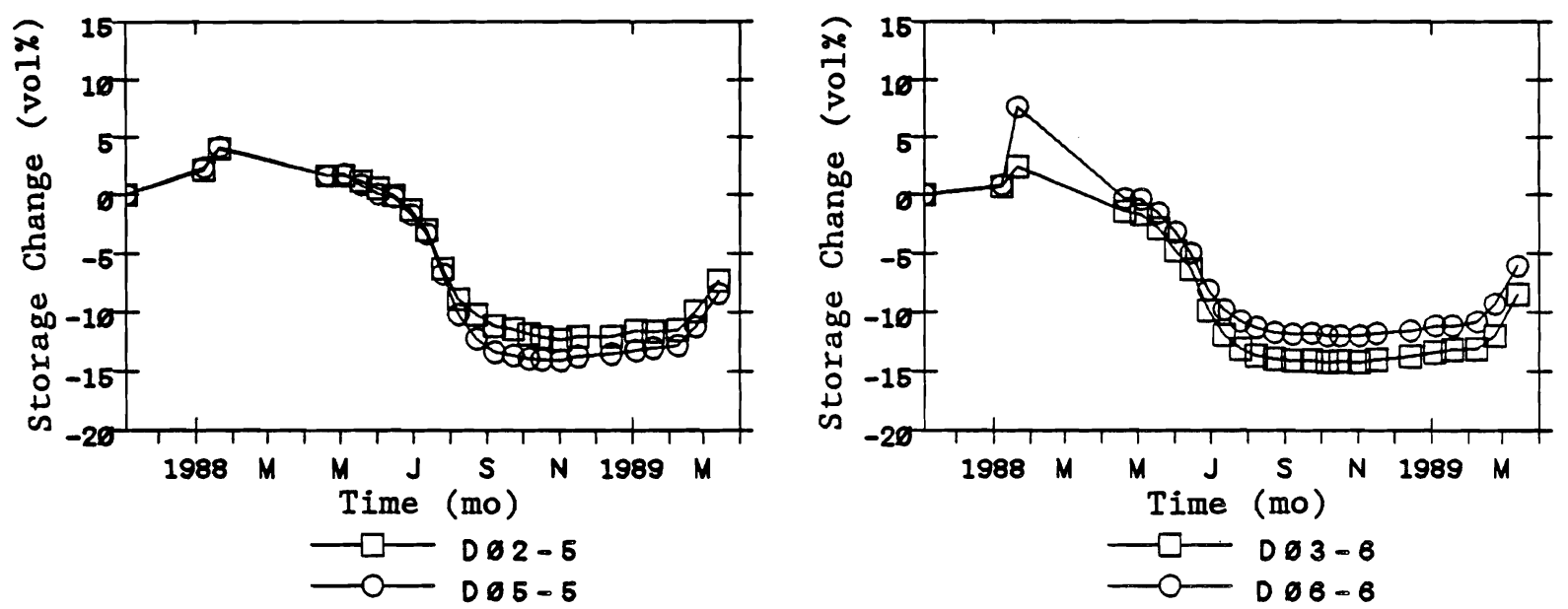

FIGURE 3.6. Water Storage Changes Within Each Treatment Over Time 


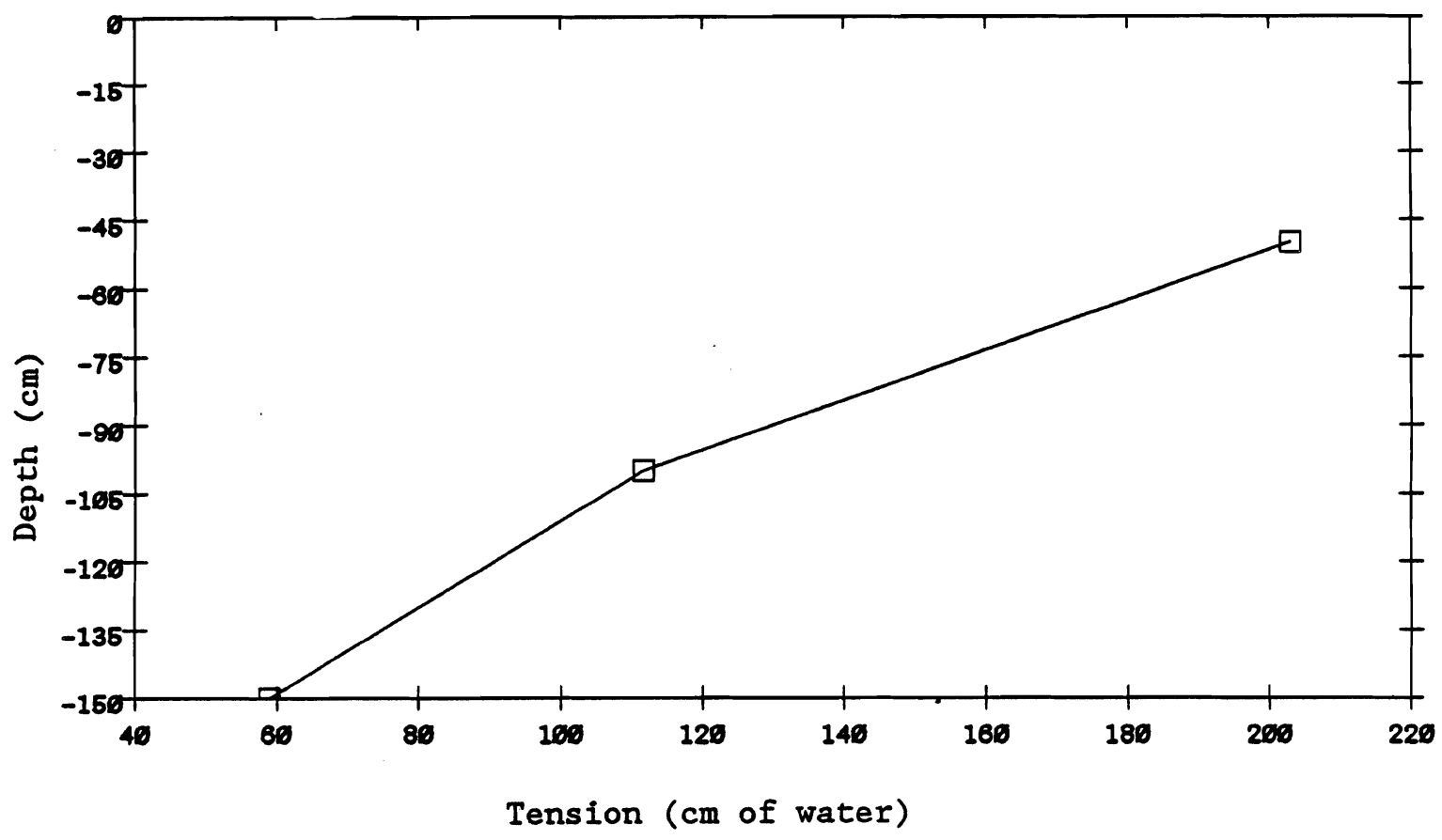

FIGURE 3.7. Soil Moisture Tension Profile in Lysimeters D09-7

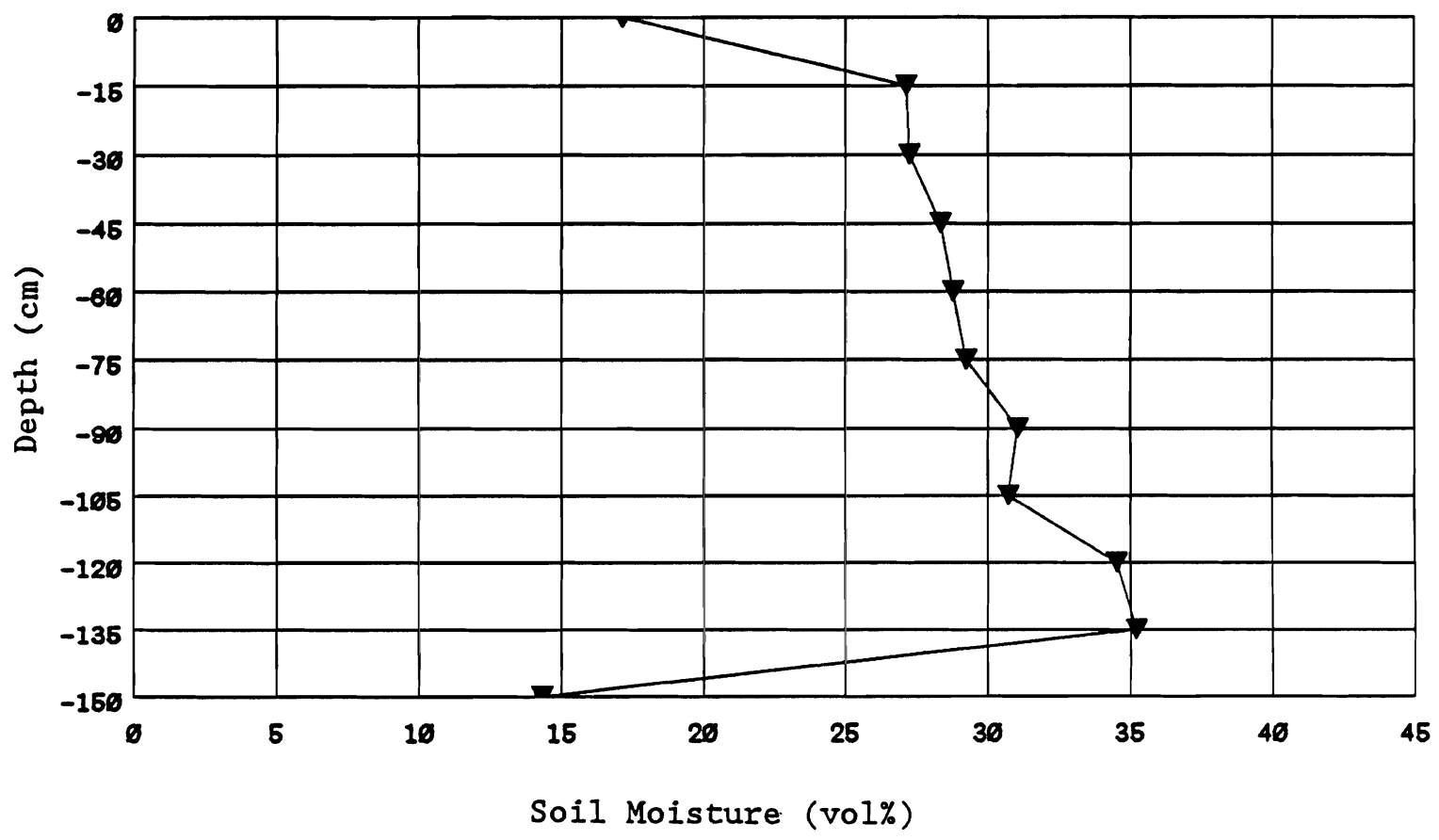

FIGURE 3.8. Soil Water Content Profile in Lysimeter D09-7 (precipitation to breakthrough) 


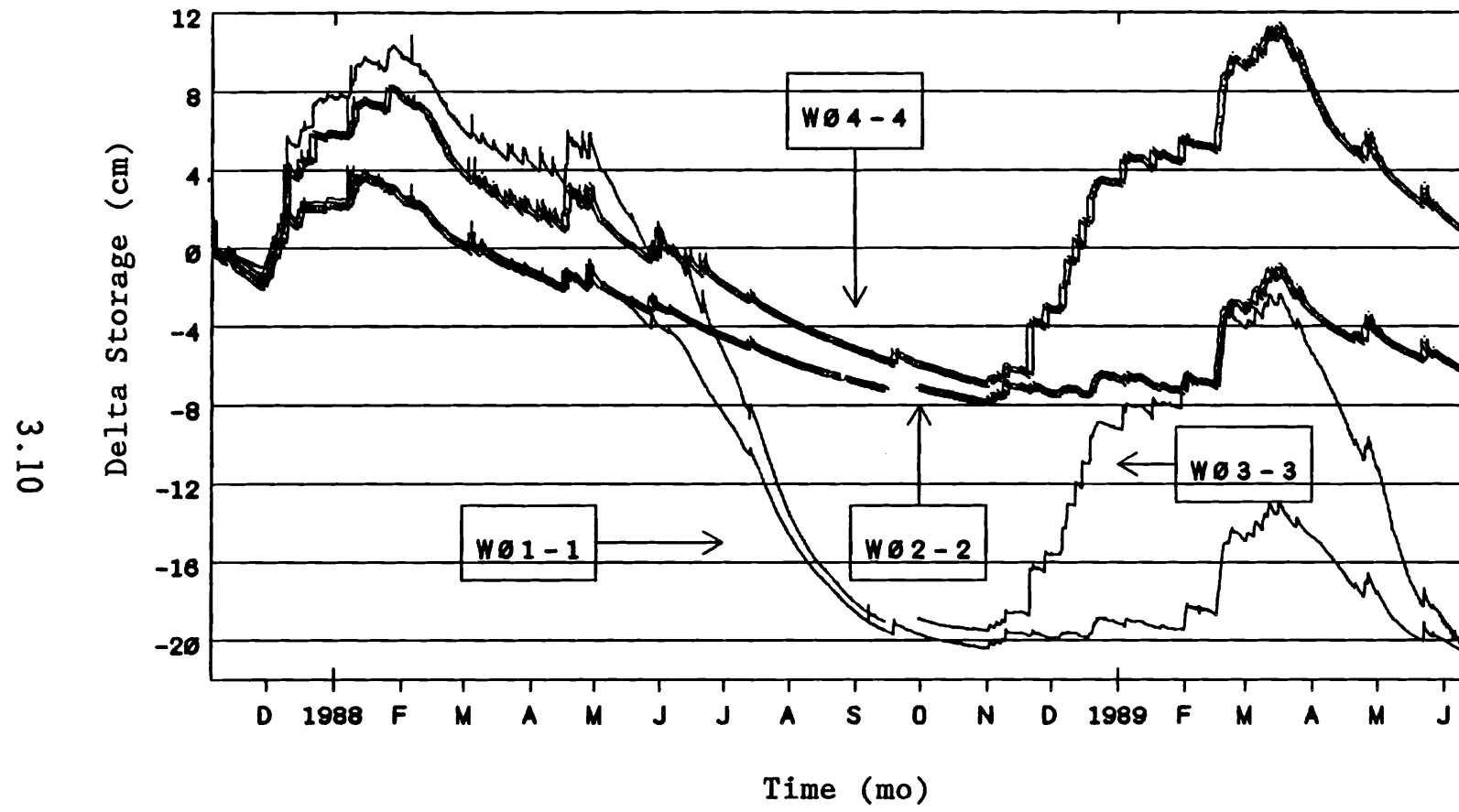

-1 Ambient Precipitation, Vegetated

-2 Ambient Precipitation, Bare

- 3 Twice-Average Precipitation, Vegetated

-4 Twice-Average Precipitation, Bare

FIGURE 3.9. Water Storage Change Based on Weight Changes in Lysimeters 
Figure 3.10 is based on the same weight data as Figure 3.9 but is adjusted to show actual water storage instead of showing just the change from the initial condition. The low points reached during mid-1988 represent the extraction limits for vegetated and nonvegetated lysimeters. The twiceaverage precipitation treatment lost more water and lost it faster than the ambient treatment until a nearly identical minimum water content was reached by both treatments. This loss pattern was expected because more available water usually leads to more vegetation with increased transpiration. The pattern of extraction indicates a parallel behavior among treatments. Common water extraction limits apparently exist for vegetated plots. A1so, common water extraction limits apparently exist for plots without vegetation, but vegetated plot extraction limits are lower than nonvegetated plot limits.

\subsubsection{Treatment Effects on Water Storage in Lysimeters}

Evaporation and evapotranspiration are separable, as shown in Figures 3.11 and 3.12. Lysimeters W01-1 and w03-3 with vegetation lost more water and at a faster rate than lysimeters W02-2 and W04-4 without vegetation. The effects of vegetation are distinguishable in Figures 3.11 and 3.12 , where it is apparent that vegetation was capable of removing about twice as much water as was removed by soil surface evaporation alone.

A remarkable similarity existed during dry periods between treatments receiving ambient and those receiving twice-average precipitation, as shown in Figure 3.13, attesting to the ability of the atmospheric environment to influence the soil to a common depth.

\subsubsection{Weighing Lysimeter and Neutron Probe Measurement Comparisons}

As soil moisture changes over time and under the influences of the seven treatments, it is possible to observe the emergence of the dominant influences. These influences will be displayed in a time sequence of graphs. It should prove helpful, however, to examine data that show the relationship between methods of measurement. Comparisons between weighing lysimeter and neutron probe measurements are shown in Figure 3.14.

The small differences are probably the result of integration errors on neutron probe measurements near the upper and lower soil boundaries. Even 


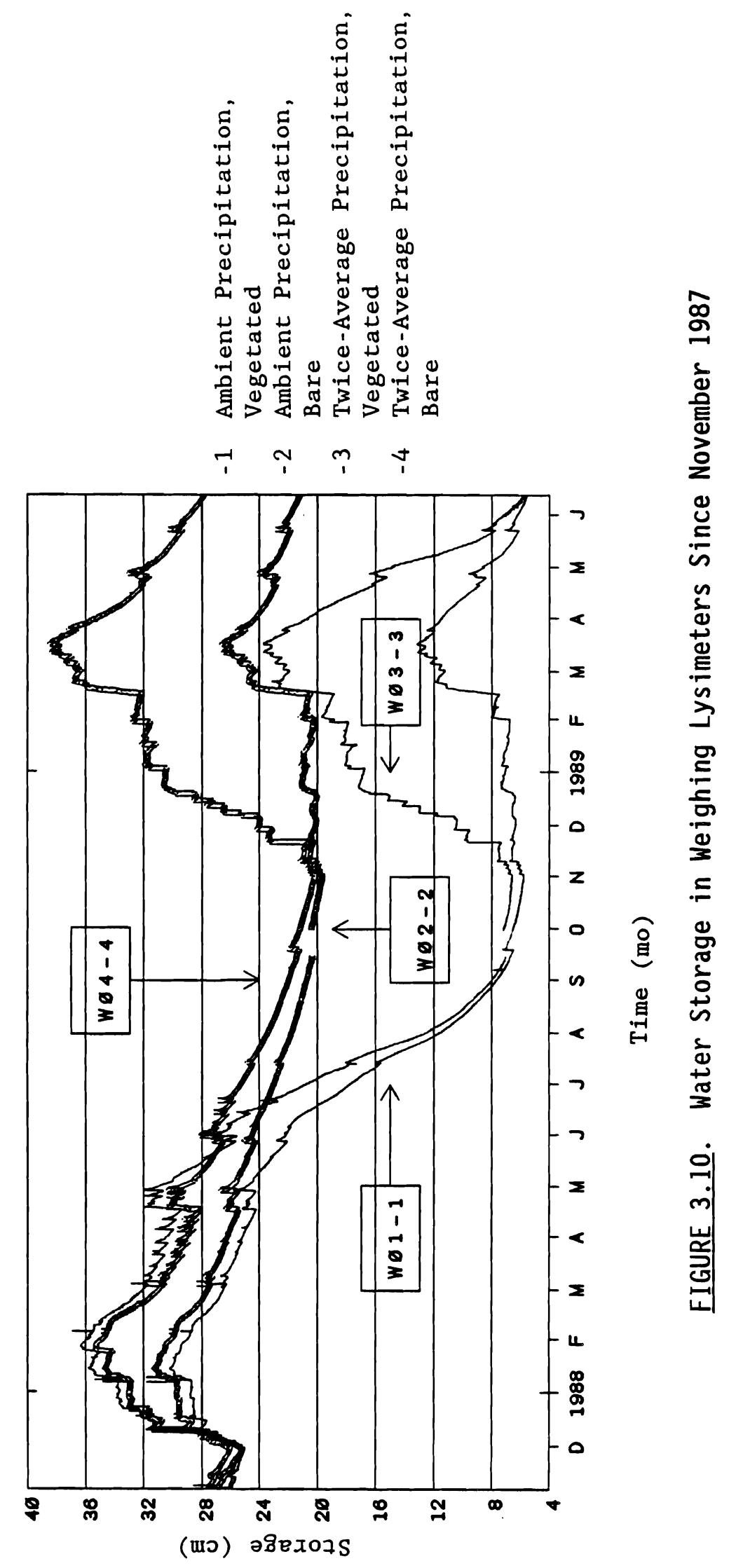




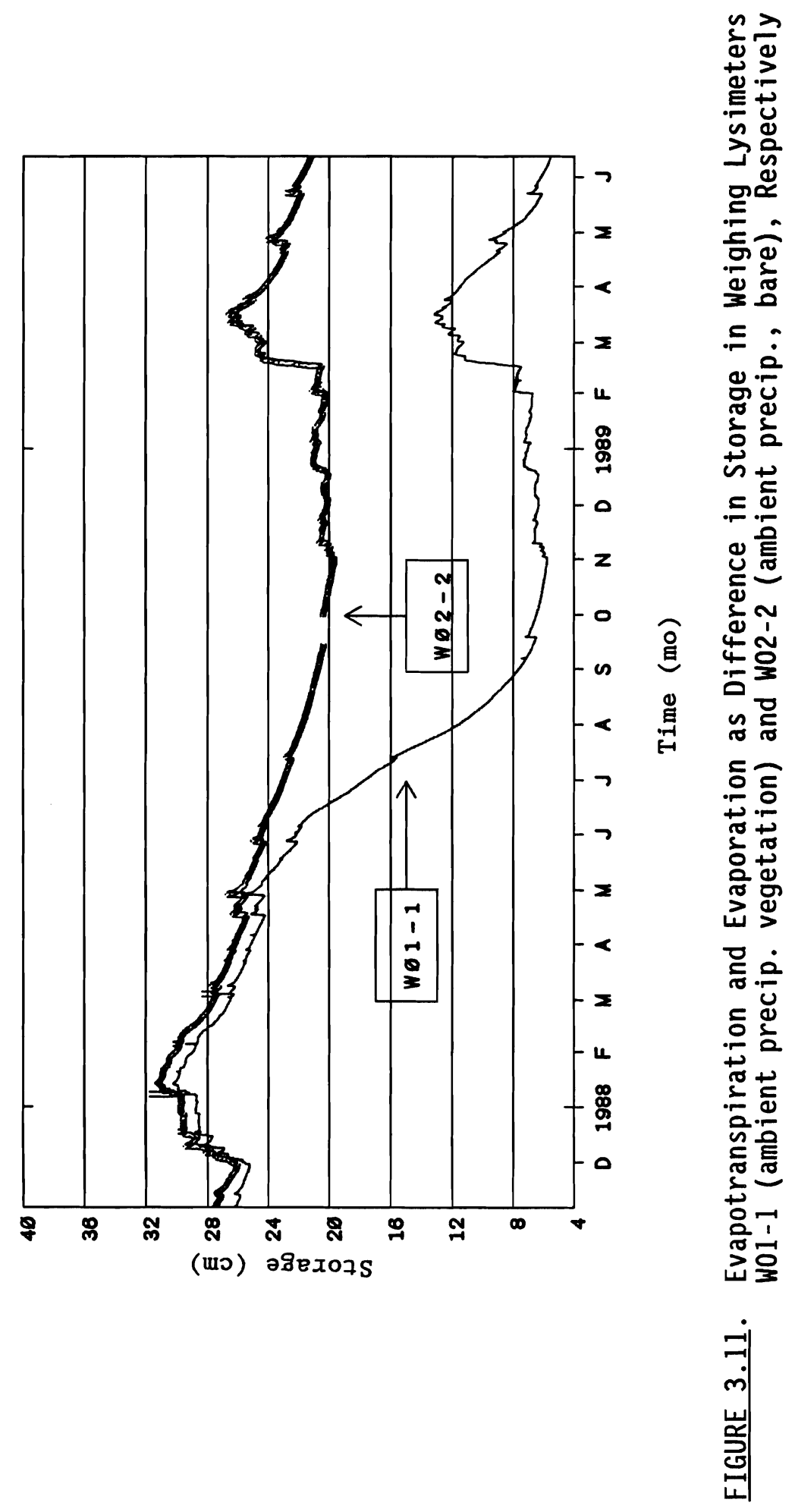




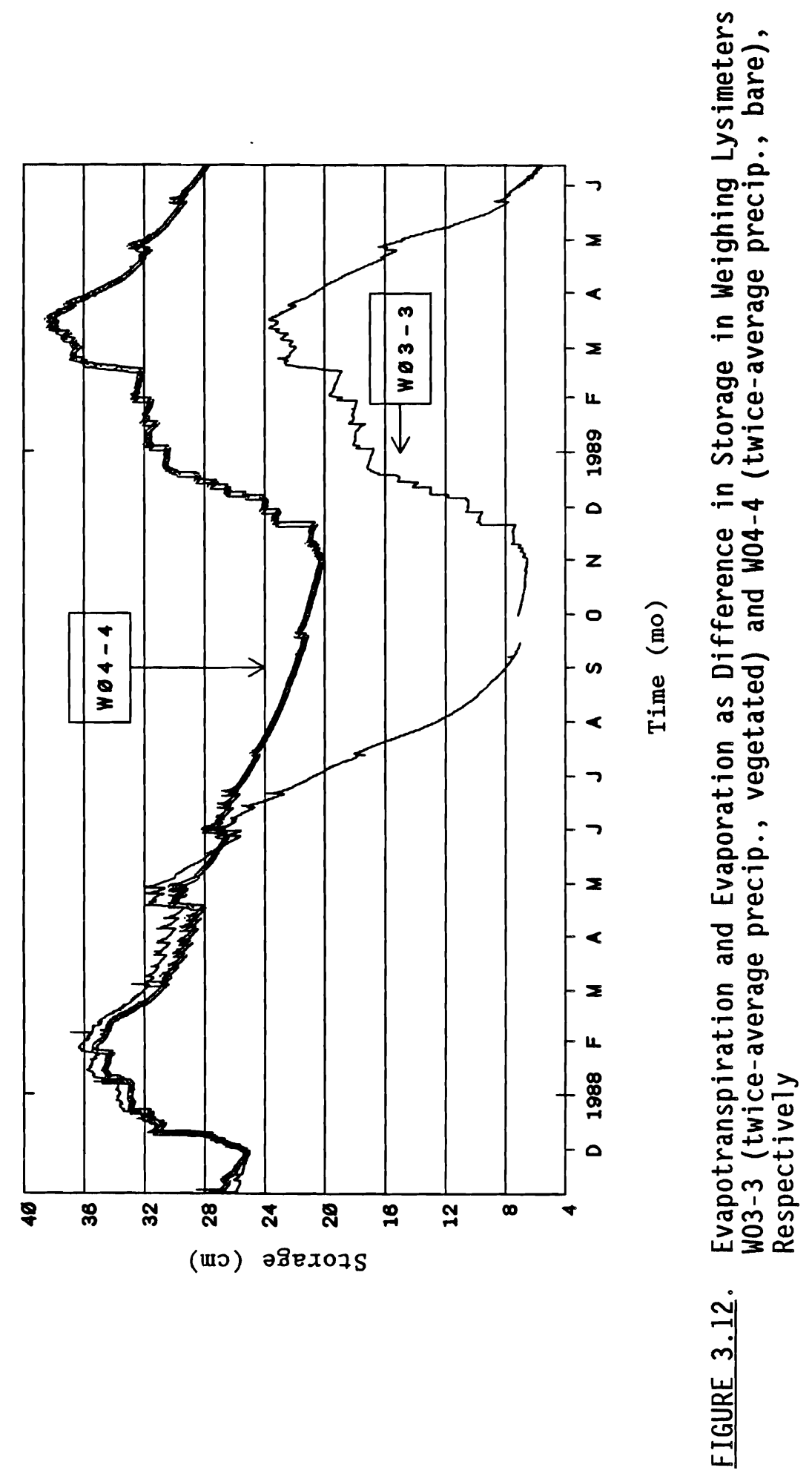




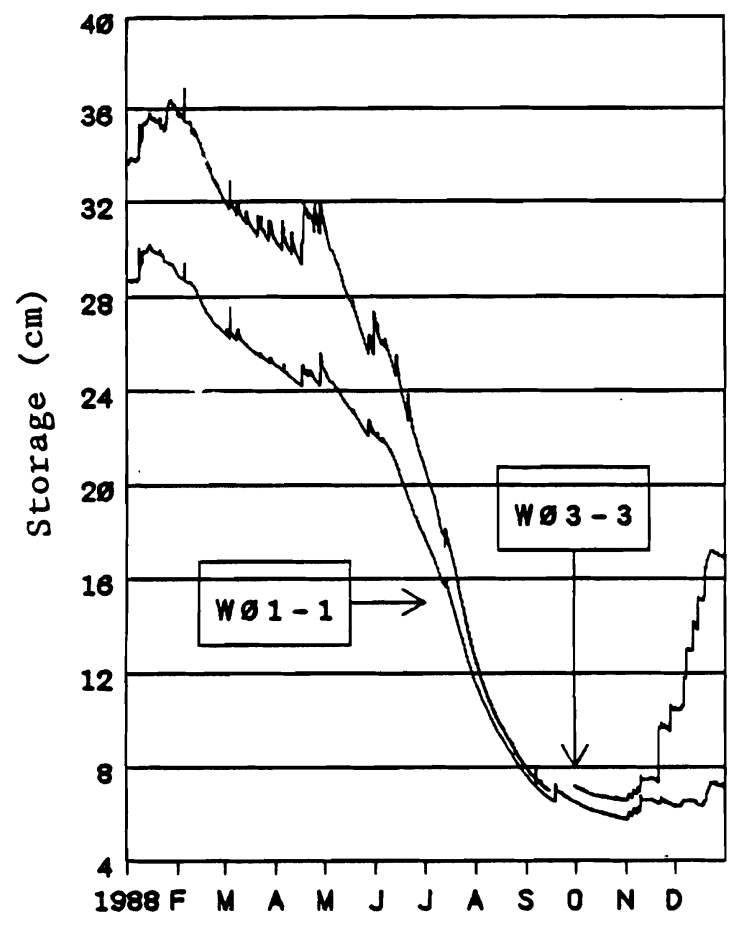

Time (mo)

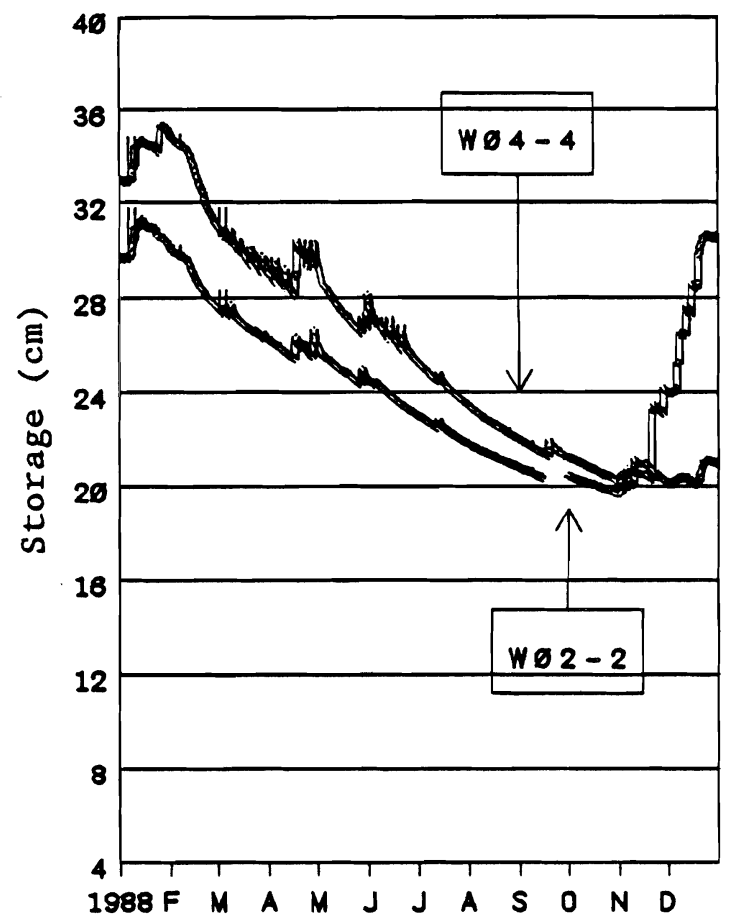

Time (mo)

-1 Ambient Precipitation, Vegetated

-2 Ambient Precipitation, Bare

-3 Twice-Average Precipitation, Vegetated

-4 Twice-Average Precipitation, Bare

FIGURE 3.13. Water Removal Patterns in Weighing Lysimeters

sma11 changes are apparently accounted in both measurements. Crossover, coupled with similarity, of the graphic plots indicates reasonable agreement between calibrations of both instruments.

\subsubsection{Soil Moisture Profile Measurements}

Initially, water was almost uniformly distributed in the soil profiles of all the lysimeters, as shown in Figure 3.15. As a consequence of imposing various treatments on the lysimeters, the water balance began to differ over time. Thus, soil moisture profiles that were similar initially, as shown in Figure 3.15, became significantly different as the influences of the different treatments began to prevail, as shown by the time sequence in Figures 3.15 through 3.22 . 


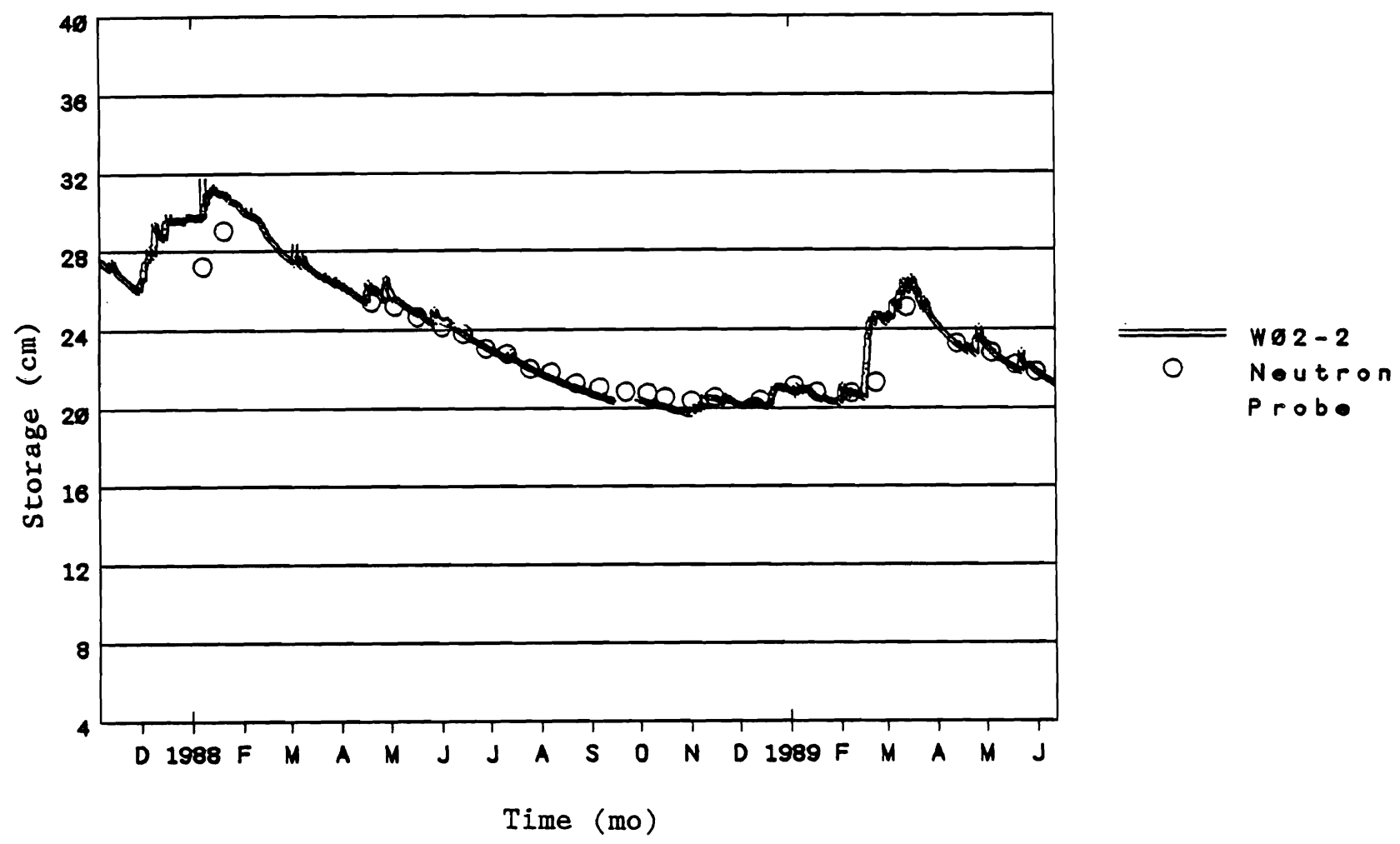

FIGURE 3.14. Comparison of Neutron Probe and Weighing Lysimeter Measurements of Water Storage

Initial moisture contents that differed no more than 6 vol\%, differed as much as 20 vol\% within 2 months as winter storms and irrigation were applied (Figure 3.16). As expected, the moisture profile change began at the surface and propagated downward. By the end of 3 months, the added moisture had penetrated to a depth of $60 \mathrm{~cm}$, and the twice-average precipitation treatment was distinguishable (Figure 3.17).

Special treatment of D09-7 and D11-7 began on March 14, 1988, and by April 20, the entire profile depth showed increased moisture (Figure 3.20). Profile moisture increased unti1 breakthrough on June 6, 1988. At breakthrough, the bottom of the profile contained about 14 vol\% more water than the same soil with uniform texture would normally hold. This increased water content and profile development demonstrated the designed function of the barrier by holding more than usual water long enough to allow it to recycle to the atmosphere while inhibiting drainage. The increased static capacity 


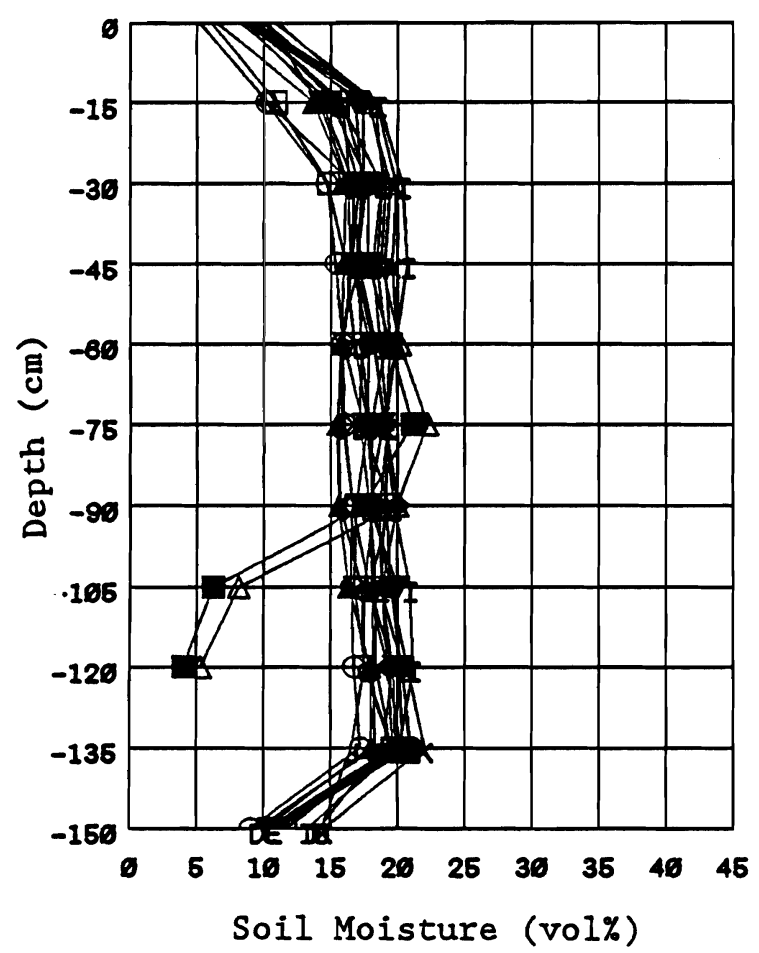

FIGURE 3.15. Initial Moisture Distribution in Lysimeter Soil Profiles

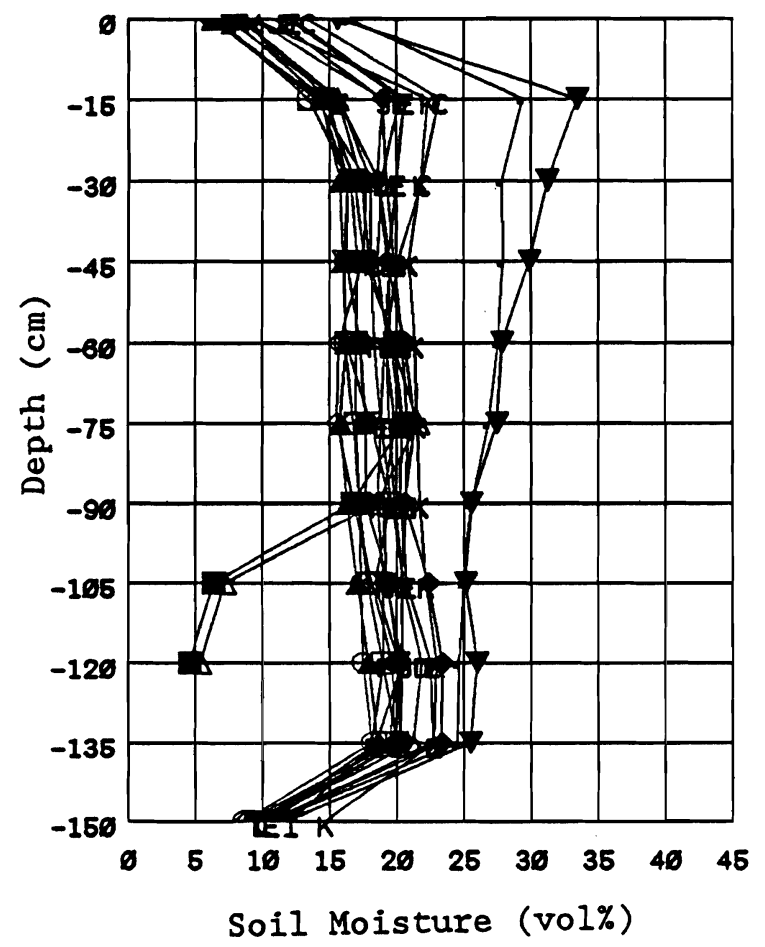

FIGURE 3.17. Soil Moisture Distribution in Lysimeters in April 1988

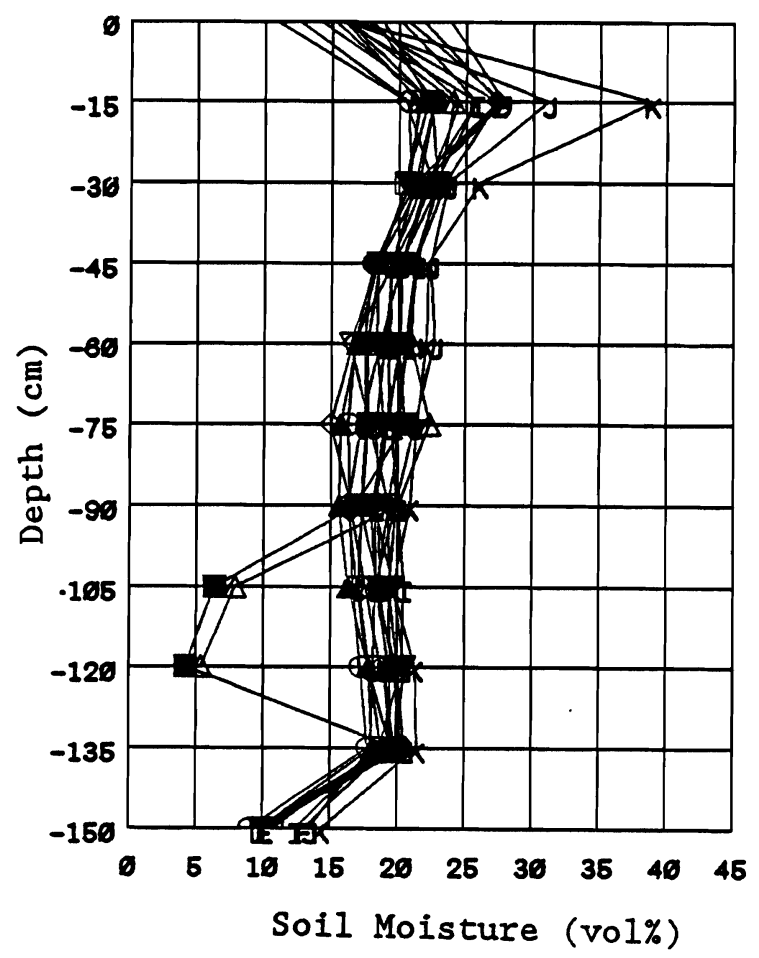

FIGURE 3.16. Soil Moisture Distribution in Lysimeters in January 1988
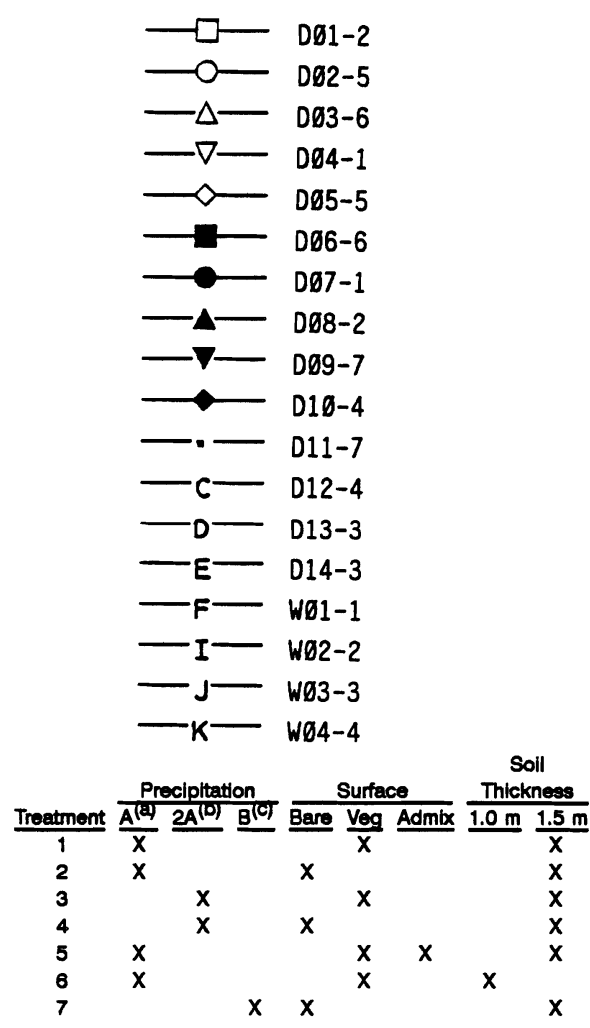

(a) Amblent precipltation.

(b) Twice average precipitation.

(c) Precipitation until breakthrough. 


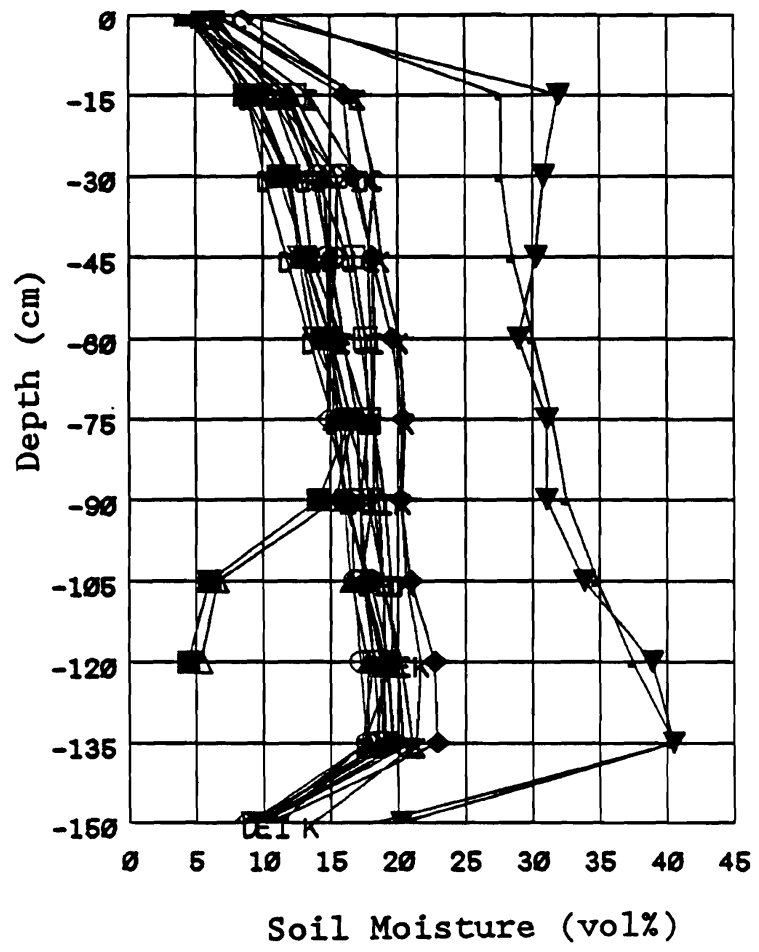

FIGURE 3.18. Soil Moisture Distribution in Lysimeters in June 1988

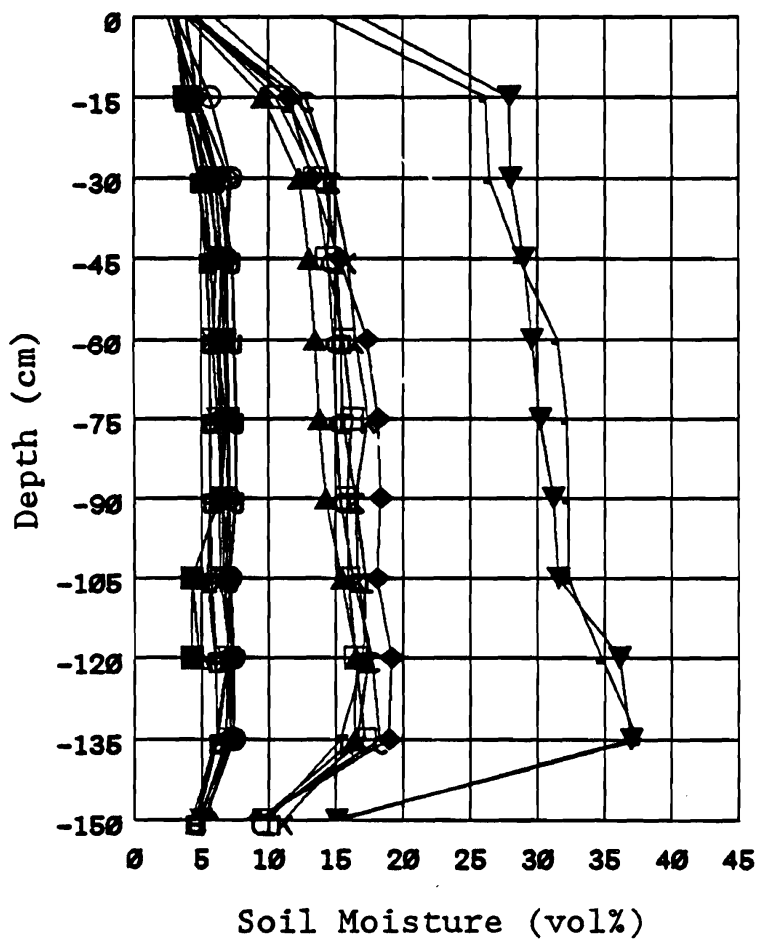

FIGURE 3.20. Soil Moisture Distribution in Lysimeters in November 1988

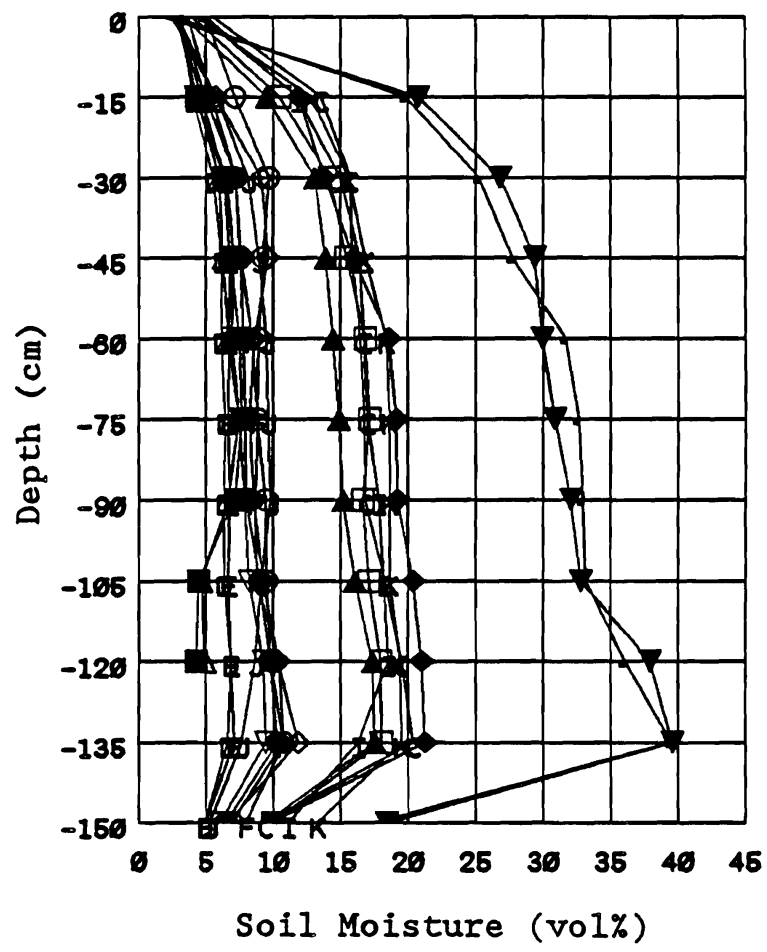

FIGURE 3.19. Soil Moisture Distribution in Lysimeters in August 1988
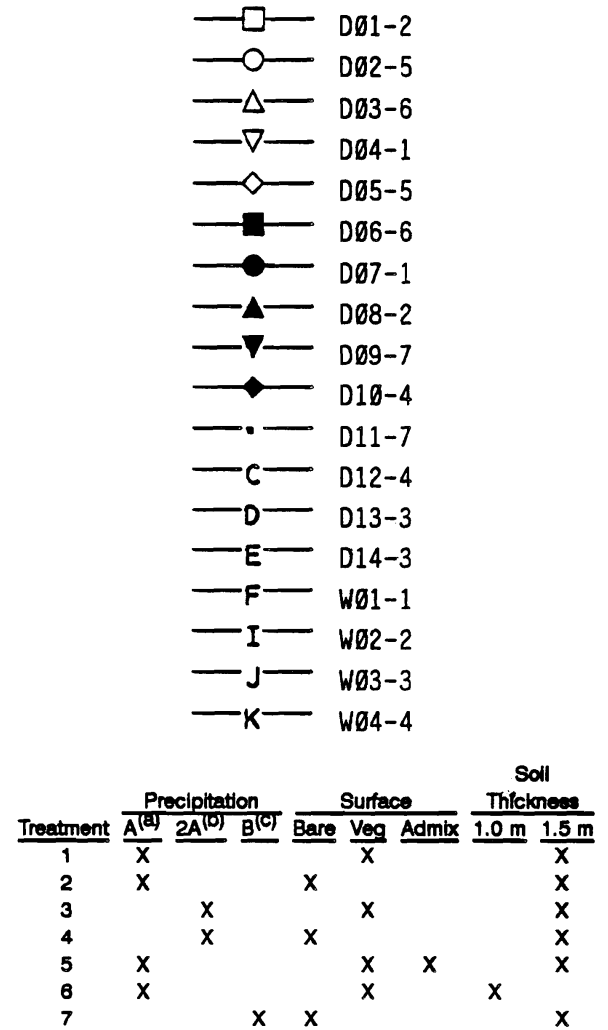

(a) Ambient precipitation.

(b) Twice average precipitation.

(c) Precipitation untll breakthrough 

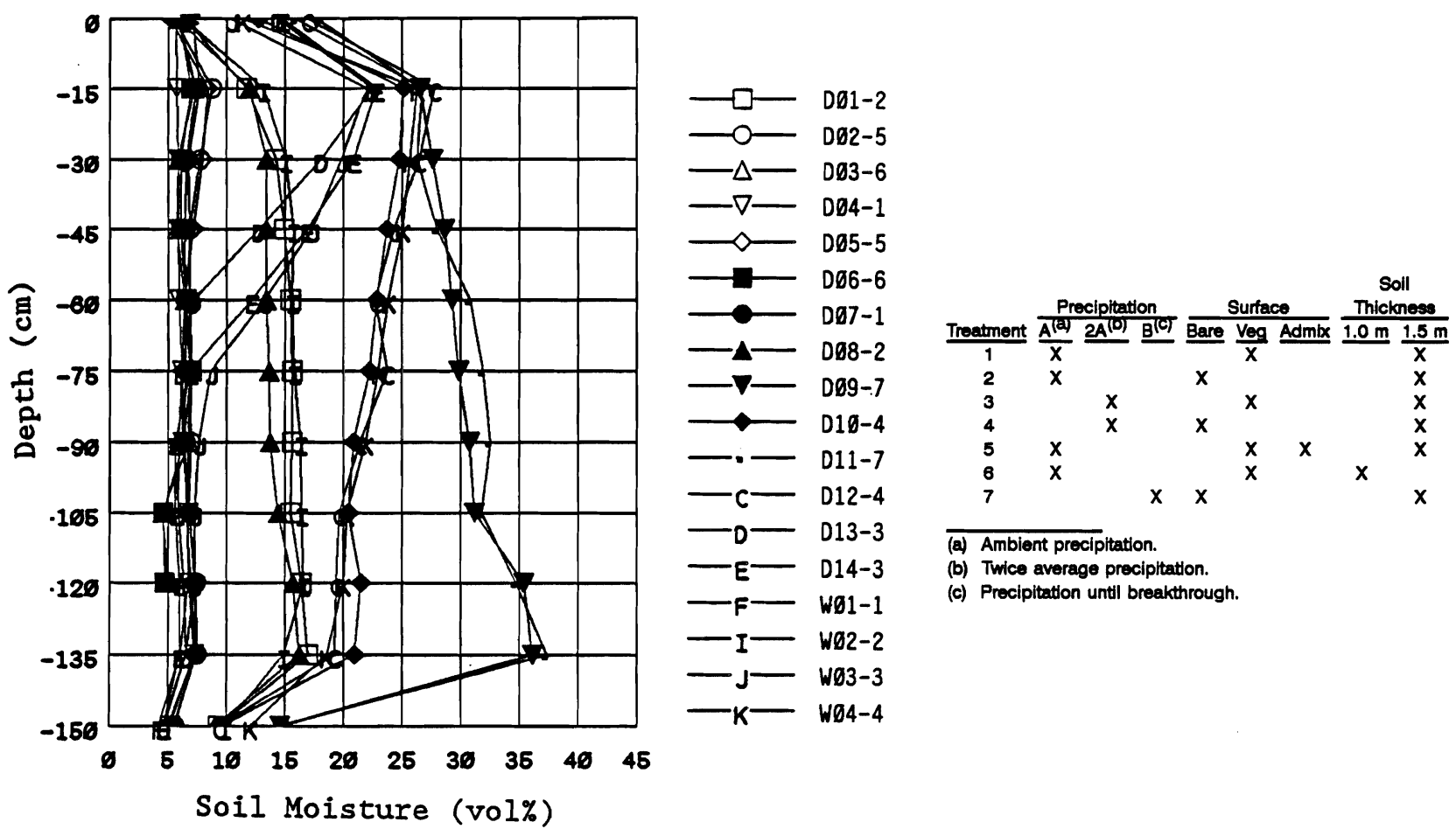

(a) Ambient precipitation.

(b) Twice average precipitation.

(c) Precipitation until breakthrough.

FIGURE 21. Soil Moisture Distribution in Lysimeters in January 1989

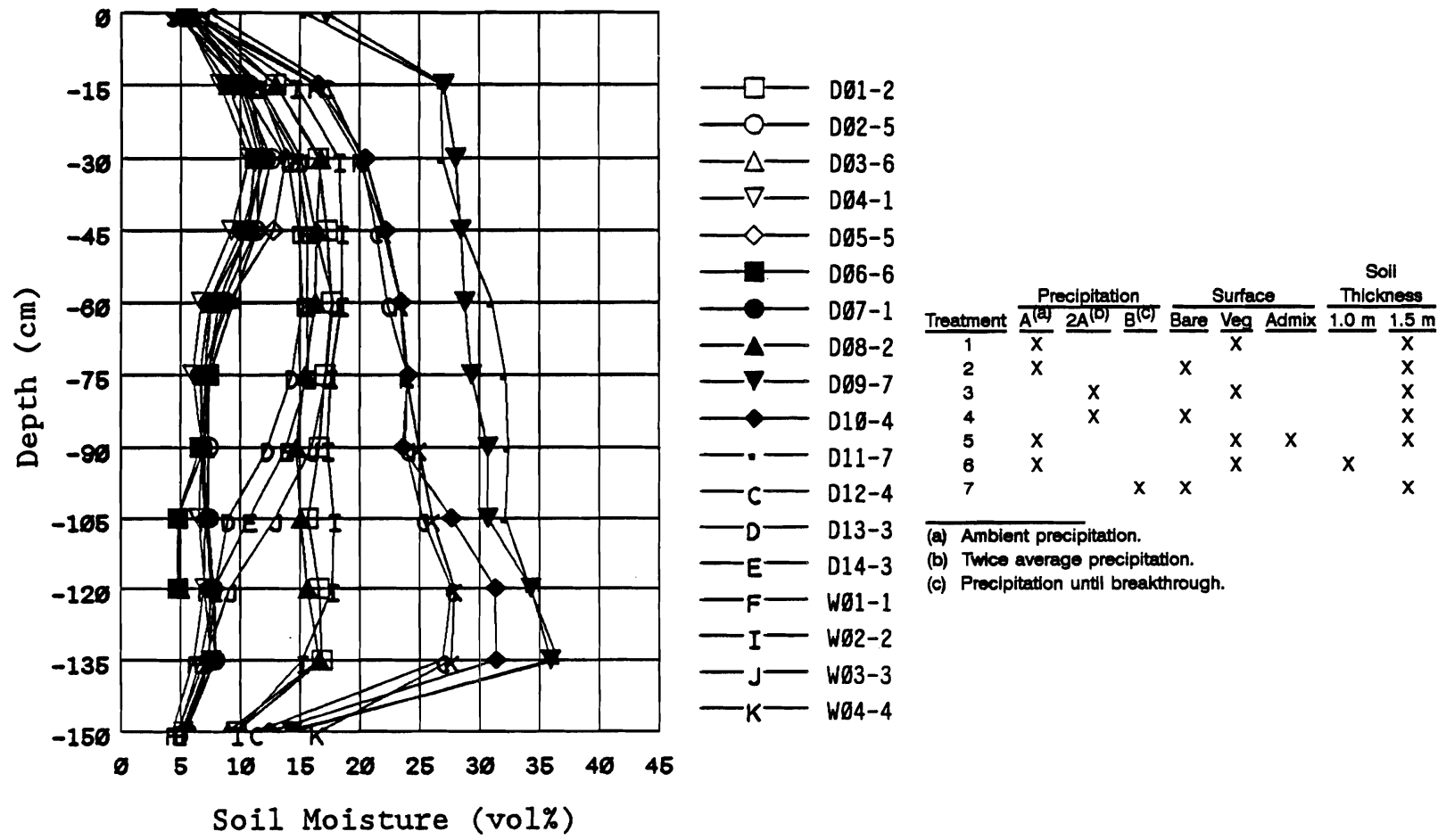

FIGURE 3.22. Soil Moisture Distribution in Lysimeters in Apri1 1989 
is shown in Figure 3.20. Figure 3.18 shows the moisture profile about 1 month after breakthrough. Drainage and profile redistribution had become negligibly small. This profile again demonstrates the effectiveness of the hydraulic discontinuity (i.e., soil layering effects) of the barrier in restricting water drainage while allowing evapotranspiration to return the water to the atmosphere. Apparently, both lysimeters were able to retain about 15 vol\% more water in the profile because of the hydraulic discontinuity than would have been possible without it.

Figure 3.23 shows the profiles of lysimeters receiving ambient, twiceaverage, and breakthrough water applications with and without the influence of vegetation. Figures 3.15 through 3.23 show how the soil water in the lysimeter profiles responded to each of the seven treatments. The distinctions between ambient and twice-average precipitation, between vegetated and nonvegetated lysimeters, and between breakthrough and nonbreakthrough profiles show how each treatment contributes to the overall, protective barrier performance.

Soil moisture profiles from November 1987, November 1988, and April 1989 are shown in Figures $3.24,3.25$, and 3.26 , respectively.

Lysimeters D10-4, D12-4, and W04-4 all show profile development similar to but below D09-7 and D11-7. No drainage had been observed through April 1989 from the treatment 4 lysimeters, although a11 received twice-average precipitation. Lysimeters D09-7 and D11-7 have been covered for 1 year, except during subsidence recovery when soil was being added to restore the surface.

\subsubsection{Initial Gamma Probe Measurements}

These initial gamma probe moisture measurements had unusually large and currently unexplained errors. The radioactive source of the gamma probe alone could account for a maximum variation up to $17 \%$, while the neutron probe alone could account for $6 \%$ on the same basis. However, measurements varied up to $50 \%$ for reasons unknown. As mentioned previously, the variation may have resulted from failure to distinguish the $622-\mathrm{KeV}$ energy peak. Gamma probe measurements were made at $5-\mathrm{cm}$ intervals. The resulting profiles from 

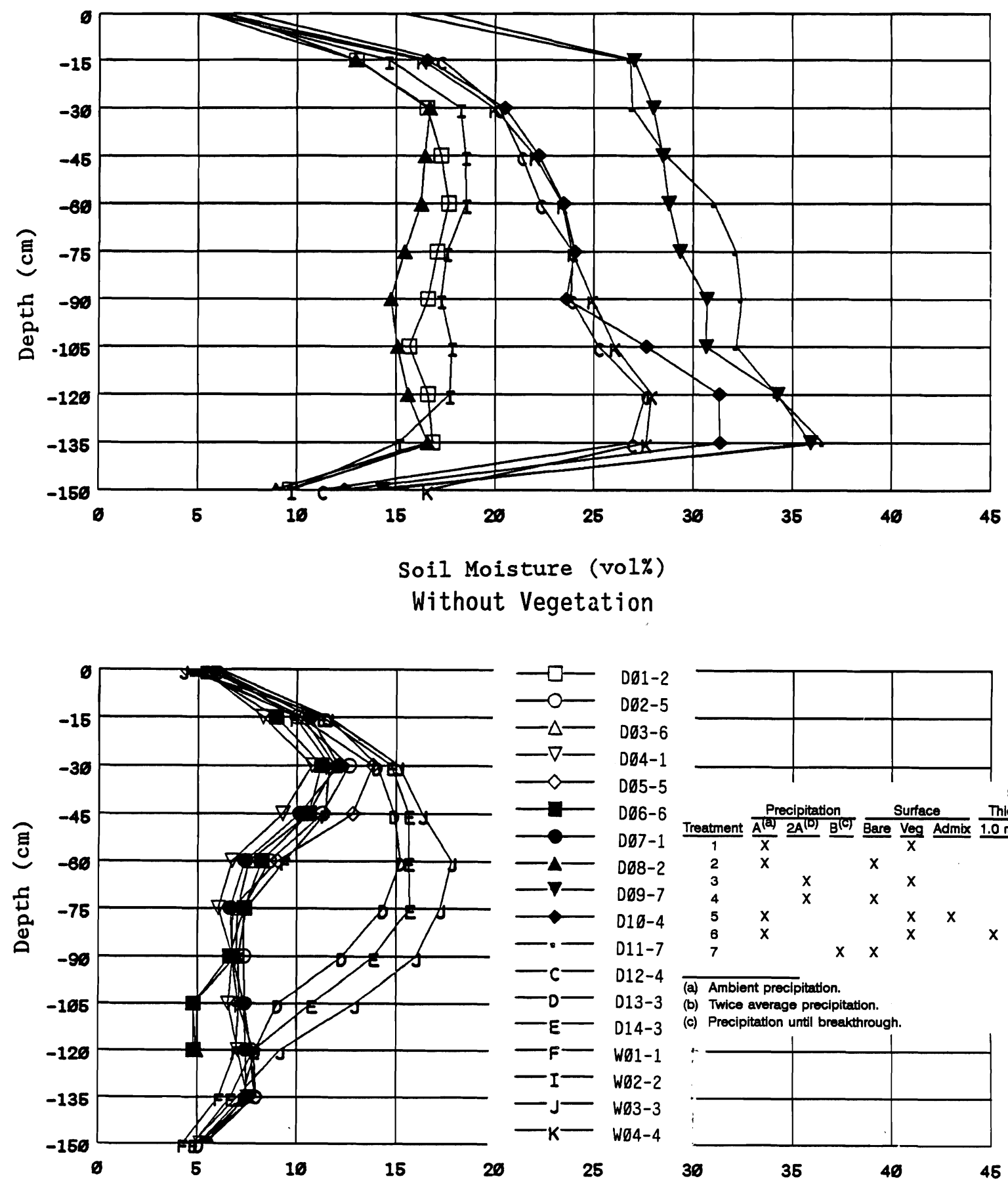

D05-5

D06-6

D07-1

D68-2

$009-7$

D10-4

D11-7

D12-4

(a) Ambient precipitation.

(b) Twice average procipitation.

D14-3

(c) Precipitation until breakthrough.

Soil Moisture (vol\%)

\section{With Vegetation}

FIGURE 3.23. Profiles of Lysimeters Receiving Ambient, Twice-Average, and Breakthrough Water Applications 

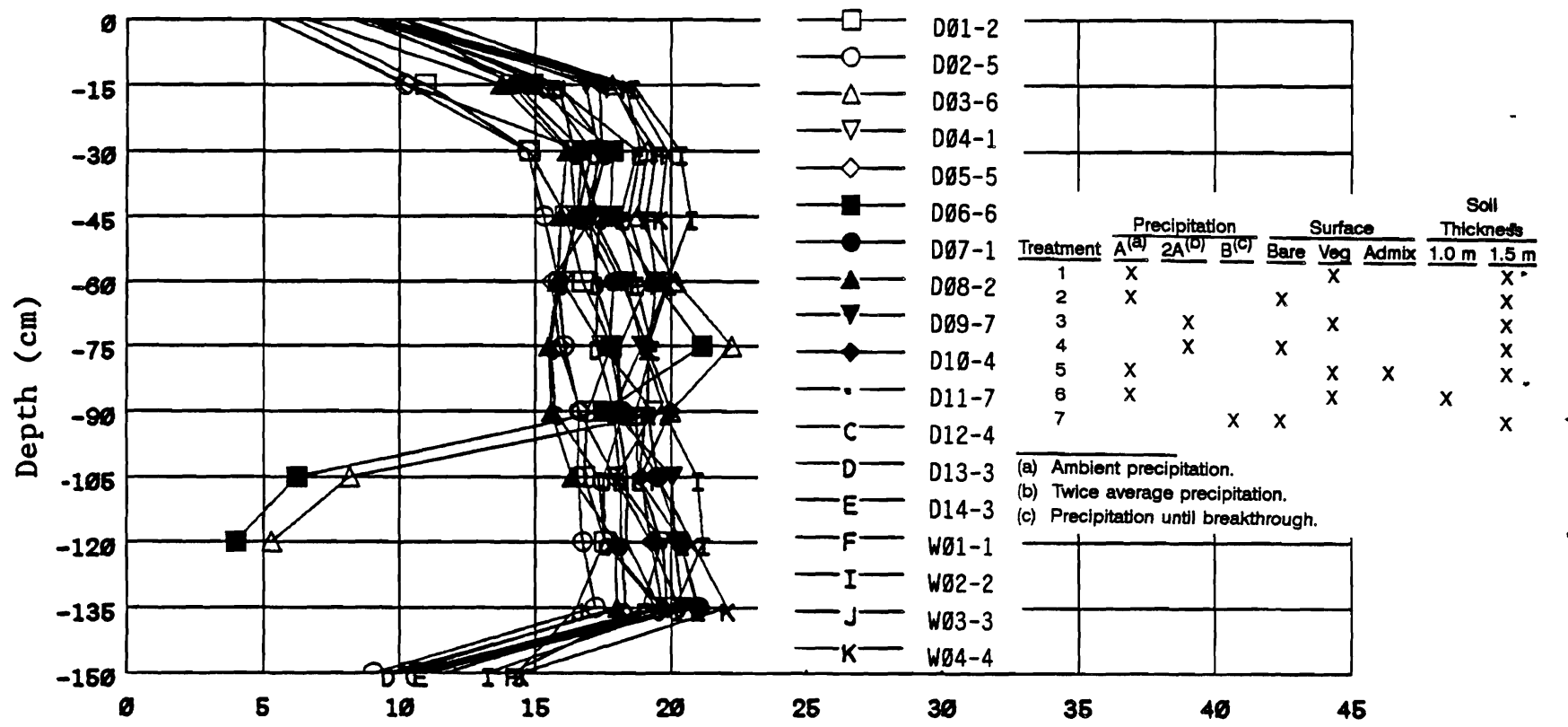

Soil Moisture (vol\%)

FIGURE 3.24. Soil Moisture Profiles in Lysimeters, November 1987

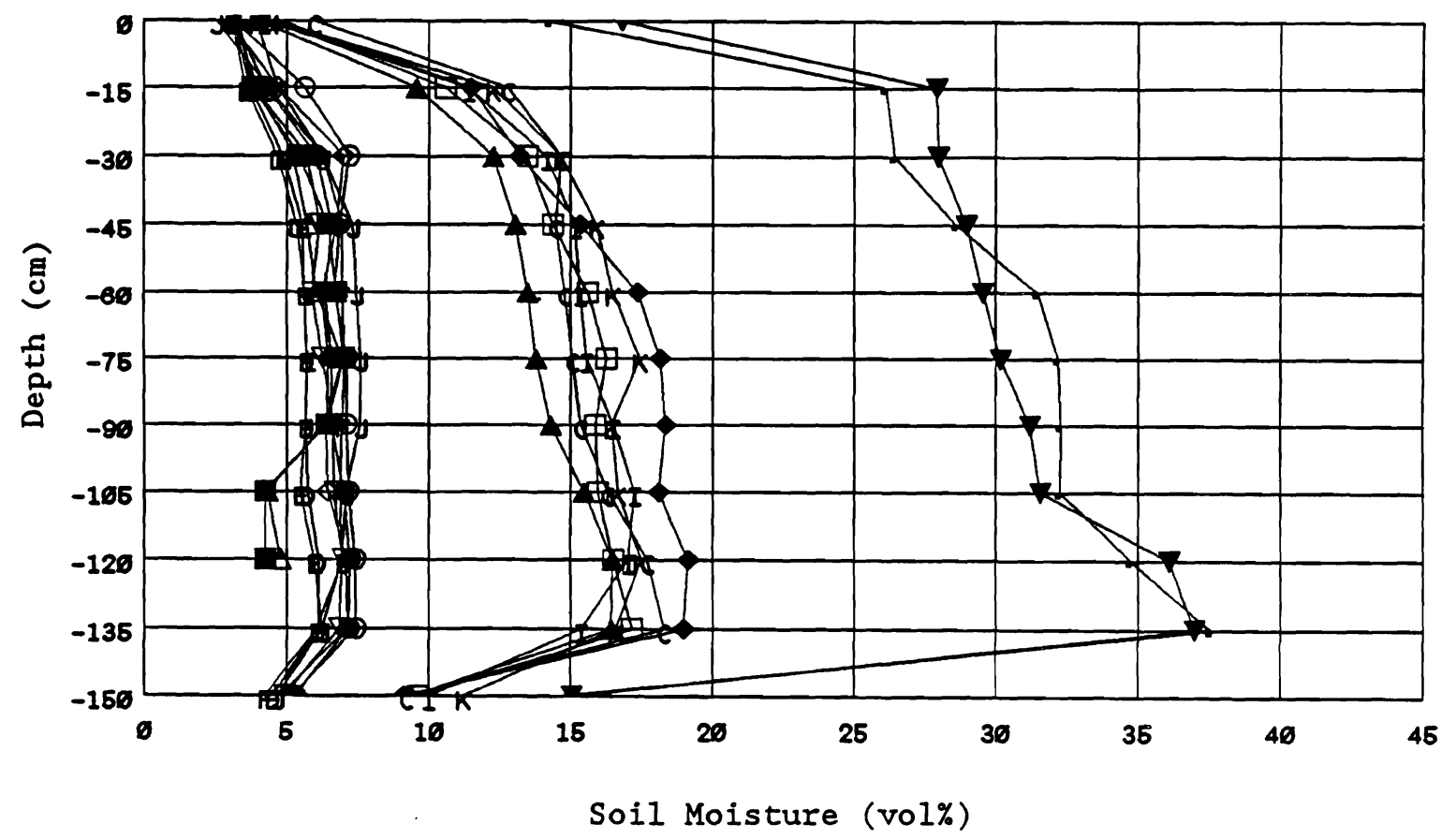

FIGURE 3.25. Soil Moisture Profiles in Lysimeters, November 1988 

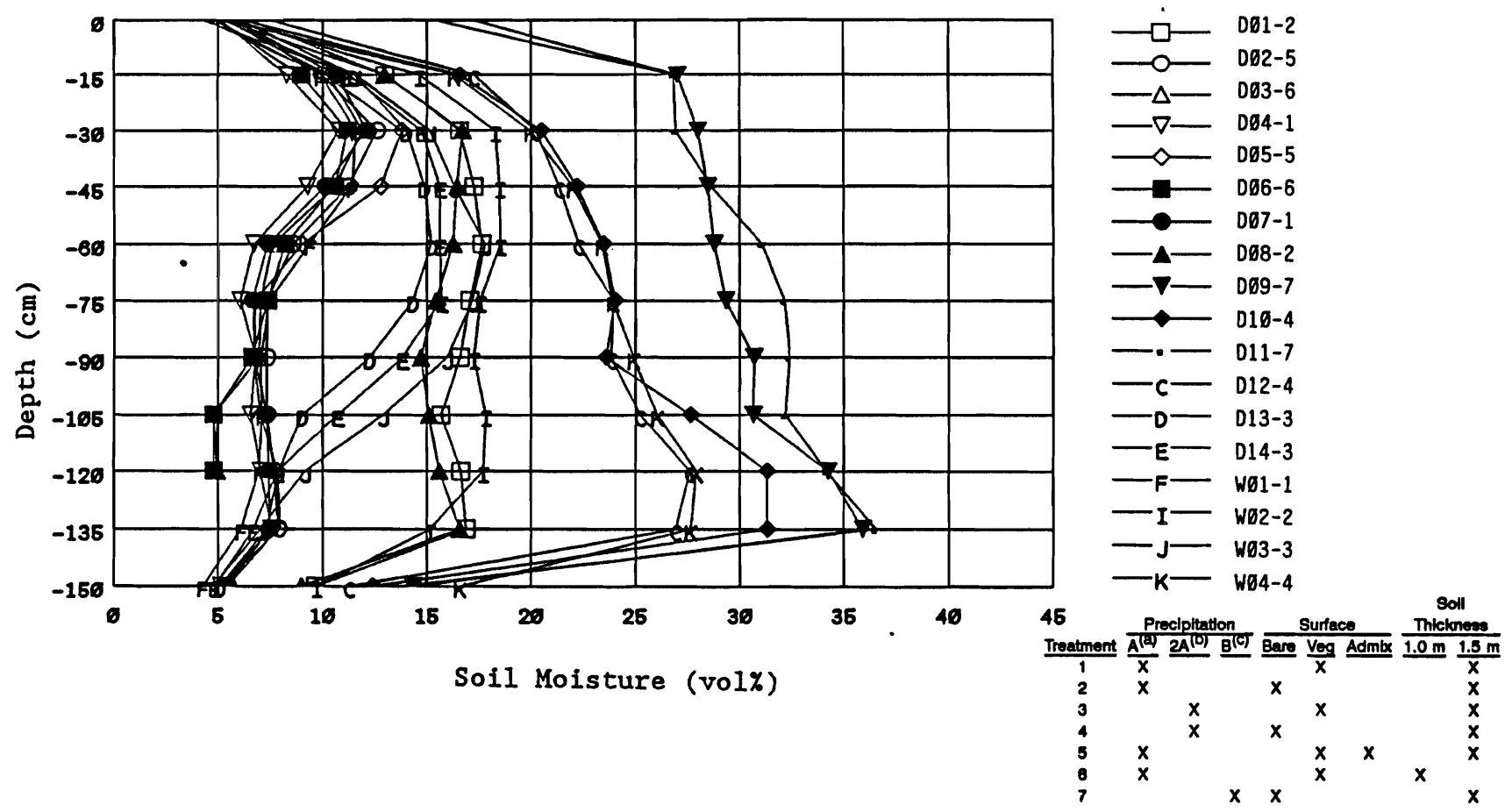

(a) Amblent precipitation.

(b) Twice average precipttation.

(c) Preclpttation untl breakthrough.

FIGURE 3.26. Soil Moisture Profiles in Lysimeters, Apri1 1989

treatment 4 are shown in Figure 3.27. Variations in profile measurements warrant returning the gamma probe to the factory for repair and recalibration.

\subsection{WATER BALANCE IN THE LYSIMETERS}

Water balance begins with initial soil moisture, adds precipitation and manually applied water, subtracts run-off, evaporation, storage, and drainage. Water balance yields the current soil water status in the lysimeters and provides an estimate of the interim changes to yield current water content.

Table 3.2 shows the water balance on May 1, 1988, November 1, 1988, and May 1, 1989. 


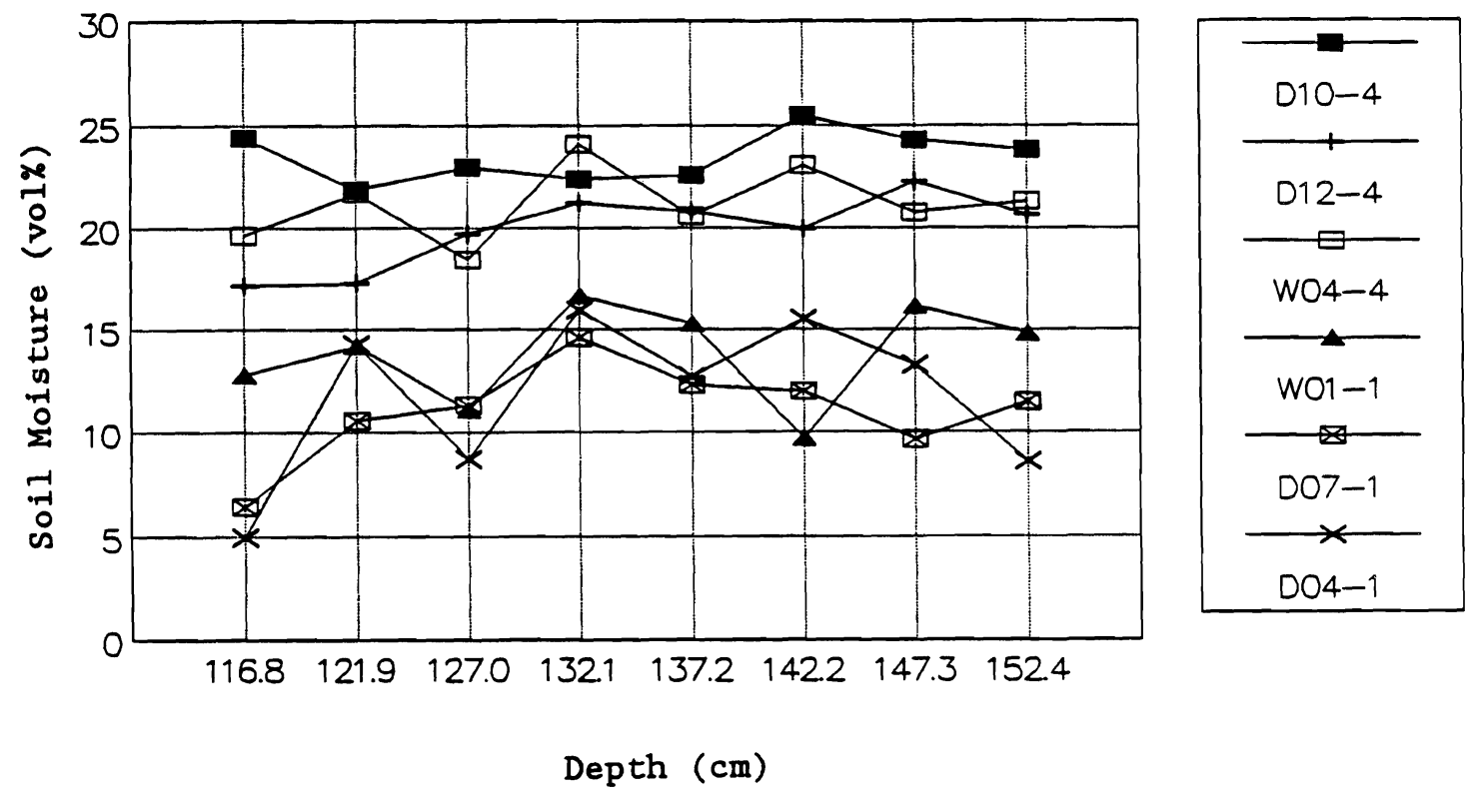

FIGURE 3.27. Soil Profiles of Treatment 4 Measured by the Gamma Probe

\subsubsection{Precipitation}

Twice-average precipitation was applied by spraybar to treatments 3 and 4 according to the schedule shown in Figure 3.28. The principal distinction between treatments 3 and 4 is vegetation, and its effect is shown in Figures 3.29 and 3.30. The effects of both evaporation and transpiration and the difference between them are apparent.

\subsubsection{Run-Off and Drainage}

The lysimeters were constructed so that the soil surface was $5 \mathrm{~cm}$ below the top edge to prevent water run-off. Not even the heaviest applications of water have produced run-off. Drainage from surface-applied water occurred only in D09-7 and D11-7 up through March 1989. Both of these 1ysimeters had water applied until breakthrough occurred. Following breakthrough and the near-cessation of profile drainage in D09-7 and D11-7, a geotextile was $\mathrm{placed}$ on their soil surfaces to prevent soil puddling. About $4 \mathrm{~cm}$ of water was applied to achieve breakthrough again and to begin a test of the effect of an extreme precipitation event, such as a 1000-year storm. However, channeling occurred at the soil-metal interfaces and soil subsidence resulted. The test was discontinued. Both lysimeters were uncovered and 
TABLE 3.2. Water Balance in the FLTF Lysimeters, by Treatment $(\mathrm{cm})(\mathrm{a})$

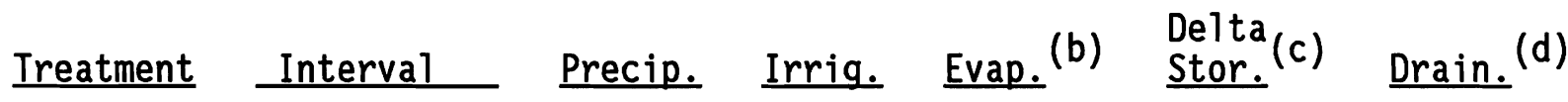
$1 \quad$ Nov $87 /$ May 88 May $88 /$ Nov 88

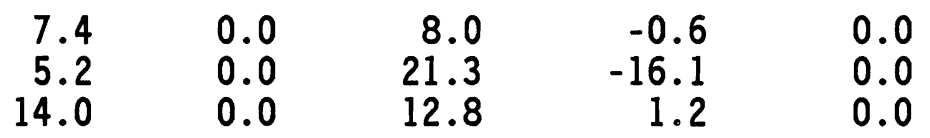

2 Nov 88/May 89

5.2
14.0

0.0

21.3

0.0

7.4

$-0.0$

0.0 May $88 /$ Nov 88 Nov 88/May 89

7.4
5.2

0.0

9.2

$-4.0$

0.0

14.0

0.0

11.9

2.1

0.0

3

Nov $87 /$ May 88

May $88 /$ Nov 88

7.4

7.9

12.6

5.2

7.8

32.8

2.7

0.0

Nov $88 /$ May 89

14.0

11.5

19.8

$-19.8$

5.7

0.0

7.4

Nov $87 /$ May 88

May $88 /$ Nov 88

Nov 88/May 89

$\begin{array}{ll}7.4 & 7.9 \\ 5.2 & 7.8\end{array}$

12.2

19.6

14.0

11.5

16.3

3.1

$-6.6$

9.2

0.0

5

Nov $87 /$ May 88

May $88 /$ Nov 88

7.4

0.0

6.1

5.2

0.0

19.9

1.3

$-14.7$

12.0

2.0

0.0

0.0

0.0

6

Nov $87 /$ May 88

May $88 /$ Nov 88

Nov $88 /$ May 89

$\begin{array}{rr}7.4 & 0.0 \\ 5.2 & 0.0 \\ 14.0 & 0.0\end{array}$

8.5
17.3
12.2

$-1.1$

$-12.1$

1.8

0.0

0.0

0.0

(a) Treatment 7 irrigated to breakthrough and covered (not tabulated here).

(b) Evaporation is the difference between the total amount applied and that stored. (In the cases with plant cover, this quantity is evapotranspiration.)

(c) Delta storage is the amount of storage change over the interval.

(d) There was no drainage from treatments 1 through 6.

surfaces allowed to dry enough to add soil and compact it. The soil surface profiles were measured and are plotted in Figure 3.31. Soil from the same source was added to each lysimeter and compacted by hand tamping. No measure of density was made, but the amount of soil added was $450 \mathrm{~kg}$ to D09-7 and $334 \mathrm{~kg}$ to D11-7. The soil surface when compacted was restored to $5 \mathrm{~cm}$ below the lysimeter rim. A vapor-tight cover was placed over both lysimeters. Water was then added by spray nozzles suspended inside the cover to wet the replaced soil until drainage occurred. Drainage has continued at a very 


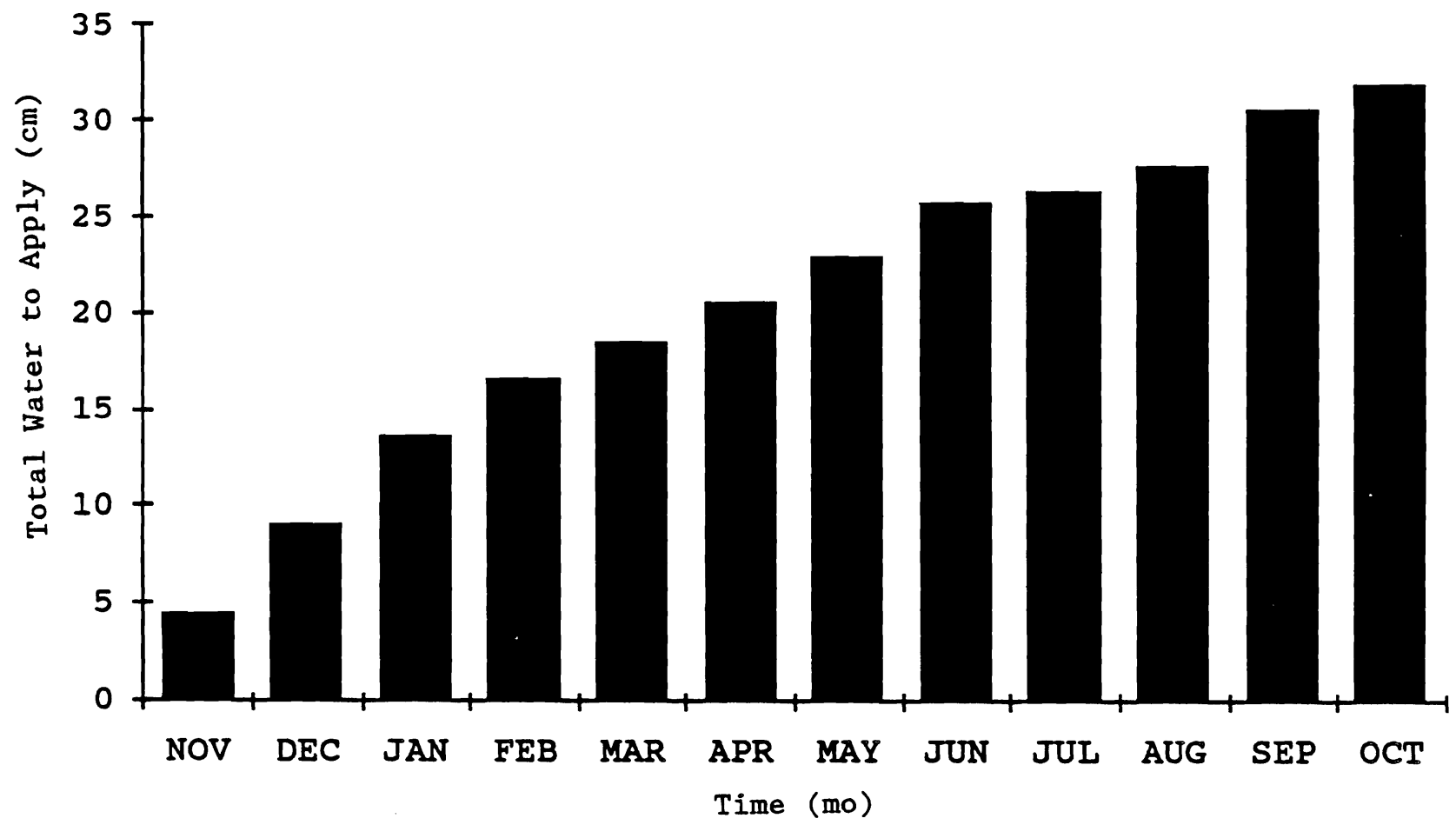

FIGURE 3.28. Twice-Average Water Application Schedule

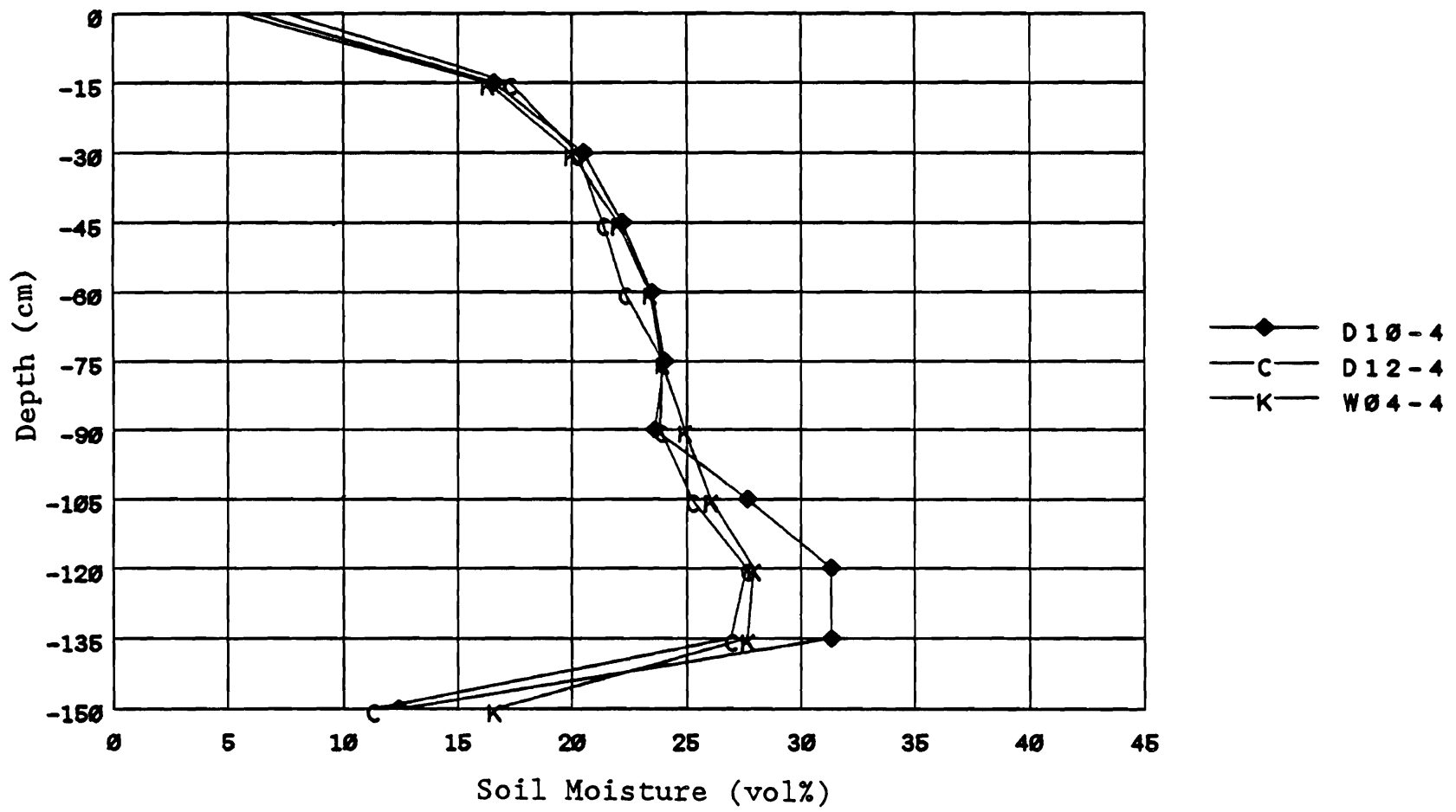

FIGURE 3.29. Profile from Twice-Average Precipitation Without Vegetation 


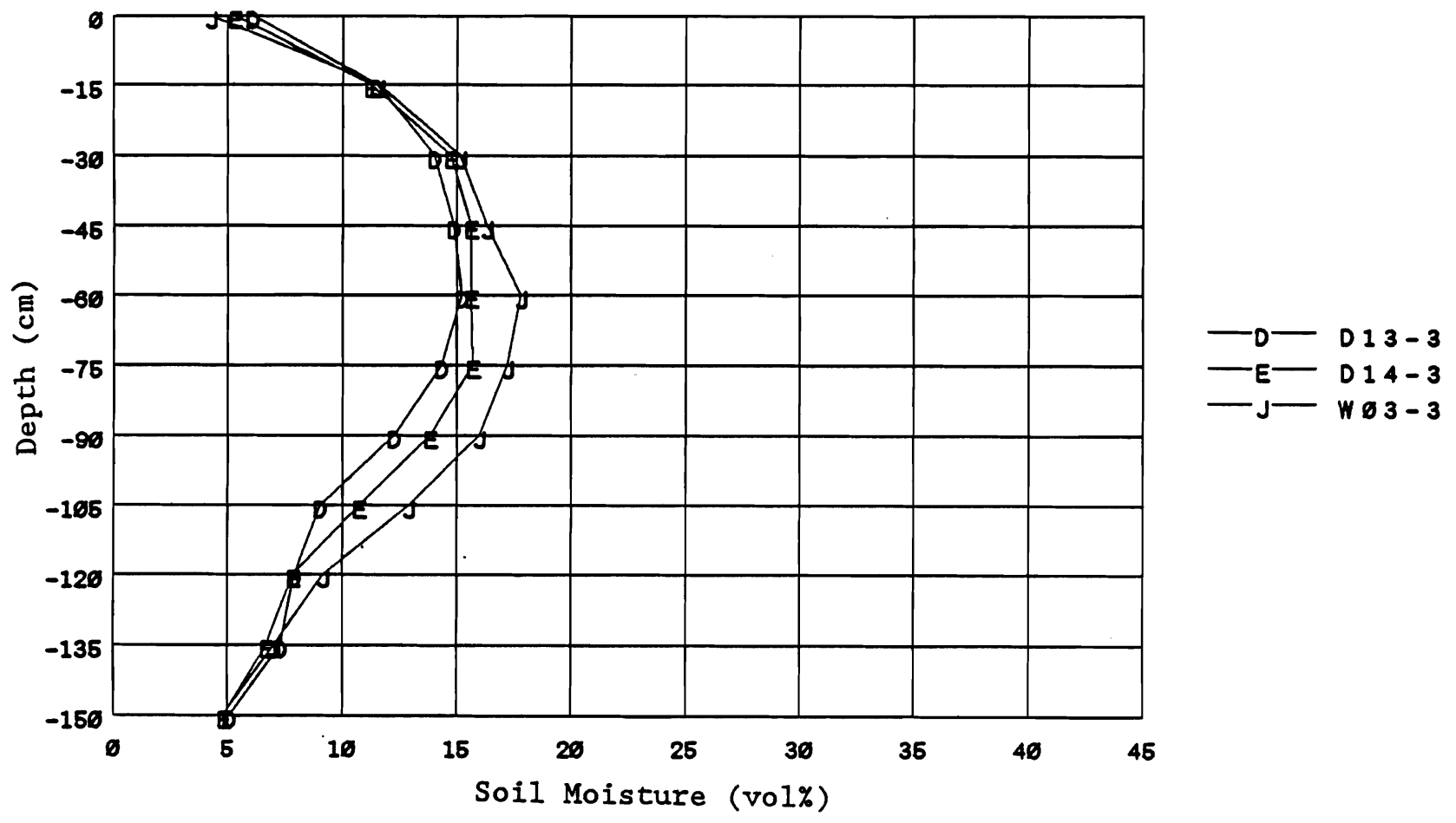

FIGURE 3.30. Profile from Twice-Average Precipitation with Vegetation

slow rate through the fall, winter, and spring seasons since breakthrough. Neither subsidence nor channeling has been observed.

\subsubsection{Water Storage}

Water storage was computed from neutron probe and lysimeter weight measurements over time. These changes were compared as a means of verifying the calibration of the neutron probe, as was done a year ago. Lysimeter storage from November 1987 to April 1989 is shown in Figure 3.32.

We believe that storage changes may be more accurately accounted by the weighing lysimeters. However, there appears to be reasonably good agreement between the two methods despite the interface errors that affect the neutron probe. If water is concentrated at either the upper or lower boundary in a way that was not accounted during calibration of the probe, errors in measurement will result. Snow or frozen water on the soil surface during the winter is an example of moisture distribution that causes error in measurement, as is saturation above the hydraulic barrier. 

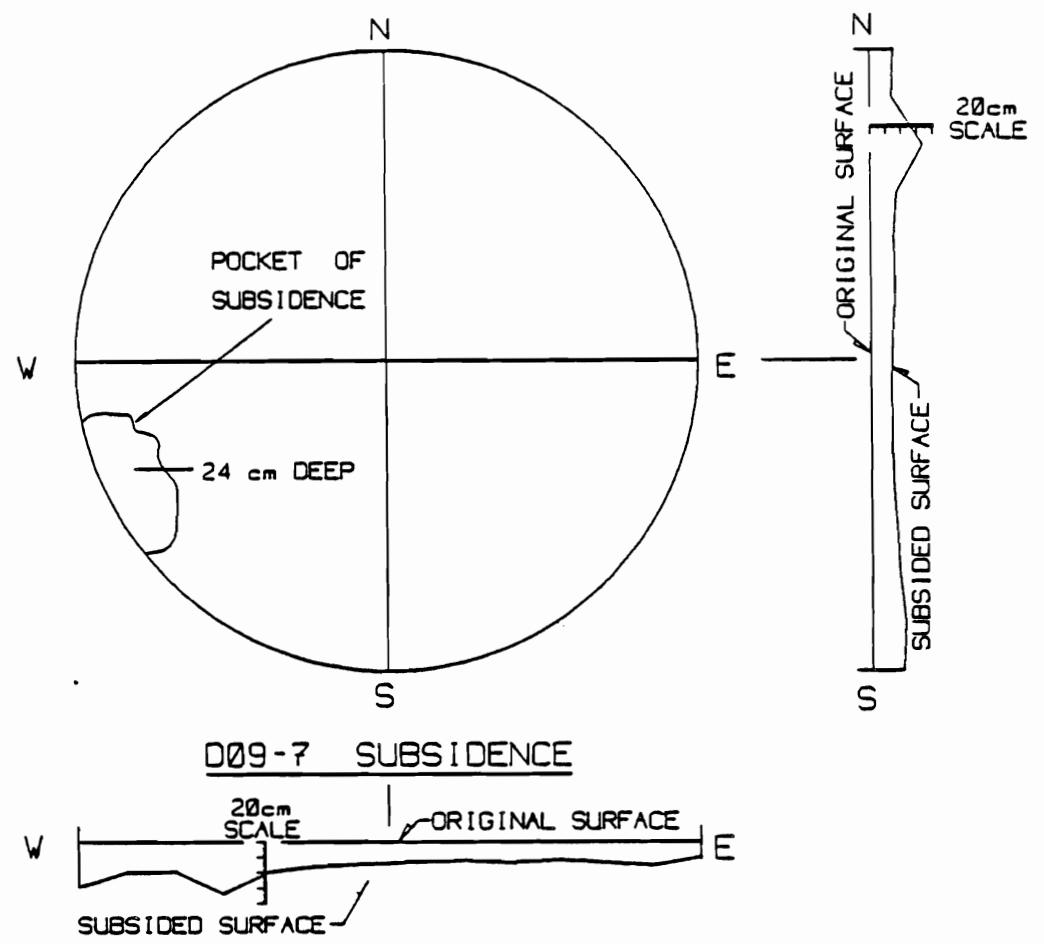

NOTE: SUBSIDENCE DEPTH IS FROM ORIGINAL SURFACE.
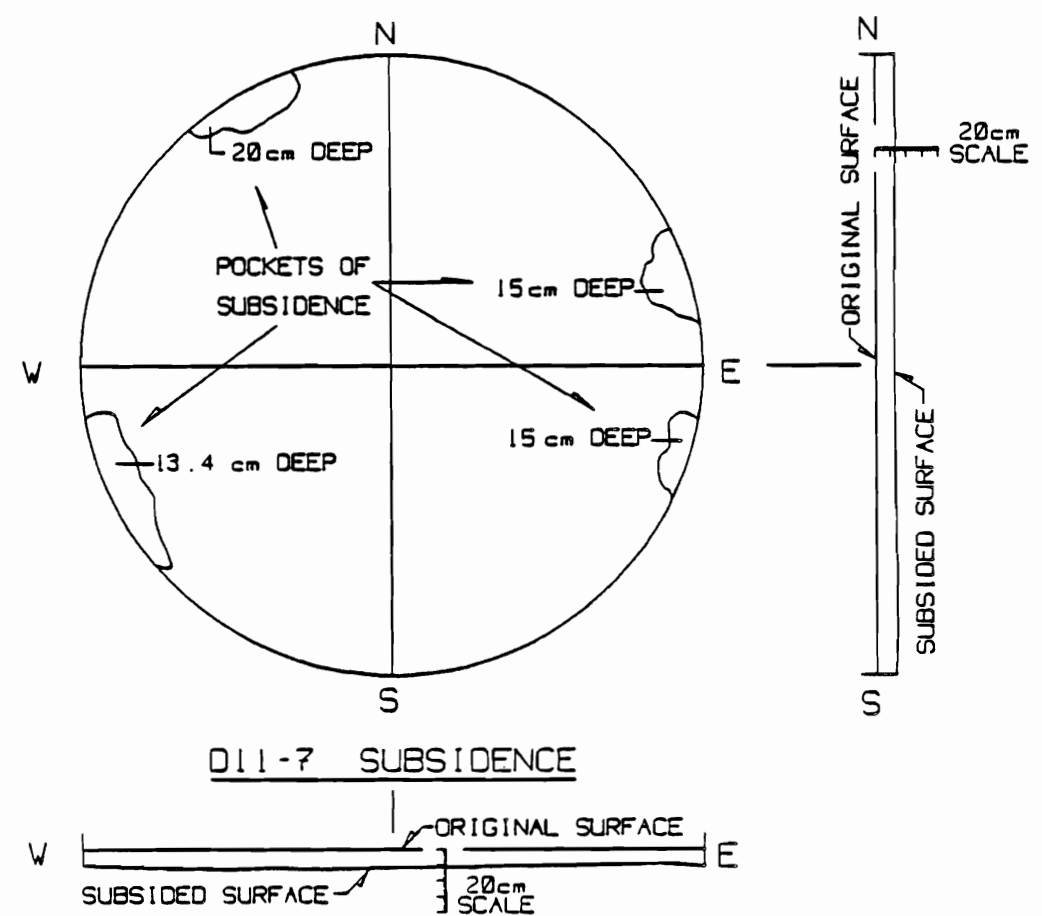

FIGURE 3.31. Soil Surface Profiles Following Breakthrough and Subsidence 
Ambient Precipitation
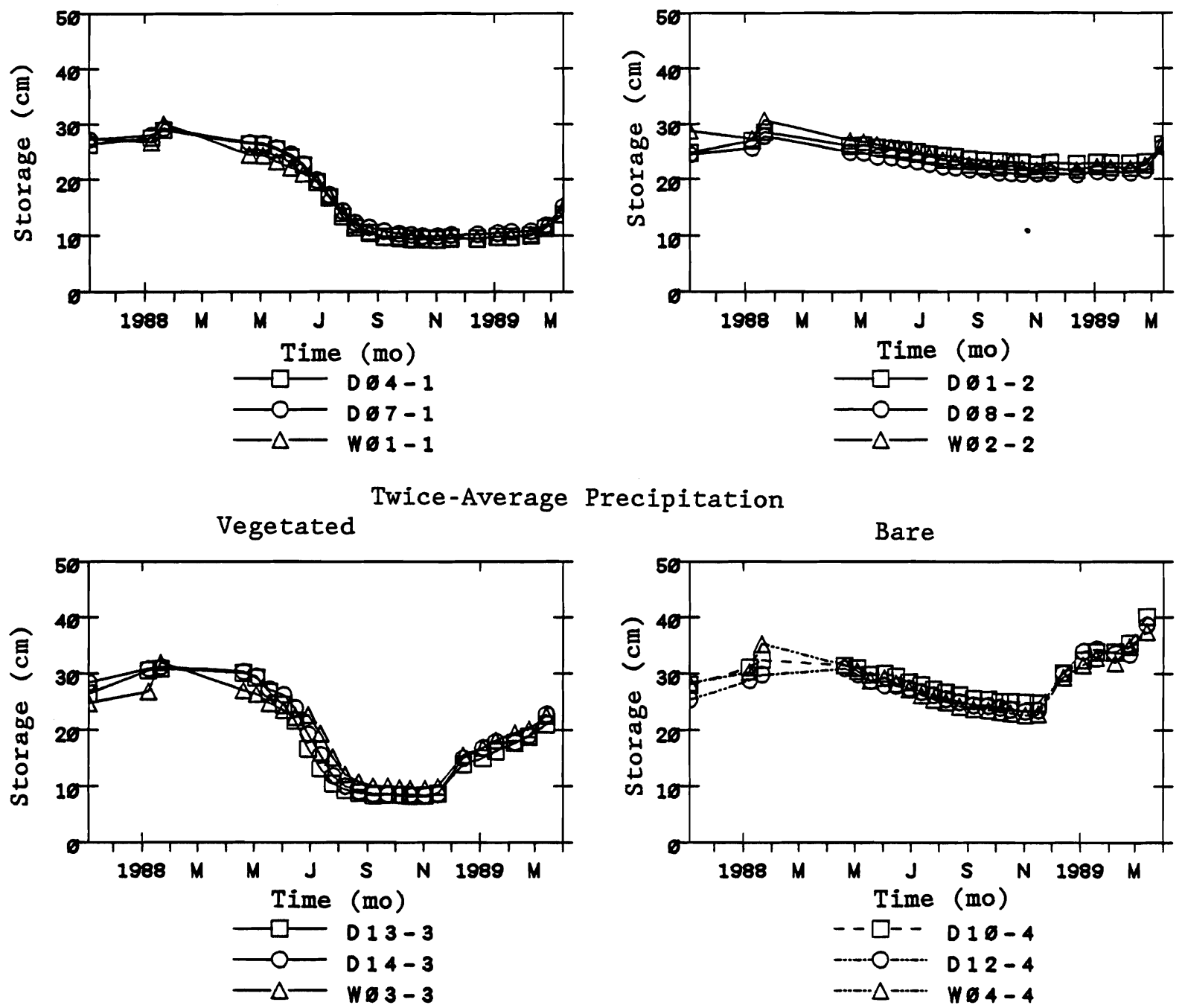

Ambient Precipitation
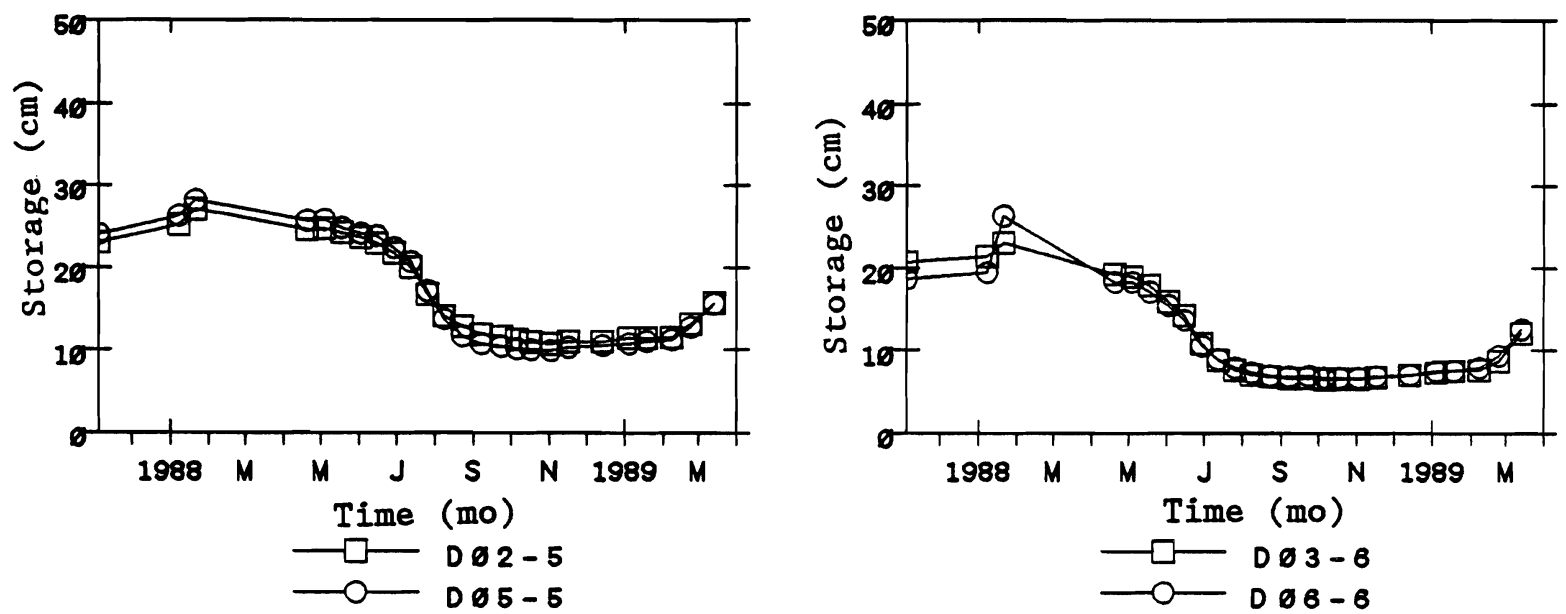

FIGURE 3.32. Water Storage by Treatment in Lysimeters (except treatment 7) 


\subsubsection{Evaporation}

Evaporation may be divided in two parts to evaluate plants for recycling water to the atmosphere: evaporation from a nonvegetated soil surface and evaporation from a vegetated surface (which includes both evaporation and transpiration). Results show that evaporation and transpiration together removed more water and removed it faster than evaporation alone, as shown in Figure 3.33. Results also show that both ambient and twice-average precipitation treatments had water removed to a nearly identical volume percentage, as shown in Figure 3.13. Apparently, plants achieved a common soil water extraction limit. Evaporation alone also caused soil water extraction to a nearly common water content.

\subsection{VEGETATION EFFECTS}

Vegetation on barriers is expected to influence the water budget of the barrier, the animals residing there, and the wind and water erosion of the barrier. The vegetation growing on the lysimeters was mainly that trans$\mathrm{planted}$ from the McGee Ranch. The reason for using plants from McGee Ranch is that the soils also came from there and the vegetation was believed to
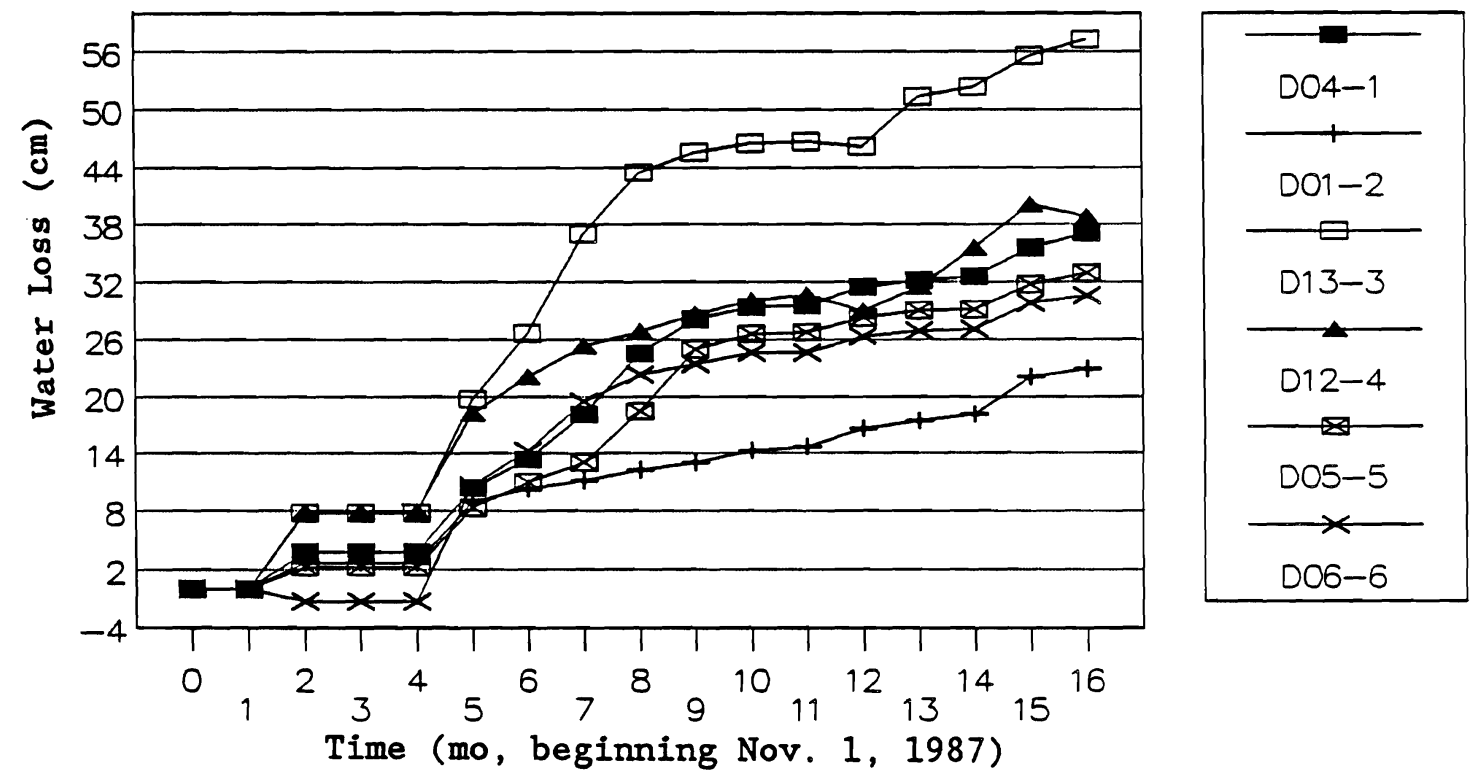

FIGURE 3.33. Water Removal from Soil by Evaporation and Transpiration 
represent climax vegetation reasonably we11. Following a 1 1/2-year growth period, the vegetation seemed to exert significant influence on all aspects of the water budget. An accounting was made of plant growth on the lysimeters.

\subsubsection{Plant Measurements}

The aerial part of the vegetation growing on the lysimeters was surveyed during early May 1989. Plant species occupying the surfaces were identified and measured for size and location within the lysimeters. Leaf area was estimated from measurements of similar size plants that were harvested outside the lysimeters.

Plant height was measured by placing a metric scale on the surface of the lysimeter and recording the height of the uppermost foliage. Plant width was measured by placing a metric scale on the soil surface, looking vertically down from directly above the plant part being measured, and reading the scale at the largest foliage reach and at $90^{\circ}$ rotation from that point.

Bunchgrasses were measured from the ground surface to the height of the inflorescence and the height of the leaf using a metric scale placed at the base of the plant. The base diameters of the bunch grasses were measured by looking vertically downward from above the top of the plant and reading the metric scale at the greatest distance occupied by contiguous base.

When all of the plants had been measured, the area of each bunchgrass base was calculated from the measurements across them. For modeling purposes, the range between the smallest and greatest area was then broken into 15 evenly proportioned increments to represent the plants on the 1ysimeters.

Poa sandbergii with dimensions similar to those at the lysimeters were difficult to find at the McGee Ranch; therefore, cumulative area values were used to represent each of the increments in the model. Areas of Poa sandbergii were calculated in the field by taking base measurements. To meet the area requirements necessary for the model, enough bunchgrasses of smaller dimension were added together to obtain an equivalent total area. The plants 
were harvested by cutting the crown of the plant as close to the ground surface as possible. Sample dimensions were recorded on the sample bag.

Inflorescence height and leaf height were measured using a metric scale, and the leaf area of each sample was measured with an area meter. After all of the samples were measured, the cumulative values of the samples were recorded according to the increments of the model. For samples containing more than one plant, average inflorescent height and leaf height were calculated, and the base areas were summed and the square root computed to represent base diameter. Vegetation measurements are shown in Table 3.3, and plant locations are shown in Figure 3.34.

\subsubsection{Root Observations}

Two clear plastic (clear tube) lysimeters were installed in 0ctober 1988 at the FLTF to observe root growth of sagebrush in the McGee Ranch fine soil under two moisture regimes. A clear tube lysimeter that was installed between drainage lysimeters D06-6 and D07-1 was designated as C03-1, and a clear tube lysimeter that was installed between D13-3 and D14-3 was

TABLE 3.3. Lysimeter Vegetation Measurements

Species Leaf Area Equivalent Measured on Other P 1 ants $\left(\mathrm{cm}^{2}\right)$

Code D02-5 D03-6 D04-1 D05-5 D06-6 D07-1 W01-1 D13-3 D14-3 W03-3

$\begin{array}{rrrrrrrrrrr}\text { Ar } & 5888 & 9900 & 8108 & 8520 & 8508 & 119 & 8579 & 13987 & 21004 & 7463 \\ \text { Or } & & 75 & 1332 & & & 1202 & 1493 & & \\ \text { Po } & 3118 & 557 & 943 & 2738 & 2616 & & 2868 & 5512 & 14082 & 9852\end{array}$

Soil Surface Area Shaded From a Surface-Normal Light Projection $\left(\mathrm{cm}^{2}\right)$

Code D02-5 D03-6 D04-1 D05-5 D06-6 D07-1 W01-1 D13-3 D14-3 W03-3

$\begin{array}{lrrrrrrrrrr}\text { Ar } & 6136 & 7143 & 6285 & 4504 & 5961 & 6854 & 9902 & 14746 & 15280 & 8984 \\ \text { Br } & & 657 & 349 & 564 & 856 & 2080 & 324 & 3681 & & 720 \\ \text { F } & & 391 & & & & & & & & 462 \\ \text { La } & & 391 & 3300 & & & & & & 6485 & \\ \text { Or } & & & 3300 & & & & \\ \text { Po } & 1129 & 1593 & 895 & 1319 & 1547 & 595 & 1828 & 3044 & 4968 & 2868 \\ \text { St } & & & 425 & & 1440 & & & \\ \text { Sy } & & 154 & & & & 4256 & 5265 & & & \\ \text { Tr } & 2500 & & & & & & & & & \end{array}$




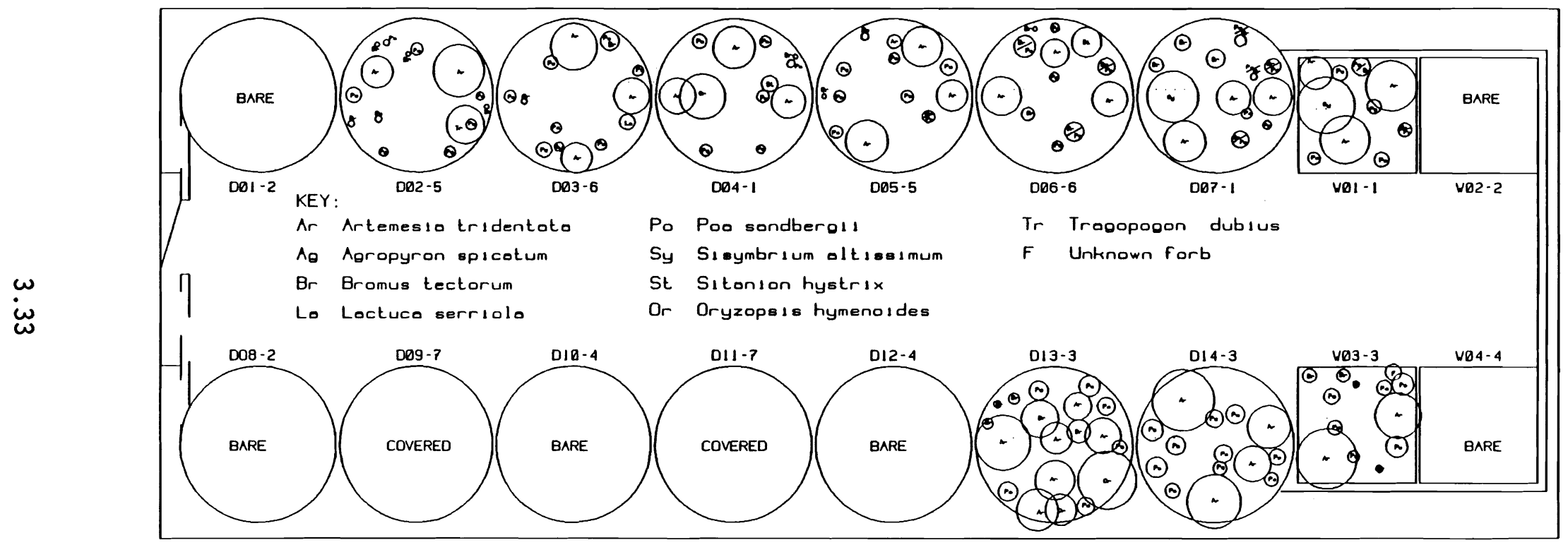

FIGURE 3.34. Vegetation Locations on Lysimeters 
designated as c06-3. The clear tube lysimeters were positioned so that they could easily be observed from the alleyway that runs between the east and west banks of lysimeters (see Figure 1.1).

Each of the two clear tube lysimeters at the FLTF is a $1-\mathrm{cm}$-thick transparent plastic tube $30 \mathrm{~cm}$ in diameter and $3 \mathrm{~m}$ long, filled with $1.5 \mathrm{~m}$ of McGee Ranch silt-loam soil over sand, grave1, and rock. These two lysimeters display the barrier profile arrangement found in the drainage lysimeters and facilitate observation of moisture movement and root growth. Moisture and root growth were observed in the C06-3, where both reached the soil-sand interface, with the root growth rate near $5 \mathrm{~cm} / \mathrm{d}$ as the roots approached the hydraulic barrier. Neither roots nor moisture was observed in the $\mathrm{CO}^{-1}$. C06-3 received twice-average precipitation, while the CO3-1 received only ambient precipitation.

In addition to observing roots in the C06-3, we used a down-hole video camera to observe roots in the mini-rhizotrons in each of the other vegetated 1ysimeters. A quantitative evaluation technique for estimating root density was reported by Upchurch and Ritchie (1983). While we followed their general technique for recording root density, we chose not to treat our samples statistically because of the dearth of data. The raw counts per mini-rhizotron are shown in Table 3.4. We believe that the increase in root count in treatment 3 is the result of added water.

TABLE 3.4. Root Counts (individual roots) from Mini-Rhizotrons in Vegetated Lysimeters

D02-5 D03-6 D04-1 D05-5 D06-6 D07-1 W01-1 W03-3 D14-3 D13-3 $\begin{array}{lllllllll}48 & 38 & 36 & 54 & 19 & 29 & 39 & 54 & \text { Water }>100\end{array}$ NOTE: Root population density was visibly higher in the -3 lysimeters, which received twice-average precipitation. Water prevented counting roots in the lower two thirds of the D14-3 rhizotron. 


\subsection{CONCLUSIONS AND RECOMMENDATIONS}

The hydraulic barrier impeded water flow, as evidenced by water pressure above the barrier during breakthrough and by the soil moisture tension and content measurements shown in Figure 3.3 following breakthrough. Twiceaverage precipitation on lysimeters without vegetation (treatment 4) added enough water to the soil profiles to cause significant water content increase down to the $150-\mathrm{cm}$ depth, but no measurable drainage was observed during the test period. Lysimeters achieving breakthrough (treatment 7 ) continued to drain a full year after initial breakthrough, which showed that the textural break impeded flow but that when breakthrough was achieved, drainage continued to empty the profile at a slow rate until at least 5 vol\% reduction in water content occurred. Weighing lysimeter errors from resolution, precision, and hysteresis were less than $0.02 \mathrm{~cm}(1 \mathrm{lb})$ of water, as shown in Figure 2.5. Water storage measured by weighing lysimeters agreed well with that measured by the neutron probe, as shown in Figure 3.14. The voltage standard seemed to vary with temperature, as shown in Figure 2.4 ; a ratiometric standard is being prepared to test and, if necessary, compensate for this problem. Nevertheless, logging errors were absent from data during the reporting interval.

Breakthrough tests completed and reported in FY 1988 were not extended into FY 1989. However, the two lysimeters treated to breakthrough (D09-7 and D11-7) were covered during FY 1989 to prevent evaporation and were monitored. During the FY 1988 tests on D09-7 and D11-7, soil water began to move downward at 25 vol\% and breakthrough occurred at 42 vol\%. Water drained slowly during the following year, leaving 36 vol\% at the bottom of the two soil profiles. The hydraulic barrier provided a stable water holding capacity increase of 11 vol\% at the lower soil boundary. The barrier increased average water storage capacity by $8 \mathrm{~cm}$ in the silt loam soil. Storage capacity in the $1.5 \mathrm{~m}$ of silt loam soil was $36 \mathrm{~cm}$ above the plant extraction limit, or $4 \mathrm{~cm}$ more than the $32 \mathrm{~cm} / \mathrm{yr}$ representing twice-average precipitation at the FLTF site. Thus, twice-average precipitation would not be enough to cause breakthrough if the silt loam soil barriers were vegetated. Without vegetation, however, evaporation depleted the soil moisture to 20 vol\%. This 
level of depletion would accommodate $16 \mathrm{~cm}$ of added water without drainage. Drainage through bare soil would depend on the time and amount of precipitation and would be expected whenever the soil moisture content reached 42 vol\%.

During FY 1989, the bare soils of treatment 4 received twice-average precipitation, and the soil moisture content approached 38 vol\%. While no breakthrough occurred, the treatment 4 soil profiles assumed shapes similar to those of D09-7 and D11-7, but with slightly less magnitude. A similar storm pattern would be expected to cause drainage through barriers with more sand or less depth. Thus, the hydraulic barrier created by layering fine over coarse soil allowed water to perch above the textural boundary for an extended time where evaporation from bare soil and transpiration from $\mathrm{plants}$ recycled the water to the atmosphere.

Water distribution in the soil profiles became treatment specific. Soil moisture values were measured in all lysimeters using the neutron probe. Initial cross calibration between the neutron probe and a weighing lysimeter led to reasonable agreement between water budgets measured by the two methods. We conclude from these tests that measurements and methods used in water budget accounting are adequate and sufficiently precise to continue evaluation of barrier performance and, furthermore, to use the data for model calibration or verification.

Twice-average precipitation treatment should be continued for at least one more year to see whether the bare soil, irrigated with two times precipitation (treatment 4) lysimeters will achieve breakthrough, as suggested by moisture profile increases observed during the past year. Gamma probe measurements should be further tested and then used at the hydraulic barriers to monitor water contents near the textural break (soil/sand interface) during the next year.

Treatment 7 (water application until breakthrough) lysimeters should be tested for steady-state conductivity before exhuming their contents to find 
out what the channeling did with the displaced soil. Thermocouple psychrometer measurements should be started in late August or early September 1989 and continue at monthly intervals for at least one year to assess thermocouple psychrometer function. 


\subsection{REFERENCES}

Gee, G. W., R. R. Kirkham, J. L. Downs, and M. D. Campbe11. 1989. The Field Lysimeter Test Facility (FLTF) at the Hanford Site: Installation and Initial Tests. PNL-6810, Pacific Northwest Laboratory, Richland, Washington.

Kirkham, R. R., G. W. Gee, and J. L. Downs. 1987. An Experimental Plan for the Field Lysimeter Test Facility (FLTF). PNL-6351, Pacific Northwest Laboratory, Richland, Washington.

Kirkham, R. R., G.W. Gee, and T. L. Jones. 1984. "Weighing Lysimeters for Long-Term Water Balance Investigations at Remote Sites." Soil Sci. Soc. Am. J. 48:1203-1205.

Rawlins, L. S., and G. S. Campbe11. 1986. "Water Potential: Thermocouple Psychrometry." In Methods of Soil Analysis, Part 1, ed. A. Klute. American Society of Agronomy, Madison, Wisconsin.

Upchurch, D. R., and J. T. Ritchie. 1983. "Root Observations Using a Video Recording System in Mini-Rhizotrons." Agronomy Journal 75:109-1015.

U.S. Department of Energy (DOE). 1987. Disposal of Hanford Defense HighLevel, Transuranic and Tank Wastes. Final Environmental Impact Statement. EIS-0113, U.S. Department of Energy, Richland Operations Office, Richland, Washington. 
APPENDIX 
APPENDIX

\section{A.1 NEUTRON PROBE CALIBRATION TEST}

As a comparator, the neutron probe must be tested in a wet and a dry transfer standard at the beginning and end of each day of use to ensure quality of measurements. The transfer standards may be any invariant medium that will absorb enough energy from fast neutrons to allow them to react with the detector while they are within its range and generate readings that bracket the extremes of the soil moisture to be measured by the neutron probe. A wax and a dry-soil standard have been prepared for this purpose. In the past, the neutron probe shield has been used as a standard, but the shield counts vary too much, as shown in Figure 2.1. In the future, shield counts should be used only to test probe function in the field where the transfer standards are unavailable and the probe appears to be operating incorrectly. In every test, 32 measurements must be made in the transfer standard. (A 32 reading set is the sample size required for the statistics used.) A stepwise procedure of the transfer standard consisted of the following:

1. Attach the digital readout unit to the hydroprobe and connect the cable from the probe to the readout unit.

2. Place the probe in the proper position in the selected transfer standard and take 32 readings. (The CPN 501DR and 503DR probes take $32,8-s$ counts automatical1y.)

3. To take automatic counts, press STD on the readout unit. The unit will display the last standard count taken. STEP through to display the chi value and the previous mean standard count. Press STD again; the readout unit wi11 inquire, NEW STD? Press ENTER; the probe will then begin taking the 32 readings to compute the new 
standard. Stand at least $5 \mathrm{ft}$ from the probe while the standard counts are being taken to minimize any effects on the standard count.

The following text describes how the standard counts are used to evaluate the function of the neutron probe (remember that the CPN 503DR and 501DR perform these operations for the user).

- Compute the average $(A)$ of the 32 readings.

- Compute the standard deviation (S) of the 32 readings using the following equation:

$$
\left.S=\left(\Sigma(X-A)^{2}\right) / 31\right)^{1 / 2}
$$

- Compute the square root of the average. $A^{1 / 2}$

- Calculate ratio: $R=S / A^{1 / 2}$ (equivalent to chi).

If $R>1.25$, the detector is not counting some of the neutrons. If $R<0.75$, the detector is counting pulses other than neutrons. If $R$ is between these values, the gage is working properly. If the $R$ value (chi) is too high or too low, repeat the test. If the average of the two tests is outside the range 0.75 to 1.25 , turn the probe electronics off for 20 min and then repeat the test. If $R$ is still outside the range, return the probe electronics to the factory for repair.

NOTE 1: The range 0.75 to 1.25 is based on a sample size of 32 and a probability interval of 0.95 . The 503 direct readout displays " $S$ " with the current standard count, "P" with the previous standard count, and "Chi" is equivalent to the ratio $\mathrm{R}$ above.

NOTE 2: Boron trifluoride detectors commonly exhibit warm-up error. Warm-up error shows up as readings that begin more than two standard deviations below average and gradually increase up to a random distribution around average. During calibration in a transfer standard, a record should be made of individual readings so as to detect malfunctions such as warm-up-induced errors (shield counts in the field may be used for this purpose). 
NOTE 3: The direct readout automatically adjusts al1 readings to a 16-s reading equivalent. Even the automatic calibration makes this adjustment after taking $32,8-5$ readings and computing the chi value. Therefore, if probe calibration is done manually, select the 16-s time interval because any other time interval will yield an incorrect chi value.

Transfer standards may be of several types. At the FLTF, a barrel of wax and a barrel of oven-dry soil were prepared as transfer standards for the neutron probe, representing high and low concentrations of hydrogen, respectively. A plastic block is being prepared as a third type of transfer standard to overcome the expansion characteristics of wax and the freezing problems of water. Oven-dry soil will remain the dry transfer standard because it provides the chemical similitude required for the zero moisture content reading.

A convenient reference is occasionally needed to test the electronic function of the neutron probe in the field. The shield count may be used for field reference to check probe function but not as a transfer standard for probe cross calibration or drift detection. If the shield count is ever used as the denominator in any count ratio calculations, its reading validity must first be proven in every case. Count ratios should be avoided in all but a very few cases because they introduce a displacement error into their ratio that has no bearing on soil moisture. Count ratios will not prevent erroneous measurements and may lead to introduction of significant errors. Calibration errors and faulty electronic function may also be detected by using some deep soil location in the field where measurements have been invariant over time.

Once calibrated for a particular soil and tested for proper function, the probe calibration factor may be further refined. The neutron probe used at the FLTF was adjusted to minimize differences between its measurements and those from the weighing lysimeter. 


\section{A.2 TROXLER GAMMA PROBE CALIBRATION CHECKOUT AND USE}

A stepwise procedure for calibration check and use of the Troxler gamma probe is described in this section. Steps 1 through 10 describe the calibration checkout and steps 11 through 20 describe the soil measurement procedure.

\section{A.2.1 Calibration Checkout}

1. With the power switch on the PHD module in the OFF position, connect the cable to the PHD module. (Never connect or disconnect the cable unless the power switch is off.)

2. Set the ratemeter range to the OFF position.

3. Turn the PHD module power switch to STDBY for 30 min to allow electrical warm-up. Observe the BATTERY FUNCTION indicator; if the needle is in the white, proceed with step 4 ; if the needle is in the red, recharge the battery by connecting the power cord to the rear panel of the readout and plugging the other end of the power cord into a 120-V, electric power outlet.

NOTE: (Work may continue while connected to the electric power, but TAKE PRECAUTIONS TO AVOID ELECTRIC SHOCK. For example, do not work in the rain or let the equipment get wet. If there is any risk of electrical shock, leave the instrument inside the FLTF to recharge the battery before continuing the tests.)

4. Set the time switch to $1 \mathrm{~min}$ (choices are $0.25,0.5,1$, and $2 \mathrm{~min}$ ). Adjust the CALIBRATE pot on the PHD module to obtain the "Peak Value" (currently at 536).

5. Remove the source carrier lid; remove the source cap and rod assembly (the one without the cable) from the calibration stand and screw the rod snugly into the source holder.

6. Reinsert the cap and rod assembly with the source holder into the calibration stand, and place the stand in some preselected test location that is at least $30 \mathrm{ft}$ away from other radioactive sources and $15 \mathrm{ft}$ away from the readout. 
7. Using the graduated rods, position the probes so that the source and the detector are centered at opposite ends of the magnesium standard (the 12-in. position on each rod).

8. When the electronic system has stabilized on STDBY for about 30 min, move the switch on the PHD module from STDBY to ON.

9. Press the START button on the SCALER and record in the laboratory record book the reading at the end of the 1 -min count.

10. Repeat step 9 for four readings. Move the power switch from $0 N$ to STDBY to conserve battery power.

NOTE: Label these as STANDARD COUNTS. If all four readings are within the current calibration standard range, continue with measurements; if not, refer to pp. 1214 of the Model 2376 manual and recalibrate. Note that during recalibration, the CALIBRATE pot must be turned very slowly to locate the $622-\mathrm{KeV}$ peak for cesium.

\section{A.2.2 Troxler Gamma Probe Use}

\section{1. (NOTE: DON'T BUHP OR DROP THE DETECTOR!)}

Remove the cap and rod assemblies from the test stand and transport them and the readout to the access tube site.

12. Place the probes in access tubes $12 \mathrm{in}$. apart, and position the probes vertically at the maximum depth to be measured by carefully lowering the DETECTOR to the bottom of the access tube, and then lifting it up to the nearest notch on the rod. Record the position of that notch. Move the SOURCE rod to the same position.

13. Turn the power switch from STDBY to ON. Press the START button on the SCALER.

14. When the count is complete (the "ERR" in the upper left corner stops blinking and is off), record the reading.

15. Raise the DETECTOR and SOURCE 2 in. and repeat steps 13 and 14 until the desired number of readings have been taken. 
16. Repeat steps 7 through 10.

17. Store the SOURCE in the SOURCE CARRIER and lock it. Place the source rod and cap back in the calibration stand. (Observe the BATTERY FUNCTION meter; if the needle is next to or in the red zone, recharge the battery.)

18. Always move the power switch on the PHD module to the OFF position before disconnecting the cable.

19. Disconnect the cable from the PHD module and carefully remove the DETECTOR from the access tube and place it back in the calibration stand. Coil the cable onto the calibration stand.

20. Store the equipment in its designated place.

In addition to measuring the water content of the soil by use of the neutron and gamma probes, we measured how tightly the soil moisture was held by using tensiometers.

\section{A.3 TENSIOMETER CALIBRATION, STANDARDIZATION, AND USE}

The following steps detail the procedure for measuring soil moisture tension in the lysimeters at the FLTF:

1. Obtain a calibrated Tensimeter from the laboratory.

2. Turn Tensimeter on and adjust zero reading to $0 \mathrm{mb}$.

3. Insert Tensimeter needle into septum on tensiometer. Just begin to remove the needle and observe the maximum reading (the largest negative number).

4. Record Tensimeter reading in appropriate laboratory record book.

5. Shut off Tensimeter (to conserve battery power).

6. If the water level is below the mark on the tensiometer site tube but is still visible, measure and record the vertical distance from the water surface to the mark. Refill the tensiometer to the mark with distilled water and replace the stopper as quickly as possible to prevent excess water loss into the soil. 
7. If the water level is not visible in the site tube, check the neutron probe readings to make sure that soil moisture is above $18 \%$ by volume; if not, record the fact and leave the tensiometer empty. If soil moisture is above $18 \%$, refill the tensiometer with a measured amount of distilled water and record the amount in the laboratory record book.

8. Return Tensimeter to laboratory.

\section{A. 4 WEIGHING LYSIMETER SCALE CALIBRATION}

The following stepwise procedure provides a means of calibrating a lysimeter platform scale that has a load on it. It does not yield the zero offset, but, if used at a time of minimum weight (such as near the end of the dry summer season), it can include the entire operating range of the scale without unloading the scale.

Remove any tiny pebbles or other debris from around the top lip of the lysimeter. Make sure that the scale suspension system is free to move in both horizontal directions by applying alternating lateral pressure in two directions at the top corner of the lysimeter. When scale movement is free, proceed with scale calibration as follows:

1. Apply a precision $1-V$ excitation from the datalogger to the full bridge on the torsion bars of the platform scale.

2. Read the voltage outputs from the torsion bars on the platform scales with a precision of $0.01 \mu \mathrm{V}$.

3. Condition the voltage signal for final memory in the datalogger by multiplying by 1 and setting a -1 offset. This gains one additional digit in instrument resolution in the final storage of the datalogger, thus making it possible to resolve $10 \mathrm{nV}$ or $0.1 \mathrm{lb}$ on the datalogger readout.

4. Set datalogger to read voltage output every $10 \mathrm{~s}$ and average six readings each minute. Concurrently, record manually the maximum 
and minimum voltages displayed on the datalogger readout as each weight change is made (this provides essential backup in case of other failures).

5. Read and record the ambient lysimeter voltage displayed before applying any calibration weight or force.

6. Apply $100 \mathrm{lb}$ of weight or force and allow $3 \mathrm{~min}$ for readout stabilization, while recording manually the maximum and minimum voltages displayed. Repeat this action until at least 1000 and not more than $2000 \mathrm{lb}$ has been added.

7. Remove 100-1b weights or force in exactly the opposite sequence to loading and allow 3 min for equilibration at each step. Again record maximum and minimum voltages displayed.

8. Transport data from final memory in the datalogger by cassette tape or telephone line to the computer where the voltage signal may be stored in a data file and then processed.

9. Process either the manual or datalogger data by adding 1 , multiplying the sum by 10,000 , and fitting a regression line through the weight-voltage pairs over the calibration range, using the following equation:

$$
S=\frac{\sum_{i}[(W s-W a)(V-V a)]_{i}}{\sum_{i}(V-V a)_{i}^{2}}
$$

where $i=$ the increment index

$S=$ slope of the regression line

Ws $=$ the standard weight added at each calibration point

Wa = average of al1 standard weights added

$V=$ the voltage reading at each calibration point

$\mathrm{Va}=$ the average of all voltage readings at calibration points. 
10. Use the slope (S) of the regression line in Equations (A.3) and (A.4) to obtain each standard calibration weight step (Wst) and each measured weight step $(\mathrm{Wm})$ :

$$
\begin{aligned}
& W s t=(V a-W a / S) * S+n * W c \\
& W m=S * V
\end{aligned}
$$

where $n$ is the number of weights added to obtain the particular reading, and $W c$ is the calibration weight size. (If 100-1b weights were used, $W c=100)$.

11. Obtain the deviations in scale performance by subtracting measured weights (Wm) from standard calibration weight steps (Wst).

$$
D_{i}=W_{s t}-W m_{i}
$$

where $D$ is the deviation of the individual reading from the calibrated weight.

12. Transmit data with a graph of deviations to HEDL for approval and certification.

This procedure assumes that the zero offset is negligible.

\section{A.5 SPRAYBAR WATER APPLICATIONS}

The following are stepwise instructions for water applications to treatments 3,4 , and 7 at the FLTF.

1. Cover nearby lysimeters with plastic if they are not to receive water.

2. Place rain gages randomly in the spray path between the center and edge of the lysimeters that are to be irrigated.

3. Connect the power cord and water hose and move the carriage manually to a lead-in position about $0.5 \mathrm{~m}$ away from the point where irrigation is to begin. 
4. Securely tighten the filter body, turn on the water, and start the drive motor.

5. Apply water past the irrigation end point about $0.5 \mathrm{~m}$.

6. When irrigation is complete, turn off the water and drain the entire system to prevent damage from freezing. Apply preweighed crushed ice when the ground is frozen.

7. Remove the power cord, retract the drive wheel from the track, and park the carriage near the FLTF vent pipe.

8. Place an angle iron stop on the track to prevent movement of the carriage when the wind blows.

Check all lysimeters for drainage. Weigh any drainage water and record the weight in the $\log$ book. Additional information on the general features of the tests and which lysimeters are to be treated with irrigation water is found in Gee et a1. (1989). 


\section{DISTRIBUTION}

No. of

Copies

\section{OFFSITE}

2 DOE/Office of Scientific and Technical Information

\section{ONSITE}

7 DOE Richland Operations Office

G. J. Bracken, A7-50

J. J. Broderick, A6-95

R. D. Freeberg, $A 6-95$

R. E. Gerton, A6-80

R. D. Izatt, $A 6-95$

G. W. Rosenwald, A6-80

J. P. Sands, A6-95

23 Westinghouse Hanford Company

M. R. Adams, H4-55

L. C. Brown, H4-51

J. W. Cammann, H4-54

R. A. Carlson, H4-55

H. F. Daugherty, R2-53

W. F. Heine, R1-15

J. M. Henderson, B2-04

D. S. Landeen, H4-54

R. E. Lerch, H4-51

H. E. McGuire, H4-51

K. W. Owens, R1-19

K. L. Petersen, H4-54

S. J. Phillips, L7-10

J. F. Re1yea, H4-54

R. C. Roos, H4-55

R. C. Routson, H4-56

M. R. Sackschewsky, H4-54

W. W. Schulz

S. A. Weigman

N. R. Wing, H4-54

D. D. Wodrich, R1-48

R. D. Wojtasek, H4-17

D. E. Wood, H4-51
No. of

Copies

56 Pacific Northwest Laboratory

L. L. Cadwe11, P7-50

M. D. Campbe11 (5), K6-77

J. W. Falco, K6-78

M. J. Fayer, K6-77

M. G. Foley, K6-84

H. D. Freeman, K2-12

G. W. Gee (20), K6-77

M. J. Graham, K6-80

J. M. Hales, K6-04

P. C. Hays, K6-86

T. L. Jones, K6-77

C. T. Kincaid, K6-77

G. V. Last, K6-96

M. W. Ligotke, K4-06

S. 0. Link, P7-50

R. W. Nel son, K6-77

K. A. Parne11, P7-18

W. T. Penne11, K6-08

W. H. Rickard, P7-50

L. E. Rogers, P7-50

R. L. Skaggs, K6-77

J. A. Stottlemyre, K6-78

G. P. Streile, K6-77

T. L. Stewart, K5-25

J. M. Thomas, P7-50

W. J. Waugh, P7-50

R. E. Wildung, P7-50

Publishing Coordination

Technical Report Files (5) 